\title{
Cytochrome P450 1A-ligand interactions: Implications for substrate specificity and inhibitor susceptibility
}

Qingbiao Huang

West Virginia University

Follow this and additional works at: https://researchrepository.wvu.edu/etd

\section{Recommended Citation}

Huang, Qingbiao, "Cytochrome P450 1A-ligand interactions: Implications for substrate specificity and inhibitor susceptibility" (2010). Graduate Theses, Dissertations, and Problem Reports. 3233.

https://researchrepository.wvu.edu/etd/3233

This Dissertation is protected by copyright and/or related rights. It has been brought to you by the The Research Repository @ WVU with permission from the rights-holder(s). You are free to use this Dissertation in any way that is permitted by the copyright and related rights legislation that applies to your use. For other uses you must obtain permission from the rights-holder(s) directly, unless additional rights are indicated by a Creative Commons license in the record and/ or on the work itself. This Dissertation has been accepted for inclusion in WVU Graduate Theses, Dissertations, and Problem Reports collection by an authorized administrator of The Research Repository @ WVU.

For more information, please contact researchrepository@mail.wvu.edu. 


\title{
Cytochrome P450 1A-Ligand Interactions: Implications for Substrate Specificity and Inhibitor Susceptibility
}

\author{
Qingbiao Huang
}

\author{
Dissertation submitted to the \\ School of Pharmacy \\ at West Virginia University \\ in partial fulfillment of the requirements \\ for the degree of
}

Doctor of Philosophy

in

Pharmaceutical and Pharmacological Sciences

Grazyna D. Szklarz, Ph.D., Chair

Patrick S. Callery, Ph.D.

Peter M. Gannett, Ph.D.

Joseph K.H. Ma, Ph.D.

Michael R. Miller, Ph.D.

Department of Basic Pharmaceutical Sciences

Morgantown, West Virginia

2010

Keywords: P450, substrate specificity, inhibitor susceptibility, molecular dynamics, docking, site-directed mutagenesis, enzyme kinetics, stoichiometry 


\section{Abstract \\ Cytochrome P450 1A-Ligand Interactions: Implications for Substrate Specificity and Inhibitor Susceptibility}

\section{Qingbiao Huang}

Cytochromes P450 are heme-containing enzymes that are involved in the metabolism of a variety of clinically important drugs, endogenous and exogenous compounds, including a number of procarcinogens. P450 1A subfamily has two members: $1 \mathrm{~A} 1$ and 1A2. P450 1A1 and 1A2 show high sequence identity $(>70 \%)$, but display different substrate specificity and inhibitor susceptibility. P450 1A2 is one of the major hepatic P450s, which metabolizes more than $11 \%$ of drugs currently on the market. Thus, we focused our attention on studies of this particular P450.

The five key active site residues that are different between P450 1A1 and 1A2 have been proposed to play an important role in determining the substrate binding orientation. We adopted phenacetin, an important substrate marker for P450 1A2, to investigate this role. Kinetic studies have shown that the L382V mutant and other mutants containing the L382V substitution exhibited markedly higher catalytic efficiency than the wild type enzyme, while other four single mutants displayed much lower activity. Stoichiometry studies indicated that the higher coupling occurred due to decreased water formation in the catalytic cycle by L382V and mutants containing the L382V substitution. Docking and molecular dynamic simulations suggested that the L382V substitution enabled the oxidation site of phenacetin to move closer to the ferryl oxygen of heme, thereby promoting phenacetin metabolism.

In order to verify the above mechanism, NMR $\mathrm{T}_{1}$ relaxation measurements were utilized to estimate the distance between protons of phenacetin and ferryl oxygen of oxoheme of P450 wild type or mutants. The results showed that the time-averaged orientations of phenacetin in the active site were very similar in P450 1A2 wild type and mutants. However, the protons at the site of oxidation of phenacetin were closer to the ferryl oxygen in P450 1A2 L382V and L382V/N312L mutants than P450 1A2 WT, which is consistent with the findings from molecular modeling.

To extend our studies, we explored the interactions between inhibitors and P450 1A2 WT and mutants. Molecular modeling techniques, including docking and molecular dynamic simulations, have been extensively used to predict possible inhibitor-enzyme interactions and describe the docking energy involved. In some cases, for example with residue Phe226, $\pi-\pi$ stacking might play a major role in these interactions. Good correlations between docking scores and inhibition constants $\mathrm{Ki}$ were obtained using AutoDock program.

The combination of molecular modeling and experimental techniques helped us to thoroughly investigate the structure-function relationships of P450 1A2. The insight we gained into the catalytic and inhibition mechanism(s) of this enzyme stresses the importance of the active site topology for $\mathrm{P} 450$ activity and provides important implications for the rational design of anticancer drugs. 


\section{Acknowledgments}

First of all, I would like to express my sincerest thanks to my advisor and mentor, Dr. Grazyna Szklarz, for her tremendous help in enlarging my knowledge in the kingdom of cytochromes P450 and guiding me how to be a professional scientist. I would also like to thank my committee members, Dr. Peter Gannett, Dr. Patrick Callery, Dr. Joseph Ma, and Dr. Michael Miller for serving on my committee and providing many helpful comments and advice, which brought me several new ideas to design my experiments and compose my dissertation.

I sincerely thank my colleagues Dr. Rahul Deshmukh and Dr. Youbin Tu for helping me to learn the experimental techniques and discussing my results. Many thanks are also given to the entire Department of Basic Pharmaceutical Sciences, faculty, staff, and graduate students for all of their assistance in this undertaking.

Finally, I would like to thank my parents, Maohua Huang and Meiying Zhang, my sister Qingchun Huang, and also my love Xiaoke Chen for all of their love, encouragement and full support. 


\section{Table of Contents}

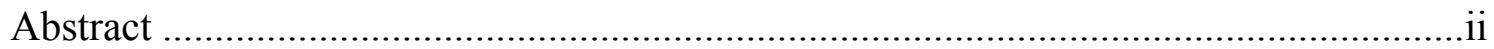

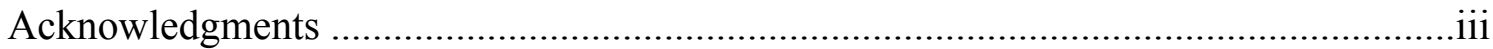

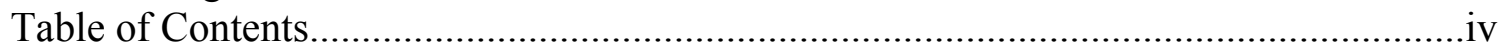

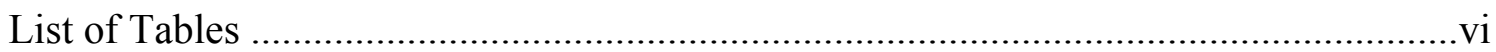

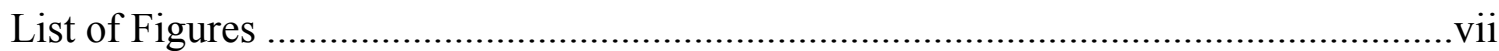

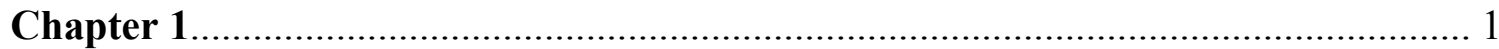

Structure-Function Relationships of Cytochromes P450

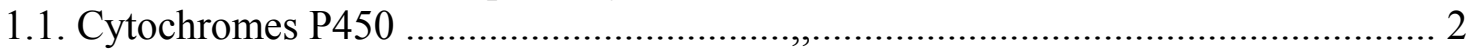

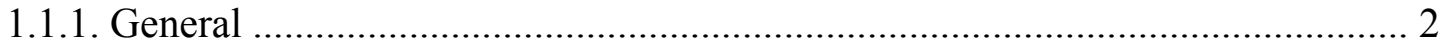

1.1.2. Structural Features ............................................................................. 3

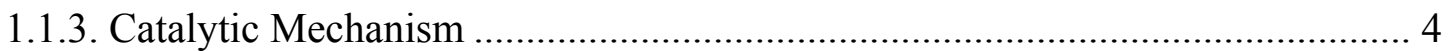

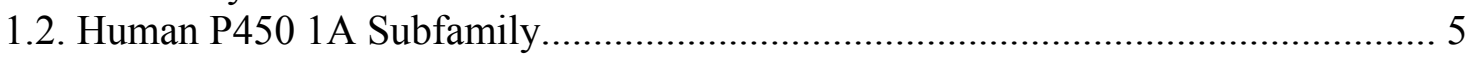

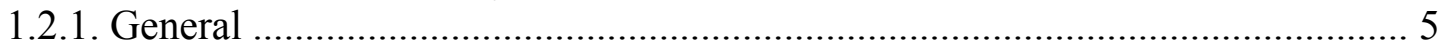

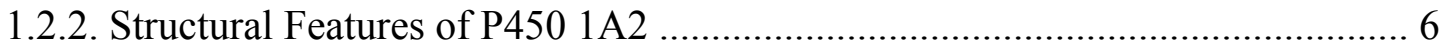

1.2.3. Substrate Specificity and Inhibitor Susceptibility ........................................... 8

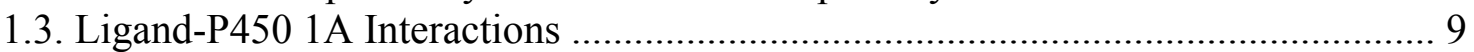

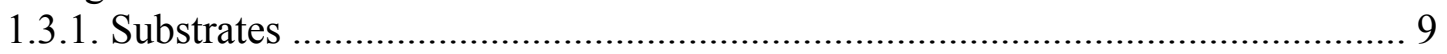

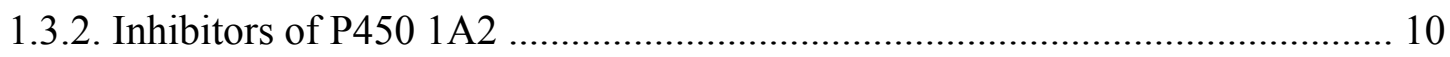

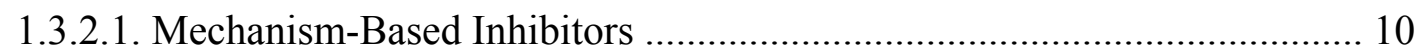

1.3.2.2. Competitive and Non-Competitive Inhibitors of P450 1A2 …................. 11

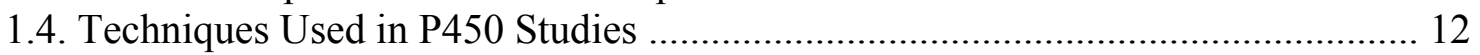

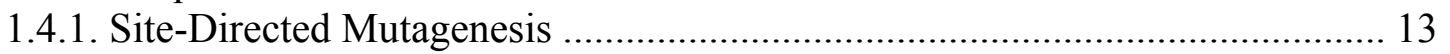

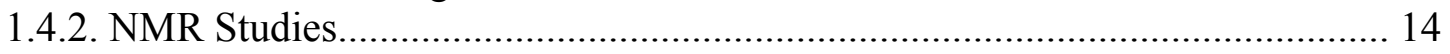

1.4.3. Molecular Modeling Techniques ................................................................ 15

1.5. An Overview of Chapters and Research Objectives ............................................. 17

Chapter 2

Significant Increase in Phenacetin Oxidation on L382V Substitution in Human Cytochrome P450 1A2

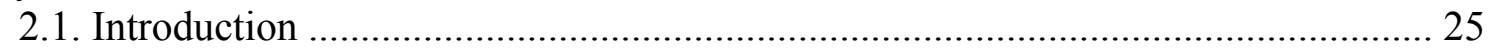

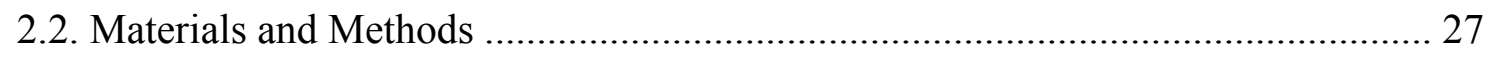

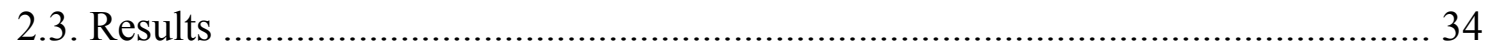

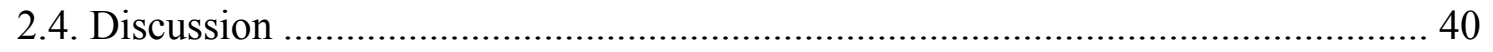

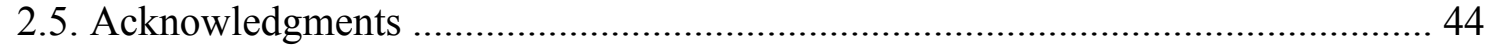

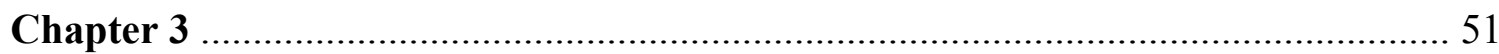

Binding of Phenacetin within the Active Site of Human Cytochrome P450 1A2 Wild Type and Mutants

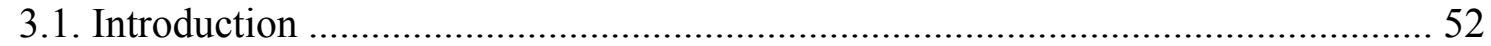

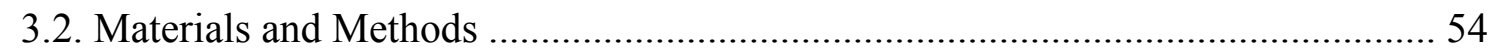

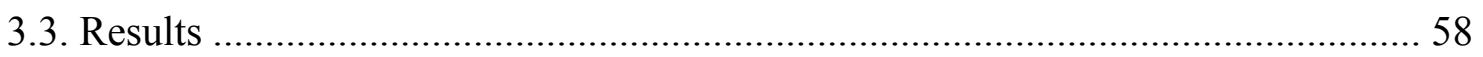

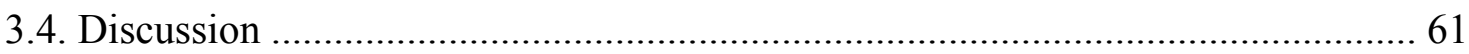

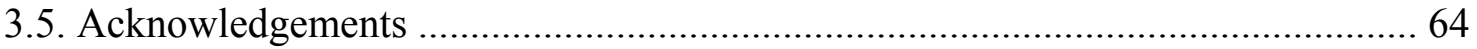




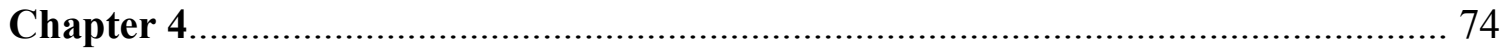
Application of Molecular Modeling to Study Cytochrome P450 1A2 Inhibition by Various Selective Inhibitors

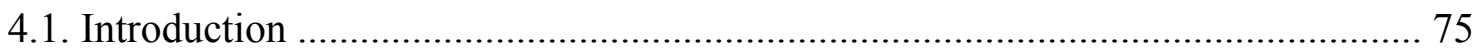

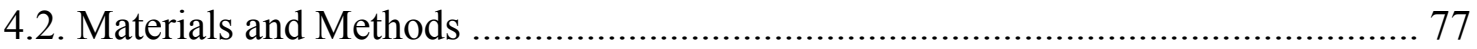

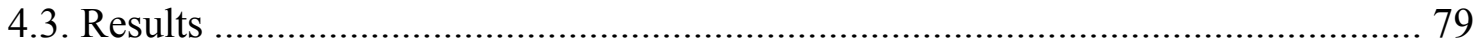

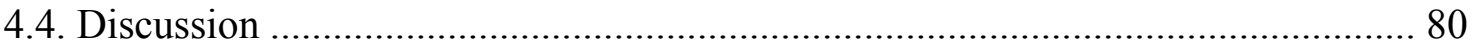

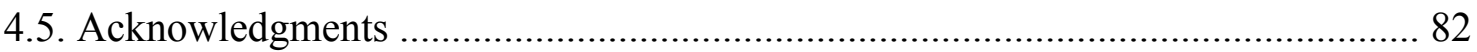

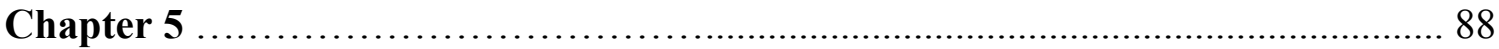

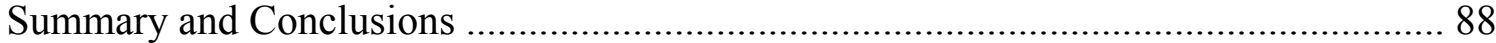

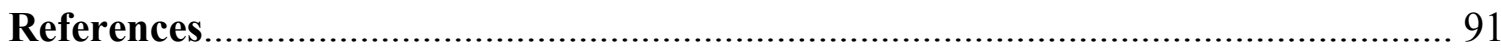

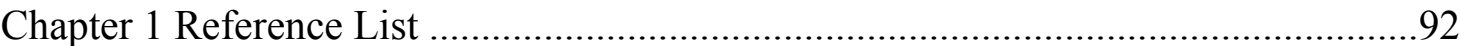

Chapter 2 Reference List ................................................................................... 98

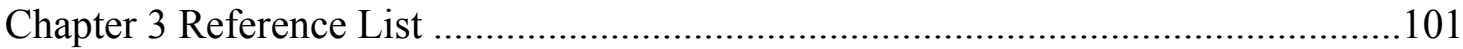

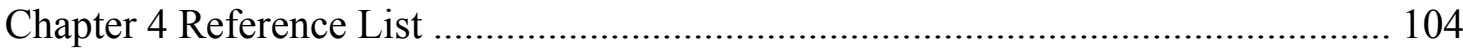




\section{List of Tables}

Table 2.1. Kinetic Parameters for Phenacetin O-deethylation by Purified P450 1A2 WT and Mutants 45

Table 2.2. Rates Determined for Phenacetin Metabolism by P450 1A2 Wild-Type and Mutants. .46

Table 2.3. Effect of Mutations on Coupling Efficiency of P450 1A2 at Different Branching Points of P450 Cycle

Table 2.4. Geometric Analysis of MD Results for P450 1A2 WT and Mutant$\mathrm{s}$ 48

Table 3.1. Spectral Binding Constants for Phenacetin with Purified P450 1A2 WT and the Mutants .65

Table 3.2. Percentages of Low Spin and High Spin in P450 1A2 WT and the Mutants in the Absence and the Presence of Phenacetin... .66

Table 3.3. $T_{1}$ and Calculated Distances of Phenacetin Protons from the Heme Iron in the Active Site of P450 1A2 WT and the Mutants .67 


\section{List of Figures}

Figure 1.1. Proportion of Drugs Metabolized by P450 Enzymes ....................................20

Figure 1.2. Common Fold of Typical Mammalian P450 2C9 (PDB: 1OG2) with Labeled

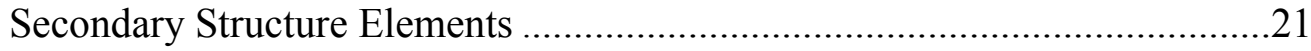

Figure 1.3. The Catalytic Cycle of Cytochrome P450 ..................................................22

Figure 1.4. The Secondary and Tertiary Structure of Human P450 1A2 (PDB: 2HI4) ...23

Figure 2.1. Binding Orientation of Phenacetin within the Active Site of P450 1A2 WT and the L382V Mutant

Figure 2.2. Ensembles of Substrate Orientations Obtained from 100 ps MD Simulations of Phenacetin-enzyme Complexes......................................50

Figure 3.1. Chemical Structure of Phenacetin...............................................................69

Figure 3.2. Phenacetin Spectral Binding Determined in P450 1A2 and Mutants by UV/ Vis Spectroscopy ....................................................... 70

Figure 3.3. Temperature Dependence of the Longitudinal Relaxation Time of the NMR Resonances of Phenacetin Protons in P450 1A2 WT and Mutants.................71

Figure 3.4. NMR Spectrum of the Protons of Phenacetin Obtained under Conditions Used for $\mathrm{T}_{1}$ Measurements

Figure 3.5. Phenacetin Binding Orientation in the Active Site of P450 1A2 WT and the L382V Mutant. .73

Figure 4.1. Binding Orientation of Furafylline within the Active Site of P450 1A2 Crystal Structure .84

Figure 4.2. The Distance $(r)$ Changes as a Function of Time during 100 ps MD simulations . .85

Figure 4.3. Histogram of Distances between the Ferryl Oxygen and Hydrogens at the Oxidation Site of Furafylline 86

Figure 4.4. The linear correlation between the docking score and experimental Ki for several selective P450 1A2 inhibitors 


\section{Chapter 1}

Structure-Function Relationships of Cytochromes P450 


\subsection{Cytochromes P450}

\subsubsection{General}

Cytochromes P450 (P450s) are heme-containing monooxygenease enzymes, which play important roles in the oxidation of endogeneous substrates and the metabolism of xenobiotics (Guengerich, 1994; Ortiz de Montellano, 2005). P450s are ubiquitous in biological systems, and more than 400 isoforms have been identified and sequenced from plants, animals, bacteria and yeast (Nelson et al., 1996). P450s are divided into two groups based on their requirements for the redox partners: class I P450s, found in mitochondria, and class II, more abundant and found in endoplasmic reticulum. Class I P450s require an iron-sulfur protein (ferredoxin) and an FAD-containing $\mathrm{NAD}(\mathrm{P}) \mathrm{H}$ ferredoxin reductase for catalysis. Class II P450s, the main xenobiotic metabolizing enzymes in mammals, require FAD/FMN-containing NADPH P450 reductase and (or) cytochrome $b_{5}$.

Hepatic P450s are primarily expressed in the liver, whereas extrahepatic P450s are mainly found in human extrahepatic tissues including intestine, lung, placenta, and lymphocytes. Any given P450 can metabolize a large number of substrates but at the same time it can exhibit overlapping substrate specificity with other P450s. P450s are involved in toxicant biotransformation, carcinogenesis, and drug metabolism, as well as endogenous compounds such as prostaglandins, biogenic amines, leukotrienes, bile acids, or vitamin D. P450s-mediated reactions include hydroxylations, epoxidations, $O-, S$ - and $N$-dealkylations, and $N$-oxidations (Rendic and Di Carlo, 1997). In humans, P450s are involved in the metabolism of about $75 \%$ of the drugs on the market and $90 \%$ of those 
drugs are oxidized by major hepatic P450s, such as P450 3A4, 2D6, 2C9, 2C19, and 1A2 (Figure 1.1) (Guengerich, 2008).

\subsubsection{Structural Features}

Despite the fact that various P450s exhibit a wide range of activities, the overall $\mathrm{P} 450$ fold is quite conservative. The triangular prism shape of a P450 is predominantly $\alpha$ helical with the orthogonal bundle architecture according to CATH classification (Orengo et al. 1997). The F/G segment, which includes F-helix, F/G-loop and G-helix, perpendicular to the conserved I-helix with the segment housing the heme cofactor, are typical structural features of cytochromes P450. The F/G segment together with the B/Cloop are some of the most flexible parts of the mammalian P450 structure and form gates for the likeliest substrate access or product egress paths to/from the active site. The long I-helix runs over the distal surface of the heme and spans the entire body of the enzyme (Figure 1.2). A conserved Thr residue in the central part of the I-helix located in the proximity of the heme cofactor might participate in $\mathrm{O}_{2}$ activation (Poulos et al., 1987). The F/G loop and the N-terminal part anchor the membrane. The proximal side of the mammalian P450s, the region encompassing helices B, C, J, J', K, L, part of the meander and the heme binding region, is responsible for the interactions with the enzymes' redox partners: NADPH-P450 reductase (CPR, which is essential for its catalytic activity) and cytochrome $b_{5}$. Another feature unique to the mammalian P450s is two additional helices, F' and G' available between the F and G helices. Although the overall fold is conserved, the precise orientation of various structural elements and the length of helices and strands display substantially differences from one P450 to another. In general, the most 
conserved regions are closest to the heme (active site) and include the proline-rich cluster (close to the $\mathrm{N}$-terminus), the loop following the $\mathrm{A}$ helix, the $\mathrm{C}$ and I-helices, the proton transfer groove, parts of the K-helix (Lisitsa et al., 2003). The major differences among P450s are observed in the preferred access/egress paths to/from the active site, the degree of flexibility in the flexible regions, the size of the active site, and the water network inside the active site (Otyepka et al., 2007).

\subsubsection{Catalytic Mechanism}

The most common reaction catalyzed by cytochrome P450 is a monooxygenase reaction. One atom of oxygen is inserted into an organic substrate (RH) and the other oxygen atom is reduced to water, as shown in the following equation (Poulos et al., 2003):

$$
\mathrm{RH}+\mathrm{O}_{2}+2 \mathrm{H}^{+}+2 \mathrm{e}^{-} \rightarrow \mathrm{ROH}+\mathrm{H}_{2} \mathrm{O}
$$

The cytochrome P450 catalytic cycle was first proposed in 1968 (Katagiri et al., 1968). The intermediate stages of a P450 catalytic cycle leading to substrate (R-H) hydroxylation are summarized in Figure 1.3. Initially, the binding of a substrate into the active site of a P450 binding displaces water ligand, which results in a shift in the ferric heme iron from low-spin $(S=1 / 2)$ towards high-spin $(S=5 / 2)$. A more positive potential of the heme iron makes the transfer of an electron favors from the redox partner to reduce the heme iron to the ferrous state. Ferrous heme iron binds oxygen rapidly to form the oxy-ferrous intermediate $\left(\left[\mathrm{FeO}_{2}\right]^{2+}-\mathrm{RH}\right)$. Delivery of a second electron from the redox partner reduces the oxy-ferrous intermediate to the peroxy-ferric intermediate $\left(\left[\mathrm{FeO}_{2} \mathrm{H}\right]^{2+}-\mathrm{RH}\right)$, which has been determined to be the rate-determining step of the 
reaction (Imai et al., 1977). Protonation produces the ferric hydroperoxo form (compound 0). A further protonation leads to the breaking of the $\mathrm{O}-\mathrm{O}$ bond, the water formation and iron-oxo intermediates $\left([\mathrm{FeO}]^{3+}-\mathrm{RH}\right)$ (compound I). Compound I attacks the nearby substrate and form an hydroxylated form of the substrate. The product $(\mathrm{R}-\mathrm{OH})$ then egresses from the active site of the enzyme and water is allowed to rebind to the ferric iron, which completes the cycle.

Uncoupling of catalytic turnover from substrate oxidation can reduce the efficiency of the enzyme by diverting the consumption of reducing equivalents towards the production of active oxygen species and water. It usually occurs in the reaction cycle at three "branch points", namely the substrate-bound oxy-ferrous, peroxy-ferric, and iron-oxo intermediates, yielding superoxide, hydrogen peroxide, and excess water formation, respectively (Fang et al, 1997). The decay of these intermediate species occurs under many circumstances, for instance, electron/proton delivery is not timely, or substrate is inappropriately positioned, or otherwise resistant to oxidative attack.

\subsection{Human P450 1A Subfamily}

\subsubsection{General}

P450 1A subfamily consists of two isomers: P450 1A1 and P450 1A2. P450 1A1 is an extrahepatic enzyme, which is expressed in the liver at very low levels but mainly expressed in other tissues including intestine, lung, placenta, and lymphocytes (Schweik1 et al., 1993; Paine et al., 1999). In contast, P450 1A2 is one of the major hepatic P450s constitutively expressed in the human liver. Both enzymes are regulated in part by the aryl hydrocarbon receptor (AhR) system and known to be induced by a variety of 
chemicals (Kawajiri and Fujii-Kuriyama, 1991; Shimada et al., 2002). P450 1A1 and $1 \mathrm{~A} 2$ share $72 \%$ amino acid sequence identity and the substrate specificities of these two enzymes often overlap. P450 1A1 is considered to play a minor role in the elimination of drugs in vivo. In contrast, P450 1A2 metabolizes about $11 \%$ of all marketed drugs (Shimada et al., 1994).

\subsubsection{Structural Features of P450 $1 \mathrm{A2}$}

P450 1A2 (Protein Data Bank: 2HI4) in complex with $\alpha$-naphthoflavone has been resolved by X-ray crystallography, with the structural refinement of $1.95 \AA$, which is shown in Figure 1.4 (Sansen et al., 2007). The crystal structure of the enzyme includes residues 34-513, with the transmembrane domain (residues 3-26) truncated. The wildtype P450 1A2 structure contains $12 \alpha$-helices designed A-L and $4 \beta$-sheets designed 1-4. Compared with mammalian P450s of known structures, the most conserved regions and the most divergent regions are very similar, as has been discussed in the section 1.1.2.

Unlike other mammalian P450s, two short segments F' and G' in P450 1A2 are $3^{10}$ helical fragments instead of typical $\alpha$-helices. In addition, P450 1A2 structure is different from either P450 3A4 or P450 subfamily 2 with respect to the length and the local structure of loop regions connecting conserved secondary structure elements due to less than $40 \%$ amino acid sequence identity (Sansen et al., 2007). P450 1A2 also contains an additional $\beta$-sheet ( $\left.\beta 3^{\prime}\right)$ between helices $\mathrm{H}$ and I, as well as a small $\alpha$-helix (K') residing at the proximal surface. Interestingly, the region connecting helices $\mathrm{C}$ and $\mathrm{D}$ possesses a Ser-rich insertion and forms a loop extending into the solvent. Another remarkable feature of P450 1A2 structure is a disrupted helix F running across the distal surface of 
the active site cavity (Sansen et al., 2007), which is unique as compared to the structures of P450 2 subfamily presenting an intact helix F in this region (Schoch et al., 2004; Yano et al., 2005). In the structure of P450 1A2, no $\alpha$-helical hydrogen-bonding pattern was observed at Val220 and Lys221, which results in one helical turn in the middle of helix F to unwind (Sansen et al., 2007). Two water molecules fill the space and water-bridged contacts between Val220 carbonyl oxygen and $\mathrm{Thr} 223 \mathrm{O}^{\gamma}$, and Lys221 carbonyl oxygen and His224 amide nitrogen are formed, respectively. The bending of helix F causes the C-terminal portion of the helix to move toward the core of the protein, which closes down the active site cavity.

In the structure of P450 1A2- $\alpha$-naphthoflavone complex, the compact active site is closed without apparent solvent or substrate access channels. The active site cavity of P450 1A2 has a medium volume of $375 \AA^{3}$ (Sansen et al., 2007), which is larger than that of P450 2A6 (260 $\AA^{3}$ ) (Yano et al., 2005), but much smaller than that of P450 3A4 and $2 \mathrm{C} 8$, with cavity volumes of $1385 \AA^{3}$ and $1438 \AA^{3}$, respectively (Schoch et al., 2004; William et al., 2000). The narrow substrate binding cavity of P450 1A2 is lined by residues on helices F and I. Helix I bends as it crosses the heme prosthetic group and its residues form one flat side of the substrate binding cavity adopt a relatively flat conformation of the peptide backbone, resulting in a remarkable coplanarity through the Ala317 side chain, the Gly316-Ala317 peptide bond, and the Asp320-Thr321 peptide bond. The side chain of Phe226 of helix F forms a parallel substrate binding surface on the other side of the active site cavity. The cavity of P450 1A2 is stabilized by strong hydrogen-bonding interactions between the side chain of Thr223 on helix F and the side chain of Asp320 on helix I. Both Thr223 and Asp320 are involved in an extensive 
network of hydrogen-bonded water molecules and side chains, including Tyr189, Val220, Thr498, and Lys500.

\subsubsection{Substrate Specificity and Inhibitor Susceptibility}

P450 1A1 and 1A2 display overlapping substrate specificities and it is clear that the narrow and flat active site cavity of P450 1A can accommodate well with planar compounds such as $\alpha$-naphthoflavone and typical P450 1A selective substrates. With respect to substrate specificity, although both enzymes are able to oxidize similar compounds, P450 1A1 metabolizes mainly benzo[a]pyrene and polycyclic aromatic hydrocarbons (PAHs) to their toxic derivatives (Kawajiri et al., 1991), whereas P450 1A2 preferentially oxidizes heterocyclic aromatic amines (Turesky et al., 1998; Gonzalez et al., 1994). Relatively small changes in the enzyme active site residues can lead to the alteration of P450 1A specificities. For instance, P450 1A1 shows a clear preference for 7-ethoxyresorufin as a substrate, whileas P450 1A2 oxidizes 7-methoxyresorufin. Reciprocal mutants P450 1A1 V382L and P450 1A2 L382V mutants reversely altered the specificity toward alkoxyresorufins when compared to the wild type enzymes (Liu et al., 2004).

$\alpha$-naphthoflavone is a potent, competitive inhibitor of P450 1A2 with Ki values of 1$50 \mathrm{nM}$ (Shimada et al., 1998; Cho et al., 2003). $\alpha$-naphthoflavone binds to P450 1A2 in a preferred orientation with the phenyl ring close to the heme iron, which makes it an inhibitor rather than a substrate for enzyme (Sansen et al., 2007). The crystal structure of P450 1A2- $\alpha$-naphthoflavone complex indicated that the distance between C $\alpha$ of Leu382 and $\mathrm{C}_{3}^{\prime}$ and $\mathrm{C}_{4}^{\prime}$ of $\alpha$-naphthoflavone is 3.9 and $4.1 \AA$, respectively, which suggests the 
restricted architecture in the active site cavity and explains the preference of P450 1A2 for shorter alkoxyresorufins (Sansen et al., 2007). The unique active site topology of P450 1A2 demonstrates how P450 1A enzymes have evolved to efficiently catalyze the oxidation of polycyclic aromatic hydrocarbons. Surprisingly, $\alpha$-naphthoflavone was readily metabolized by $\mathrm{P} 4501 \mathrm{~A} 1$ to form $\alpha$-naphthoflavone-5,6-diol and $\alpha$ naphthoflavone-5,6-oxide (Bauer et al., 1995). The different preferences of P450 1A1 and $1 \mathrm{~A} 2$ toward $\alpha$-naphthoflavone metabolism could be explained by the fact that the site of limited P450 1A2 oxidation would be at the other end of the molecule relative to the site of P450 1A1 oxidation (Sansen et al., 2007).

\subsection{Ligand-P450 1A Interactions}

\subsubsection{Substrates}

Substrates of P450 1A1 are planar polyaromatic hydrocarbons, which are comprised of two to four fused aromatic rings. The selective substrate for P450 1A1 is 7ethoxyresorufin, which has four hydrogen bond acceptor atoms. P450 1A1 does not appear to play an important role in the metabolism of many drugs because of its extrahepatic locations of expression. The selective substrates for P450 1A2 are heterocyclic amines and amides, which are more polar than P450 1A1 substrates. Despite these differences, many of the substrate and inhibitor probes used to study P450 $1 \mathrm{~A} 1$ and $1 \mathrm{~A} 2$ are nonspecific in their recognition between the two enzymes. For example, caffeine has been shown to be a nonspecific in vitro probe for P450 1A2, since P450 1A1 is also able to metabolize this substrate (Tasaneeyakul et al., 1992). Similarly, the resorufin substrates, 7-ethoxyresorufin and 7-methoxyresorufin both undergo 
dealkylation by P450 1A1 and P450 1A2, though the efficiencies of the reaction are different (Nerurkar 1993).

Due to the importance of P450 1A2 in drug metabolism, the substrate probes for this enzyme have been intensively studied. Several compounds, including phenacetin, caffeine and theophylline have been used as substrate probes for P450 1A2 in vivo. The major reactions that they participate in are phenacetin $\mathrm{O}$-deethylation, caffeine $\mathrm{N}$ demethylation, and theophylline $N$-demethylation, respectively. Among those, phenacetin $O$-deethylation reaction is the most important marker reaction for P450 $1 \mathrm{~A} 2$. Phenacetin undergoes $O$-deethylation by $\mathrm{P} 450 \quad 1 \mathrm{~A} 1 / 1 \mathrm{~A} 2$ to yield the product acetaminophen, and it has been used to evaluate the catalytic activity of P450 1A2 in vivo and in vitro or to investigate its activity and regulation.

Most of the P450 1A2 substrates are hydrophobic with high $\operatorname{LogP}$ values, which indicates that hydrophobic interactions are mainly involved in their binding to P450 1A2 (Lewis et al., 2003). The common features of ligands for P450 1A2 are of one to two hydrophobic regions, an aromatic ring and a hydrogen bond acceptor (Zhou et al., 2009). The planar active site architecture in P450 1A2 is well adapted for the oxidation of relatively large aromatic compounds.

\subsubsection{Inhibitors of P450 $1 \mathrm{~A} 2$}

\subsubsection{Mechanism-Based Inhibitors}

Mechanism-based inhibitors also called "suicide" inhibitors are transformed by P450s into reactive species that cause P450s inactivation prior to the release from the active site. The reactive metabolites which are formed within the active site may cause irreversible 
inhibition through different mechanisms: (a) binding to hydrophobic regions of the active site, (b) coordination to the heme iron atom, and (c) entering into specific hydrogen bonding or iron interactions with active site residues (Correia and Ortiz de Montellano, 2004). Mechanism-based inhibitors of P450 1A2 includes several therapeutic drugs such as carbamazepine, dihydralazine, furafylline, isoniazid, rofecoxib, and zileuton. Furafylline is a highly selective inhibitor of P450 1A2 in humans and exhibits a potent inhibitory effect on phenacetin $O$-deethylase activity, a reaction catalyzed by P450 1A2, with an $\mathrm{IC}_{50}$ value of $0.07 \mu \mathrm{M}$ (Sesardic et al., 1990). Interestingly, furafylline does not inhibit P450 1A1, as accessed by aryl hydrocarbon hydroxylase activity of placental samples from women who smoked cigarettes (Sesardic et al., 1990).

Drugs behaving as potent mechanism-based inhibitors of P450 1A2 may explain some drug-drug interactions in patients. For example, when theophylline and the Rwarfarin were co-administrated with a P450 1A2 selective inhibitor rofecoxib, the concentration of theophylline and the R-warfarin displayed a significant increase since P450 1A2 was inhibited by rofecoxib (Bachmann et al., 2003; Schwartz et al., 2000). Administration of furafylline was associated with an elevated plasma levels of caffeine, due to inhibition of caffeine oxidation, a reaction catalyzed by P450 1A2 (Sesardic et al., 1990).

\subsubsection{Competitive and Non-Competitive Inhibitors of P450 $1 \mathrm{A2}$}

Another class of P450 inhibitors involves competitive and non-competitive inhibitors, which occupy the active site (competitive) or somewhere else in the enzyme (noncompetitive), making the active site no longer able to accommodate the substrate. 
Typical competitive and non-competitive P450 1A2 inhibitors are relatively small molecules, usually containing methyl, chloro, or fluoro substitutions such as fluvoxamine, ANF. Fluvoxamine is a potent selective P450 1A2 inhibitor with $\mathrm{IC}_{50}$ of $0.12-0.30 \mu \mathrm{M}$ (Brosen et al., 1993; Rasmussen et al., 1995; von Moltke et al., 1996; Becquemont et al., 1997). Isosafrole and other selective serotonin reuptake inhibitors such as fluoxetine, norfluoxetine, and sertraline are also selective inhibitors of P450 1A2, which inhibited P450 1A2-mediated 7-ethoxyresorufin $\mathrm{O}$-deethylase activity with low $\mathrm{Ki}$ values of 0.7 , 4.4, 15.9, 8.8, 9.5 and 5.5 $\mu \mathrm{M}$, respectively (Rasmussen et al., 1995; von Moltke et al., 1996; Pastrakuljic et al., 1997).

In addition, compounds such as $\alpha$-naphthoflavone, ellipticine, 7-ethoxycoumarin, 7ethoxyresorufin, caffeine, 5- and 8-methoxypsoralen, nifedipine, propranolol, paraxanthine, theophylline, caffeine, 5- and 8-methoxypsoralen, nifedipine, propranolol, paraxanthine, and theophylline inhibited phenacetin $O$-deethylation catalyzed by P450 $1 \mathrm{~A} 1$ or $1 \mathrm{~A} 2$ and displayed high-affinity towards human liver phenacetin $O$-deethylase. $\alpha$ naphthoflavone and 7-ethoxycoumarin were approximately 10 -fold more potent as inhibitors of P450 1A2 than 1A1 (Tassaneeyakul et al., 1993).

The effects of flavone and five hydroxylated derivatives on the methoxyresorufin $O$ demethylase activity catalyzed by P450 1A1 and 1A2 were examined by Zhai et al. (Zhai et al., 1998). The results showed that flavone displayed higher inhibitory effects on P450 $1 \mathrm{~A} 2\left(\mathrm{IC}_{50}=0.066 \mu \mathrm{M}\right)$ than on P450 1A1 $\left(\mathrm{IC}_{50}=0.14 \mu \mathrm{M}\right)$. Four hydroxylated flavone derivatives, namely 3-hydroxy-, 5-hydroxy-, 7-hydroxy-, and 3,7-dihydroxyflavone, also strongly inhibited P450 1A1 $\left(\mathrm{IC}_{50}<0.1 \mu \mathrm{M}\right)$ and P450 1A2 $\left(\mathrm{IC}_{50}<0.3 \mu \mathrm{M}\right)$ (Zhai et al., 1998). 


\subsection{Techniques Used in P450 Studies}

\subsubsection{Site-Directed Mutagenesis}

Site-directed mutagenesis has been widely used for probing the active sites and other functional regions of P450 enzymes by the substitution of certain amino acid residues, and it is an important tool in studies of P450 structure-function relationships. Sitedirected mutations of specific amino acids are useful in determining the roles of certain residues in various processes, such as substrate binding and recognition, the interactions with redox partners, oxygen binding and its activation, heme binding and membrane association (Atkins and Sligar, 1989; Johnson, 1992; Lewis, 1998).

Members of P450 1A family have been extensively studied in our lab and many other laboratories. Sequence alignment of P450 1A1 and 1A2 indicated that residues in five positions of substrate recognition sequences (SRS) are different from each other (Liu et al., 2004). Some reciprocal mutations, for example, P450 1A1 S122T, N221T, G225V, L312N, V382A, and P450 1A2 T124S, T223N, V227G, N312L, L382A, resulted in the exchange of substrate (alkoxyresorufin) specificity of the enzymes (Liu et al., 2004). In addition, based on mutagenesis and homology modeling studies of P450 1A2, a series of residues in the substrate recognition sequence (SRS) regions (for example: Arg108, Thr124, Thr223, Glu225, Phe226, Lys250, Arg251, Lys253, Asn312, Asp313, Glu318, Thr319, Asp320, Thr321, Val322, Leu382, Thr385, and Ile386) has been shown to play a role in P450 1A2-ligand interactions. Residues in the non-SRS regions, such as Lys99, Arg137, Gln141, Phe186, Phe205, Val227, Lys453, Arg455, and Thr501, also play a role in P450 1A2-ligand interactions (Zhou et al., 2009).

Site-directed mutagenesis has also been applied to investigate regions where redox 
partners bind with P450s. A mutation study on P450 2B4 suggested that residues including the $\mathrm{C}$-helix, the $\mathrm{C} / \mathrm{D}$-loop, the $\mathrm{K}$ helix and the loop preceding it are responsible for CPR and cytochrome $b_{6}$ (Bridges, et al., 1998). Surprisingly, the sites expected to bind the CPR and cytochrome $b_{6}$ overlap to a large extent (Clarke et al., 2004).

\subsubsection{NMR Studies}

One of the most important applications for NMR in P450 studies involves NMR $\mathrm{T}_{1}$ relaxation measurements, which have been employed to estimate substrate-heme distances for many substrate-P450 pairs: tienilic acid, lauric acid, and diclofenac with P450 2C9 (Poli-Scaife et al., 1997); codeine and 1-methyl-4-phenyl-1,2,3,6tetrahydropyridine with P450 2D6 (Modi et al., 1996; 1997); cholesterol with P450scc (Jacobs et al., 1987); acetaminophen with P450s 1A1 and 2B1 (Myers et al., 1994); caffeine with P450 1A2 (Regal and Nelson, 2000) and laurate and 12-bromolaurate with P450 BM3 (Modi et al., 1995), as well as flurbiprofen and the effector dapsone with P450s 2C9 (Hummel et al., 2004), and cooperative binding of acetaminophen and caffeine with P450 3A4 (Cameron et al., 2007). In addition, solid-state deuterium magic angle spinning NMR was utilized to study binding of adamantine- $\mathrm{d}_{16}$ to P450 101A1 by measuring the average distance between the deuteriums and the heme iron (Lee et al., 1999).

NMR can also provide valuable information on the dynamics of substrate binding to proteins and the associated conformational changes by observing chemical shifts for specific residues, which are first isotopically labeled. For examples, $1 \mathrm{D}$ and $2 \mathrm{D}{ }^{1} \mathrm{H}$ NMR provided information on the structural features of the binding site of P450 101A1 (Wei et al., 2005) and P450 2C9 (Poli-Scaife et al., 1997). Camphor binding to P450 101A1 
studied via $\mathrm{T}_{1}$ relaxation measurements combined with ${ }^{1} \mathrm{H}_{-}{ }^{13} \mathrm{C}$ HSQC studies of $\left[{ }^{13} \mathrm{CH}_{3}\right]$ threonine-labeled P450 101A1 suggested that camphor binds at a peripheral site at a location near the proposed entry channel (Yao et al., 2007).

\subsubsection{Molecular Modeling Techniques}

With the availability of crystal structures of P450s, especially major human drugmetabolizing $\mathrm{P} 450 \mathrm{~s}$, such as $\mathrm{P} 4502 \mathrm{~A} 6,2 \mathrm{~B} 4,2 \mathrm{C} 5,2 \mathrm{C} 8,2 \mathrm{C} 9,3 \mathrm{~A} 4$ and $1 \mathrm{~A} 2$, various computational approaches have been utilized to predict the P450s involved in the metabolism of xenobiotics and the sites of oxidation (de Groot, 2006; Zhou et al., 2006; Afzelius et al., 2007; Sykes et al., 2008). Molecular modeling provides a better understanding on rationalization and prediction of the catalytic activity, ligand specificity, and regiospecificity of metabolism of P450s. Thus, it is of interest in facilitating the solution of challenges faced in drug design and is used for high-throughput screening (HTS) of large number of compounds in the pharmaceutical industries (Isin and Guengerich, 2008).

Molecular modeling techniques, such as automated docking and molecular dynamics simulations are used to design site-directed mutagenesis experiments to explore the active site for amino acid residues determining ligand binding and regiospecificity of

metabolism by P450. Recently, molecular dynamics methods have been conducted to predict binding constants and to examine changes in activities upon site-directed mutagenesis in P450 1A1 and 1A2 (Liu et al., 2003; 2004; Tu et al., 2008).

Models capable of predicting the possible involvement of P450s in the metabolism of drugs are important tools in drug discovery and development. Those models are also 
helpful to predict and identify the potential drug-drug interactions in clinic. The simplest approach to predicting the activity/binding of a compound is quantitative structureactivity relationships (QSAR) using both experimental and calculated properties. Pharmacophore modeling, on the other hand, overlays structures of ligands or properties of ligands in 3D-space in an attempt to describe the physical, spatial and chemical properties of the active/binding sites. In P450 1A1, pharmacophore models for PAHs and a variety of small non-PAH substrates were constructed. P450 1A1 active site was described as a hydrophobic cleft and hydrogen bonding and aromatic interactions were suggested (Jerina et al., 1982; Kadlubar and Hammons, 1983; Yang, 1988). For P450 1A2, 3D-QSAR methods were used to construct a model for quinolone-type antibacterial inhibitors (Fuhr et al., 1993), showing four pharmacophore features (two positive and two negative potentials), as well as for models based on 12 heterocyclic amines, which suggested positions of likely hydrogen bonding atoms or placement of hydrophobic/bulky groups (Lozano et al., 2000).

The limited number of crystal structures of P450 led to the development of P450 homology models based on known P450s whose crystal structures have been solved, assuming that P450s are structural homological. The constructed models have been successfully utilized to identify or confirmed key residues, evaluate enzyme-substrate interactions, and explain changes in region- and stereospecificity of substrate oxidation, as well as alterations in inhibition and activation upon the residue substitution for those enzymes whose crystal structures have not been determined (Szklarz and Halpert, 1997; 1998; Szklarz et al., 2000).

However, these in silico methods for studying ligand-P450 interactions have had 
limited success in accurately predicting the site(s) of metabolism and the binding orientation(s) for a particular compound, likely due to the complexity of P450 enzymes, which show a significant degree of conformational flexibility and wide substrate diversity. This approach may provide a source of information as a starting point for biotransformation scientists (Afzelius et al., 2007, Caron et al., 2007) but more experimental data are required to support and verify the simulation data based on molecular modeling studies.

\subsection{An Overview of Chapters and Research Objectives}

The principle objective of our studies was to elucidate the mechanisms involved in the interactions between P450 1A2 and its substrates/inhibitors. We have chosen a 1A2selective substrate phenacetin and a number of inhibitors with different inhibition mechanisms, such as competitive and mechanism-based inhibition, to investigate the substrate specificity and inhibitor susceptibilities of this P450. Five residues located in the active site that are different between P450 1A1 and 1A2 play a role in determining the specificity of enzymes, as demonstrated in the case of alkoxyresorufin metabolism (Liu et al., 2004, Tu et al., 2008). In order to extend our studies, phenacetin was chosen as another probe substrate to examine the role of these key residues in determining substrate specificity, catalytic rates, and the binding orientation of phenacetin within the active site. In addition, P450 1A2 selective inhibitors, as another type of enzyme ligand, have been included in our studies. The central hypothesis for our studies is that substrate/inhibitor dynamics in the active site and the interactions between the substrate/inhibitor and the P450 determine enzyme specificity. A combination of theoretical techniques, such as 
docking and molecular dynamics, and experimental approaches, including site-directed mutagenesis, NMR and functional analyses, has been utilized to study structure-function relationships of P450 1A2.

In Chapter 2, we described the enzyme kinetics and stoichiometry results obtained with P450 1A2 and phenacetin as a substrate, using an approach basically very similar to that applied previously to study alkoxyresorufin $O$-dealkylation catalyzed by P450 1A1/1A2 (Liu et al., 2004; Tu et al., 2008). Enzyme kinetic assays demonstrated that P450 1A2 L382V and multiple mutants containing the L382V substitution displayed higher catalytic efficiency than P450 1A2 WT, whereas four other single mutants showed decreased turnover rates. Stoichiometry studies indicated that catalytic activities of P450 $1 \mathrm{~A} 2 \mathrm{~L} 382 \mathrm{~V}$ and multiple mutants containing the $\mathrm{L} 382 \mathrm{~V}$ substitution increased due to less water formation (lower uncoupling rate). Molecular dynamics simulations suggested that the mechanism through which the substitution of Leu382 with a small Val promotes phenacetin oxidation involves the movement of the substrate closer to the oxo-heme, which assists in the initial hydrogen abstraction.

Chapter 3 describes the results of NMR studies, which have been undertaken to verify previous modeling outcomes. NMR provides a direct experimental evidence to support or disprove the 'distance' theory proposed by molecular modeling studies. We estimated and compared the distances between the protons of phenacetin and the ferryl oxygen of the heme for P450 1A2 WT and mutants using NMR $\mathrm{T}_{1}$ relaxation measurements. The protons at the oxidation site of phenacetin are closer to the ferryl oxygen of the heme for P450 1A2 L382V and L382V/N312L mutants than in the case of the WT enzyme.

Binding of inhibitors in the active site of the enzyme is frequently investigated in 
studies of structure-function relationships of P450s. Our results for P450 1A2 and several inhibitors are presented in Chapter 4. Molecular modeling was extensively utilized to reveal the interactions between various inhibitors and the enzyme. We focused on the possible interactions and binding energy between the inhibitor and the enzyme. 


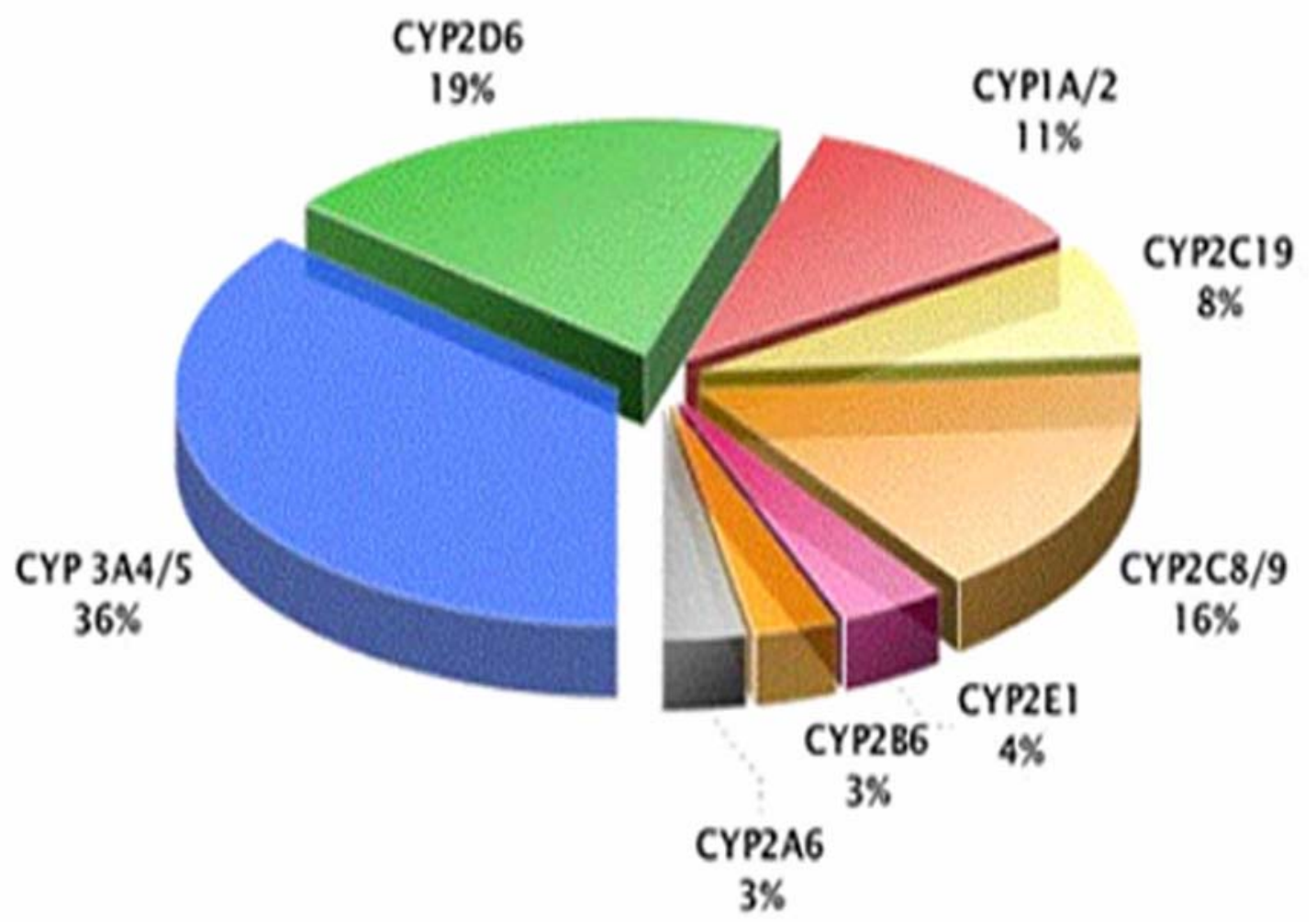

Figure 1.1. Proportion of Drugs Metabolized by P450 Enzymes

Adapted from Wrighton and Stevens, 1992 (22):1-21. Although 14 human families of P450 enzymes have been identified, approximately $95 \%$ of all drug oxidation occurs through the action of six P450 enzymes: P450 1A2, P450 2C8/9, P450 2C19, P450 2D6, $\mathrm{P} 450$ 2E1, and P450 3A4/5. 


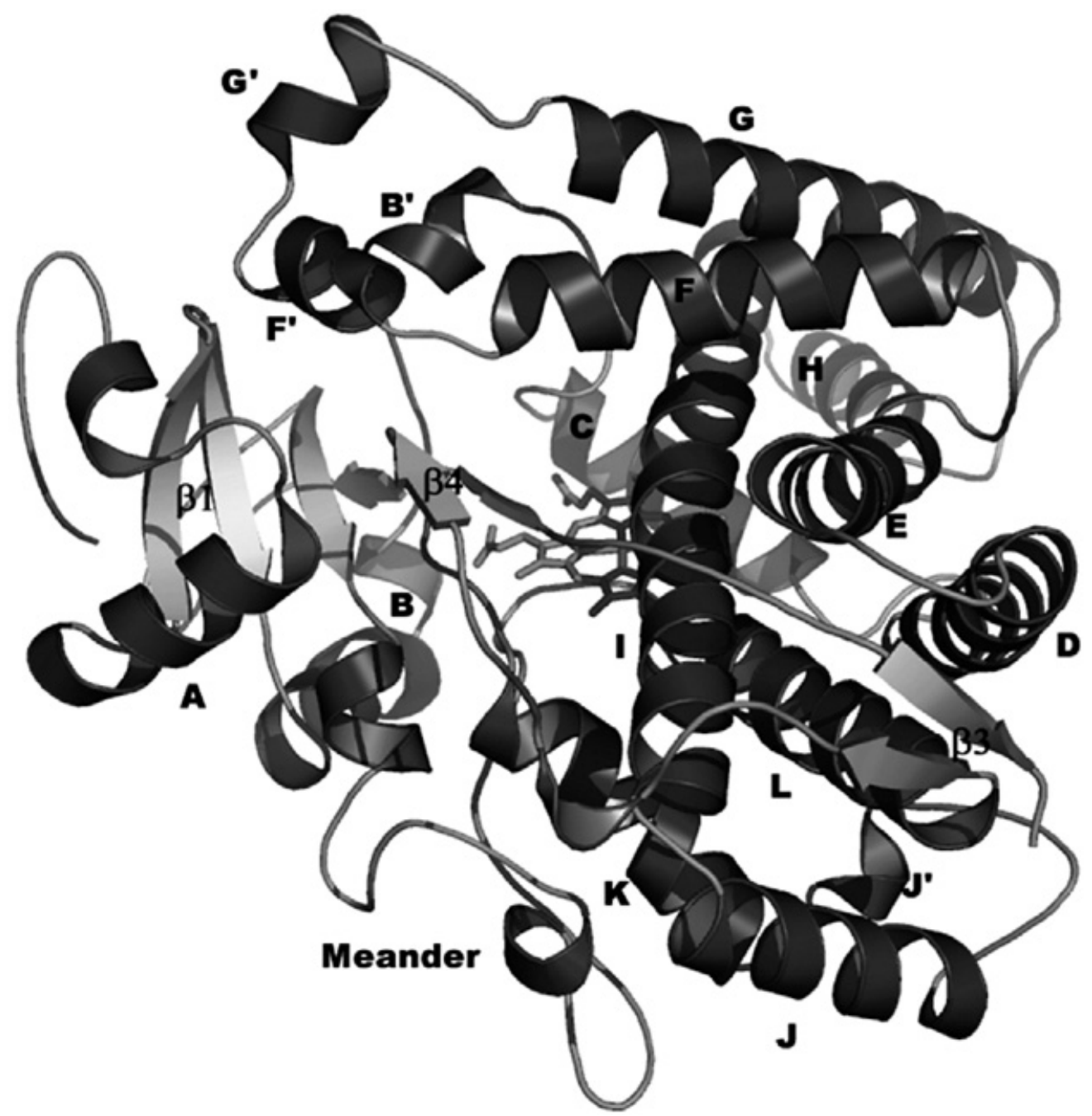

Figure 1.2. Common Fold of Typical Mammalian P450 2C9 (PDB: 1OG2) with Labeled Secondary Structure Elements

Adapted from Otyepka et al., 2007 (1770):376-389. 


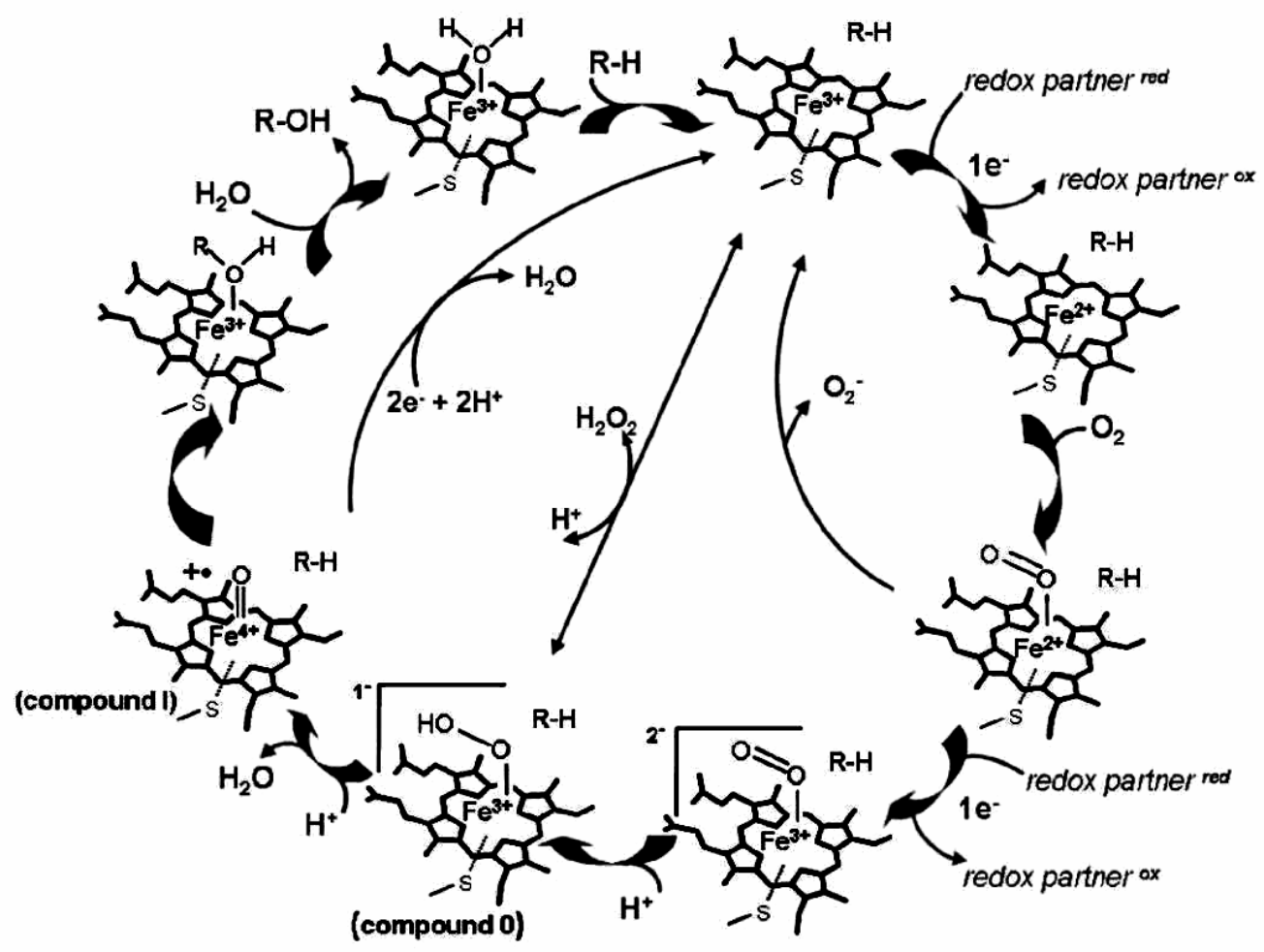

Figure 1.3. The Catalytic Cycle of Cytochrome P450

The heme depicts as the heme macrocycle, with the oxidation state of the heme iron indicated. The proximal heme ligand (cysteine thiolate, indicated as an S-atom linked to the iron) and distal ligand (a water molecule, changing to dioxygen as the cycle progresses) are also indicated.

Adapted from online http://sites.google.com/site/modelingunibas/P540_cyclus-customsize-644-457.jpg. 


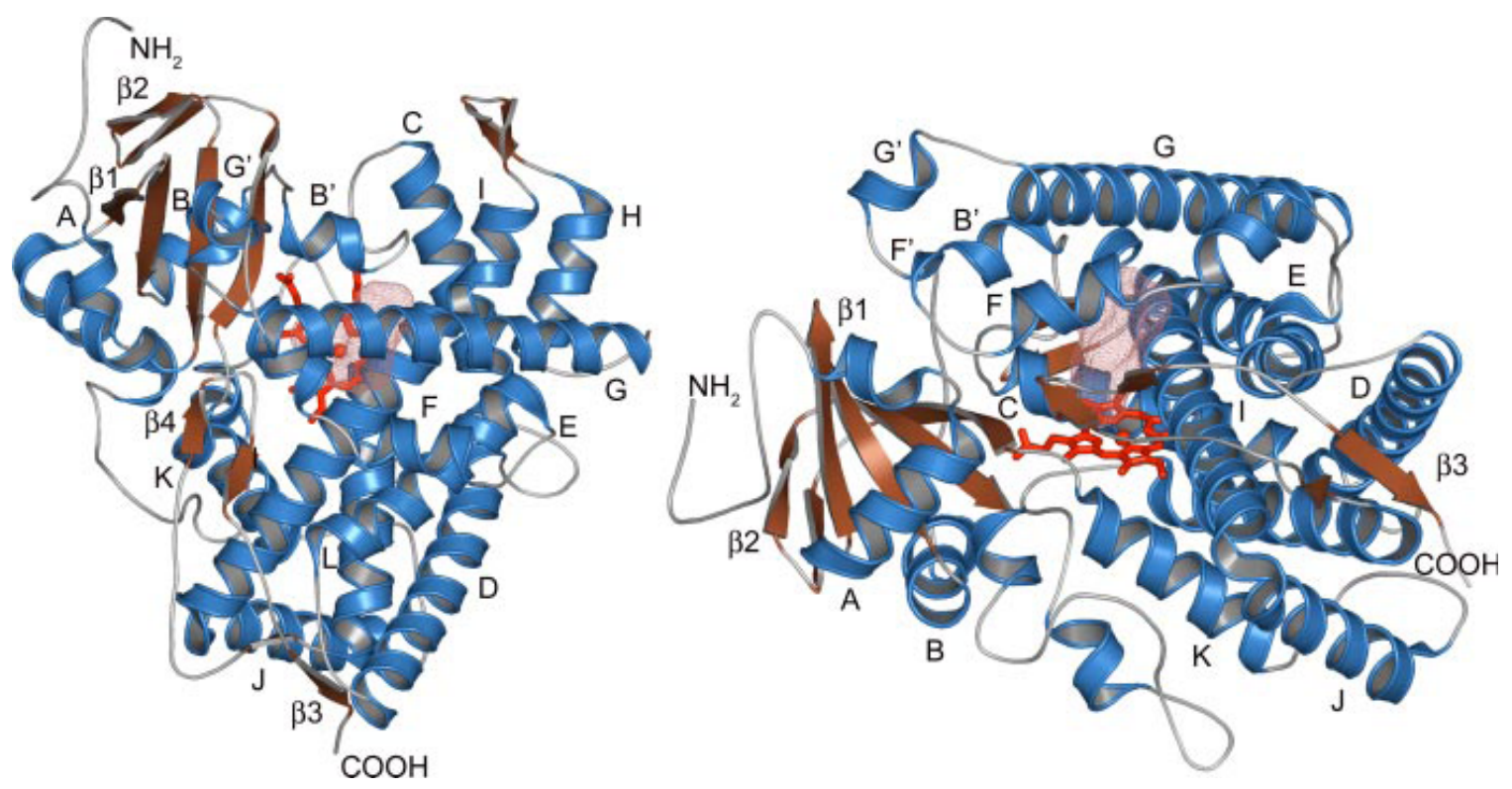

Figure 1.4. The Secondary and Tertiary Structure of Human P450 1A2 (PDB: 2HI4)

The $\alpha$-helices are in blue and the $\beta$-strands are in brown. These secondary structure elements are designated A-L and 1-4, respectively, and are sequentially identified from the $\mathrm{N}$ terminus. The heme prosthetic group is represented in sticks and is in red. The substrate binding cavity is illustrated as a red mesh surface.

Adapted from Sansen et al., 2007 (282):14348-14355. 


\section{Chapter 2}

Significant Increase in Phenacetin Oxidation on L382V Substitution in Human Cytochrome P450 1A2

Adapted from Drug Metabolism and Disposition [doi:10.1124/dmd.109.030767 (2010)] 


\subsection{Introduction}

Cytochromes P450 (P450s) are heme-containing monooxygenase enzymes, which are involved in the metabolism of numerous exogenous and endogenous compounds. P450s are ubiquitous in living organisms, with at least 50 families and 82 subfamilies found in different species. Human P450 1A subfamily has two major isoforms: P450 1A1 and 1A2. P450 1A2, one of the major P450s in the human liver, was first characterized as a phenacetin O-deethylase (Distlerath et al., 1985). Currently, it is estimated that this enzyme metabolizes approximately $11 \%$ of all drugs in humans (Shimada et al., 1994). Despite the fact that P450 1A2 participates in the deactivation and detoxification of xenobiotics, the main interest in this enzyme is because of the metabolic activation of a large number of chemical carcinogens (Guengerich and Shimada, 1991; Levis et al., 1994).

In humans, P450 1A2 shares 72\% amino acid sequence identity with P450 1A1, but the substrate specificities and inhibitor susceptibilities of these enzymes are different. For example, substrates such as phenacetin and 7-methoxyresorufin are primarily metabolized by P450 1A2 with high catalytic efficiency, whileas P450 1A1 displays weak capability to oxidize those substrates. On the other hand, 7-ethoxyresorufin is preferentially oxidized by P450 1A1 (Nerurkar et al., 1993; Burke et al., 1994). The structural basis for such functional differences between highly related enzymes can be investigated using a variety of techniques, including molecular modeling and experimental methods, such as site-directed mutagenesis and NMR. More recently, the crystal structure of P450 1A2 was solved by X-ray crystallography (Sansen et al., 2007), and thus, it provides a practical model for structure-function studies. 
Our previous studies on structure-function relationships of P450 1A1 indicated that Val382 played an important role in binding of alkoxyresorufin substrates (Liu et al., 2003). The sequence alignment between P450 $1 \mathrm{~A} 1$ and $1 \mathrm{~A} 2$ indicated that five active site residues that are different between these enzymes (Ser122, Asn221, Gly225, Leu312 and Val382 in P450 1A1 and the corresponding residues in P450 1A2: Thr124, Thr223, Val227, Asn312 and Leu382) might be involved in determining substrate specificity (Liu et al., 2004). This result was confirmed by the finding that five reciprocal mutations in P450 1A1 and 1A2 altered enzymatic activity with alkoxyresorufins as substrates. Moreover, mutations at position 382 in both P450 1A1 and P450 1A2 shifted substrate specificity from one enzyme to another (Liu et al., 2004). Further computational and experimental studies with multiple P450 1A2 mutants confirmed the importance of this residue for alkoxyresorufin oxidation (Tu et al., 2008). Therefore, it would be of interest to examine the effect of these mutations on oxidation of other types of substrates.

In the current study, we chose phenacetin as a substrate. This compound has been used as the most common marker for P450 1A2 activity in the in vitro studies of $45 \%$ of new drugs by investigators in the pharmaceutical industry (Yuan et al., 2002). The objective of the present study was to investigate whether any reciprocal mutations in P450 1A2 may alter phenacetin oxidation and to examine the potential mechanism(s) that might be involved. Five single mutants and four multiple mutants containing the L382V substitution were evaluated using a combination of molecular modeling and experimental methods. These included enzyme kinetics and stoichiometry studies, as well as molecular dynamics (MD) simulations of phenacetin in the active site of P450 1A2 mutants to facilitate the interpretation of experimental results. This study should provide 
an increased understanding of the biochemical aspects of substrate specificity in the P450 family of enzymes.

\subsection{Materials and Methods}

Materials. Phenacetin, acetaminophen, 2-hydroxy acetanilide, sodium dithionite, NADPH, ampicillin, isopropyl- $\beta$-D-thiogalactopyranoside (IPTG), $\delta$-aminolevulinic acid, CHAPS, dilauroyl-L-3-phosphatidyl choline (DLPC) and phenylmethanesulfonyl fluoride were from Sigma-Aldrich (St. Louis, MO). Nickel-nitrilotriacetic acid agarose and a gel extraction kit were purchased from QIAGEN (Valencia, CA). Potassium phosphate, EDTA, acetic acid and high-performance liquid chromatography-grade methanol were purchased from Thermo Fisher Scientific (Waltham, MA). All the other chemicals used were of analytical grade and were obtained from standard commercial sources.

Protein Expression and Purification. The clones of P450 1A1 WT, 1A2 WT and P450 1A2 single mutants, T124S, T223N, V227G, N312L and L382V, all of them containing a His-tag for easy purification, were constructed earlier (Liu et al., 2003;2004). P450 1A2 His-tag multiple mutants, L382V/T223N, L382V/N312L, L382V/T223N/ $\mathrm{N} 312 \mathrm{~L}$ and L382V/T124S/N312L, were also constructed previously (Tu et al., 2008). The P450 enzymes were expressed in Escherichia coli DH5 $\alpha$ cells and purified essentially as described previously (Liu et al., 2004; Tu et al., 2008). During the purification, the addition of $5 \mathrm{mM}$ caffeine in the purification buffers helped to stabilize P450 1A2 proteins. The substrate caffeine was removed completely from the enzyme 
preparation during the ultrafiltration stage, as verified by HPLC. Rat P450 reductase was expressed in E. coli and purified according to an established procedure (Liu et al., 2003). The final purity of the enzymes was assessed by SDS-polyacrylamide gel electrophoresis. Western blots were performed using anti-human P450 1A1/1A2 (Oxford Biomedical Research, Oxford, MI), and P450 proteins were visualized as described previously (Kedzie et al., 1991). P450 content was determined by reduced CO/reduced difference spectra (Omura and Sato, 1964), and protein was measured using Folin phenol reagent (Lowry et al., 1951).

P450 Activity Assay. Phenacetin O-dealkylase activities of P450 1A2 WT and mutants were determined by HPLC measurements as described previously (von Moltke et al., 1996) with some modifications. The reaction mixtures contained $0.5 \mu \mathrm{M}$ P450 1A2, $1 \mu \mathrm{M}$ P450 reductase, and $45 \mu \mathrm{M}$ DLPC in $100 \mathrm{mM}$ potassium phosphate buffer, $\mathrm{pH}$ 7.5. The enzymes and DLPC were preincubated for $2 \mathrm{~min}$ at $37^{\circ} \mathrm{C}$ before the dilution. For kinetic assays, phenacetin was added at concentrations ranging from 0 to $1000 \mu \mathrm{M}$, and the mixture was incubated for another $3 \mathrm{~min}$ at $37^{\circ} \mathrm{C}$. The reaction was initiated by adding NADPH to a final concentration of $1 \mathrm{mM}$ in a total volume of $1 \mathrm{ml}$, and conducted for $30 \mathrm{~min}$. The reaction was terminated by the addition of $5 \mu 1$ of $60 \% \mathrm{HClO}_{4}$ and the reaction mixture was put on ice for $10 \mathrm{~min}$. Ten microliters of 2-hydroxy acetanilide $(100 \mu \mathrm{M})$ was then added as an internal standard for HPLC determination. The reaction mixture was centrifuged at $1000 \mathrm{~g}$ for $5 \mathrm{~min}$, and $100 \mu \mathrm{l}$ of the supernatant was removed and used directly for HPLC analysis. The product acetaminophen was eluted from a $\mathrm{C}_{18}$ column (Alltech Associates, Deerfield, IL) with a mobile phase of 
methanol $/ 0.1 \%$ acetic acid (30:70, v/v; flow rate, $1.5 \mathrm{ml} / \mathrm{min})$, and monitored at $254 \mathrm{~nm}$. The product was quantified using acetaminophen standards. The kinetic parameters $\left(\mathrm{V}_{\max }\right.$ and $\left.k_{\mathrm{cat}}\right)$ were calculated using nonlinear regression with GraphPad Software Inc, (San Diego, CA) Prism software.

Binding Constant Determination. Spectral binding constants for phenacetin bound in the active site of P450 1A1 WT and P450 1A2 enzymes were obtained using difference visible spectroscopy (Modi et al., 1995). Solutions (800 $\mu$ l) contained 0.5 $\mu \mathrm{M}$ P450 1A2 WT or the mutants in $100 \mathrm{mM}$ phosphate buffer, containing $20 \%$ glycerol and $0.1 \mathrm{mM}$ EDTA, $\mathrm{pH}$ 7.4. Two microliters of different concentrations of solutions of phenacetin in menthol was added to the sample cuvette, and the same volume of menthol was added to the reference, and UV spectra were then recorded. The data were analyzed by nonlinear regression analysis using Microsoft (Redmond, WA) Excel software.

NADPH Oxidation. The rate of NADPH oxidation was determined spectrophotometrically at $340 \mathrm{~nm}$ in a cuvette thermostated at $37^{\circ} \mathrm{C}$. The reaction mixture was similar to that used for the phenacetin assay and contained $0.5 \mu \mathrm{M}$ P450 enzyme, $1 \mu \mathrm{M}$ P450 reductase, $45 \mu \mathrm{M}$ DLPC and $1 \mathrm{mM}$ phenacetin in a $100 \mathrm{mM}$ potassium phosphate buffer, $\mathrm{pH} 7.5$, in a volume of $980 \mu 1$. The reaction was initiated by the addition of $20 \mu \mathrm{l}$ of $50 \mathrm{mM}$ NADPH. The NADPH oxidation rates were recorded for about 3 minutes at $340 \mathrm{~nm}$ from the beginning of the reaction. The molar extinction coefficient of 6.22 per millimolar per centimeter for NADPH at $340 \mathrm{~nm}$ was used to obtain oxidation rates in nanomole per minute per nanomole of P450. Three $50-\mu 1$ 
aliquots of the reaction mixture were removed after 1,2, and 3 min and quenched with 50 $\mu 1$ of $10 \% \mathrm{CF}_{3} \mathrm{COOH}$. The triplicate-quenched reaction mixture was then used to measure hydrogen peroxide $\left(\mathrm{H}_{2} \mathrm{O}_{2}\right)$.

$\mathrm{H}_{2} \mathrm{O}_{2}$ Production. The reaction mixtures from the NADPH oxidation assay were used to measure the production of $\mathrm{H}_{2} \mathrm{O}_{2}$ using the xylenol orange iron (III) assay (Jiang et al., 1990; Fang et al., 1997) with slight modifications. The coloring agent was prepared by mixing 100 volumes of $125 \mu \mathrm{M}$ xylenol orange in $100 \mathrm{mM}$ sorbitol and 1 volume of $25 \mathrm{mM}$ of fresh ferrous $\left(\mathrm{Fe}^{2+}\right)$ ammonium sulphate in $2.5 \mathrm{M} \mathrm{H}_{2} \mathrm{SO}_{4}$. The calibration curve was prepared using the quenched reaction mixture, which was supplemented with $\mathrm{H}_{2} \mathrm{O}_{2}$ at concentrations ranging from 0 to $10 \mu \mathrm{M}$. The $\mathrm{H}_{2} \mathrm{O}_{2}$ standard solutions were prepared fresh on the day of the assay by dilution of a $30 \% \mathrm{H}_{2} \mathrm{O}_{2}$ stock solution. The reaction mixture was incubated at room temperature for $1 \mathrm{~h}$. Absorbance was recorded using a Beckman Counter, Inc. (Fullerton, CA) spectrophotometer set at $560 \mathrm{~nm}$ to obtain the concentration of $\mathrm{H}_{2} \mathrm{O}_{2}$ produced in nanomole per minute per nanomole of $\mathrm{P} 450$.

Oxygen Consumption. The reaction was conducted using a Mitocell (Strathkelvin Instruments Ltd, Glasgow, U.K.), which was connected to a water bath thermostated at $37^{\circ} \mathrm{C}$. The reaction mixture was prepared in a similar way to that for the NADPH oxidation assay. Nine hundred eighty microliters of the sample was placed in the chamber of the Mitocell, and once a steady baseline was established, the reaction was initiated by the addition of $20 \mu \mathrm{l}$ of NADPH. The oxygen consumption was recorded over 5 min as micromolar per hour, which was then converted to nanomole per minute 
per nanomole of P450.

Molecular Modeling Methods: General. Molecular modeling simulations were conducted using a Silicon Graphics Octane workstation with Insight II software (Accelrys, San Diego, CA). The crystal structure of P450 1A2 (Protein Data Bank code: 2hi4) was obtained courtesy of Dr. Eric F. Johnson (The Scripps Research Institute, La Jolla, CA) (Sansen et al., 2007). The heme cofactor was removed and replaced with the oxoheme cofactor. Substrate phenacetin was constructed with Insight II/Builder module and optimized. The models of P450 1A2 single and multiple mutants were constructed from the crystal structure of P450 1A2 WT by the replacement of selected amino acid(s) and further refinement of the structures according to the previously established procedure (Liu et al., 2003, 2004; Tu et al., 2008). MD simulations and energy minimization were carried out using the Insight II/Discover module with the consistent valence force field supplemented with parameters for heme and ferryl oxygen, as described earlier (Paulsen and Ornstein, 1991, 1992). The nonbond cutoff was $16 \AA$, and all the other parameters were set at their default values. Structural refinement of P450 1A2 WT and mutants involved 1000 steps of minimization using steepest descent gradient followed by 10-ps MD and then another 1000 steps of steepest descent minimization. The optimized structures were used for the subsequent docking studies.

Docking of Phenacetin into the Active Site of CYP1A2 WT and Mutants. Initially, phenacetin was manually placed into the active site of P450 1A2 WT and the mutants on the distal side of the oxoheme. Docking of phenacetin was performed with Insight II 
(Accelrys)/Affinity module using default parameters, as described previously (Liu et al., 2004; Ericksen and Szklarz, 2005; Tu et al., 2008). Residues within $10 \AA$ of the initial phenacetin position comprised the flexible region of the receptor (P450 1A2 WT and mutants) during all the docking runs. The Affinity docking method uses both the Monte Carlo search technique and simulated annealing approach, followed by the minimization protocol to generate low-energy substrate binding orientations. A distance-dependent dielectric constant was applied to simulate charge screening by water molecules. The 10 lowest-energy phenacetin binding orientations obtained from Affinity docking were selected for further analysis.

MD Simulations of Enzyme-Substrate Complexes. MD simulations were performed to investigate phenacetin mobility in the active site and the effect of mutations on substrate orientation. The starting configuration for MD simulations chosen from Affinity docking represented the productive binding orientation of phenacetin leading to its O-dealkylation and had the lowest potential energy rank. The MD simulations of each phenacetin-enzyme complex were performed at $310 \mathrm{~K}$ in vacuo essentially as described earlier (Liu et al., 2004;Tu et al., 2008). The substrate, heme, and protein residues within $10 \AA$ from the initial substrate position were flexible without any restraints, whereas the remainder of the protein was fixed. A distance-dependent dielectric constant was used to simulate aqueous environment, and the nonbond cutoff distance was $16 \AA$. After 5-ps MD equilibration phase, the MD simulations were continued for $100 \mathrm{ps}$, and 400 frames obtained every 250 fs were extracted to record the snapshots of each enzyme-substrate complex. 
In addition, to evaluate the effect of explicit solvent on phenacetin dynamics in the active site, we performed 100-ps MD simulations on solvated enzyme-substrate complexes using a similar protocol. The enzymes chosen were P450 1A2 WT and the L382V mutant. The enzyme-substrate complexes were solvated using crystallographic water molecules from P450 1A2 crystal structure and optimized before MD with 1000 steps of steepest descent minimization using a nonbond cutoff of $16 \AA$ and dielectric constant of 1. Similar to previous MD simulations, only protein residues, heme, substrate, and solvent within a $10-\AA ̊$ radius of the initial substrate position were permitted to move, whereas the remainder of the protein and other water molecules were fixed. This ensures that none of the moving solvent molecules escape from the vicinity of the active site. In contrast to previous MD simulations, the flexible region also included 21 water molecules surrounding phenacetin. For the aqueous simulations, the dielectric constant was set to 1 . All the other parameters were the same as for the previous enzyme-substrate simulations without explicit solvent present.

All the MD trajectories were examined using Insight II (Accelrys)/Analysis module. To score the likelihood of hydroxylation, each sampled frame of a given enzymesubstrate complex was evaluated using the following geometric criterion: $r \leq 3.5 \AA$ and $\theta$ $\geq 120^{\circ}$, where $\mathrm{r}$ represents the distance between the ferryl oxygen and the hydrogen of the substrate to be abstracted; $\theta$ represents the angle between ferryl oxygen, the hydrogen atom to be abstracted, and the carbon at the oxidation site, as described previously (Ericksen and Szklarz, 2005; Tu et al., 2008). Trajectory data from 100-ps MD simulations were extracted and graphed using Microsoft Excel. The MD frames where the geometric criterion, $\mathrm{r} \leq 3.5 \AA$ and $\theta \geq 120^{\circ}$, was satisfied were counted as hits. The 
number of hits is a useful indicator of whether a P450 1A2-mediated phenacetin $O$ deethylation occurred.

\subsection{Results}

Kinetics of Phenacetin O-Deethylation by P450 1A2 WT and Mutants. P450 1A2 enzymes were expressed in E. coli and purified. The overall yield of the procedure was approximately 20 to $40 \%$, similar to that reported previously (Liu et al., 2004; Tu et al., 2008). The purity of P450 1A2 WT and mutants verified by SDS-Polyacrylamid gel electrophoresis and Western blots indicated that they were at least 95\% pure. The spectrum of the $\mathrm{Fe}^{\mathrm{II}}-\mathrm{CO}$ complex exhibited a characteristic peak at $450 \mathrm{~nm}$, with little or no P420 formation. The holoenzyme content of the enzymes was usually in the range of 40 to $60 \%$, as previously observed in our laboratory.

Kinetic parameters, $k_{\text {cat }}, \mathrm{K}_{\mathrm{m}}$ and substrate specificity $\left(k_{\mathrm{cat}} / \mathrm{K}_{\mathrm{m}}\right)$, were determined for purified P450 1A2 WT and mutants using a range of substrate phenacetin concentrations. Phenacetin undergoes $O$-deethylation to form acetaminophen as the main product of the reaction. Kinetic parameters for P450 1A2 WT and mutants are shown in Table 2.1. Compared with P450 1A2 WT, the mutations affected both $k_{\text {cat }}$ and $\mathrm{K}_{\mathrm{m}}$. The P450 1A2 L382V mutant and multiple mutants containing the L382V mutation displayed 2- or 3fold higher $k_{\text {cat }}$ than the WT enzyme. Four other single mutants, namely, T124S, T223N, V227G, and N312L, exhibited much lower $k_{\text {cat }}$ than the WT.

As shown in Table 2.1, the $\mathrm{K}_{\mathrm{m}}$ values for P450 1A2 WT and mutants varied greatly. In general, the $\mathrm{K}_{\mathrm{m}}$ values for all the mutants were more than $50 \%$ lower than for the WT $(\sim 60 \mu \mathrm{M})$. The lowest values of $\mathrm{K}_{\mathrm{m}}$ were observed for several mutants containing the 
L382V substitution, including L382V $(\sim 6 \mu \mathrm{M}), \quad$ L382V/T223N $(\sim 8 \mu \mathrm{M})$, and L382V/T124S/N312L $(\sim 10 \mu \mathrm{M})$, which suggests that the L382V mutation significantly increased the binding affinity of the enzyme for phenacetin. The substrate specificities of the $\mathrm{L} 382 \mathrm{~V}$ mutant and multiple mutants containing the L382V mutation, expressed as $k_{\text {cat }} / \mathrm{K}_{\mathrm{m}}$, were at least 5 -fold higher than that of the WT (Table 2.1). In particular, the relative substrate specificities of $\mathrm{L} 382 \mathrm{~V}$ and L382V/T223N mutants were more than 20fold higher, which is extremely high. Incidentally, phenacetin is less efficiently metabolized by P450 1A1 WT, $\left(k_{c a t} 0.5 \min ^{-1}\right.$ and $\left.\mathrm{K}_{\mathrm{m}} 66 \mu \mathrm{M}\right)$, with $k_{c a t}$ close to one third of the value observed with P450 1A2 WT (see Table 2.1) and the $k_{\text {cat }} / K_{\mathrm{m}}$ ratio lower than 0.01 .

Phenacetin binding constants were also determined for P450 1A2 WT and some mutants. P450 1A2 WT and the N312L mutant showed similar phenacetin binding, with binding constants of $17.1 \mu \mathrm{M}$ and $10.2 \mu \mathrm{M}$, respectively. In contrast, the $\mathrm{L} 382 \mathrm{~V}$ and the L282V/N312L mutants displayed much lower values for binding constants, namely, 0.7 $\mu \mathrm{M}$ and $3.5 \mu \mathrm{M}$, indicating tighter substrate binding. P450 1A1 WT exhibited much weaker binding, with a binding constant of $57 \mu \mathrm{M}$.

Stoichiometry of Phenacetin O-Deethylation. To assess whether the L382V mutation affected P450 1A2 coupling efficiency of reducing equivalents to acetaminophen formation, stoichiometry experiments were conducted. The rates of NADPH oxidation, hydrogen consumption, product formation, $\mathrm{H}_{2} \mathrm{O}_{2}$, and excess water production for phenacetin oxidation by P450 1A2 WT and mutants are shown in Table 2.2. The excess water formation was calculated from the difference between the rates of 
NADPH oxidation and rates of $\mathrm{H}_{2} \mathrm{O}_{2}$ and product formation (Excess $\mathrm{H}_{2} \mathrm{O}=\mathrm{NADPH}-$ $\mathrm{H}_{2} \mathrm{O}_{2}$ - product). The amount of water was also obtained from the difference between the rate of oxygen consumption and rates of $\mathrm{H}_{2} \mathrm{O}_{2}$ plus product formation $\left[\mathrm{H}_{2} \mathrm{O}=2\left(\mathrm{O}_{2}-\right.\right.$ $\mathrm{H}_{2} \mathrm{O}_{2}$ - product)], as reported by others (Fang et al., 1997), giving the values which were very similar (within 5\%) to those derived from the previous equation (data not shown). The coincubation of phenacetin with P450 1A2 L382V and three multiple mutants, L382V/T223N, L382V/N312L and L382V/T223N/N312L, resulted in consumption of both NADPH and oxygen by the mutants at rates $\sim 2$-fold greater than those with the WT enzyme. Likewise, the formation of product acetaminophen, as well as byproducts such as $\mathrm{H}_{2} \mathrm{O}_{2}$ and water, were 2 to 3 times higher in the case of these mutants. The exception was the $\mathrm{L} 382 \mathrm{~V} / \mathrm{T} 124 \mathrm{~S} / \mathrm{N} 312 \mathrm{~L}$ mutant, which seemed to utilize NADPH at a rate similar to the WT enzyme, but displayed increased consumption of oxygen, along with increased product and $\mathrm{H}_{2} \mathrm{O}_{2}$ formation. On the other hand, four single mutants, T124S, T223N, V227G and N312L, are similar or less efficient than the WT with respect to NADPH oxidation, oxygen consumption, hydrogen peroxide, and water production but exhibit a substantial decrease in product formation.

Table 2.3 presents the effects of mutations on the coupling efficiency of P450 1A2, both overall and at specific P450 uncoupling branching points. The ratios of product formation to NADPH oxidation, accounting for the overall efficiency of P450 1A2 coupling of reducing equivalents to product, were higher for $\mathrm{L} 382 \mathrm{~V}$ and multiple mutants containing the L382V substitution than for the WT. In contrast, other single mutants, T124S, T223N, V227G and N312L, exhibited significantly decreased coupling efficiencies compared to the WT enzyme (20-30\% of WT). All of the enzymes displayed 
similar ratios of $\mathrm{H}_{2} \mathrm{O}_{2}$ production to $\mathrm{O}_{2}$ consumption, which suggests that the mutations had no effect on uncoupling at the first and second branching points of the P450 cycle. On the other hand, significant differences between the enzymes were observed with respect to the $\mathrm{H}_{2} \mathrm{O}$ /product ratios used to measure uncoupling at the third branching point. Thus, for the L382V mutant and multiple mutants containing the L382V substitution, these ratios were generally lower than that for the WT, whileas for the other single mutants, these ratios were 3 -fold higher. Therefore, low activities of the four single mutants were likely caused by dramatically increased uncoupling to water, whereas the increase in activity in the L382V-containing mutants resulted from decreased water formation.

Molecular Modeling Analyses. Using the crystal structure of P450 1A2, molecular modeling studies have been conducted to understand the effects of single and multiple mutations on enzyme-substrate interactions and substrate mobility, as well as to explain the alterations of catalytic efficiency. Figure 2.1 depicts binding orientations of phenacetin within the active sites of P450 1A2 WT and the L382V mutant. In general, the binding orientation of phenacetin in both enzymes was very similar. However, the replacement of Leu382 by a smaller Val increased the volume of the active site and allowed the hydrogens at the oxidation site of phenacetin to approach closer to the ferryl oxygen of the heme, which facilities hydrogen abstraction. The average distance between the hydrogens at the oxidation site of phenacetin and the ferryl oxygen of the L382V mutant was $3.1 \AA$, compared to $3.7 \AA$ for the WT enzyme. Similar results were also obtained for the L382V/T223N and L382V/T223N/N312L mutants. In contrast, both 
hydrogens at the oxidation site of phenacetin were much farther away from the ferryl oxygen in the active sites of T124S, T223N, V227G, and N312L mutants (data no shown). These findings correlate well with the results of kinetic and stoichiometric studies described previously and suggest that the L382V substitution not only increases catalytic efficiency ( $\left.k_{\text {cat }}\right)$ of P450 1A2 but also decreases $\mathrm{K}_{\mathrm{m}}$ and enzyme uncoupling.

To examine the tendency of phenacetin to remain in the productive binding orientation in the active site of the enzyme, $100 \mathrm{ps}$ of MD simulations were performed, as described under Materials and Methods. After the 5-ps MD equilibration phase, the energy of the system remained constant throughout the simulations. The mobility of the substrate varied with the mutant: we observed fairly low mobility for the WT enzyme, L382V, T124S, and L382V/T223N/N312L mutants, with root mean square deviation (RMSD) from the initial substrate orientation of 1 to $2 \AA$, moderate mobility for V227L and N312L mutants with RMSD of 2 to $4 \AA$, and a high phenacetin mobility in the case of T223N and L382V/T223N mutants (RMSD $>4 \AA$ ).

The productive binding orientations of phenacetin were determined using geometric parameters, distance $\mathrm{r}$ and angle $\theta$, as described under Materials and Methods. These parameters were then plotted based on 400 recorded snapshots for each enzyme-substrate complex. The representative plots, those for P450 1A2 WT, N312L, L382V, and L382V/T223N mutants, showing the ensembles of substrate orientations, are presented in Fig. 2.2. The region where the geometric criterion $\left(r \leq 3.5 \AA\right.$ and $\left.\theta \geq 120^{\circ}\right)$ is satisfied is gray, and the points (or frames) located within represent all the snapshots of each enzyme-substrate complex where phenacetin was bound in the productive binding orientation. The distribution of the MD frames for each enzyme-substrate complex 
displayed varied. Overall, phenacetin showed higher occupancy within a productive binding region (counted as hits) in the $\mathrm{L} 382 \mathrm{~V}$ and $\mathrm{L} 382 \mathrm{~V} / \mathrm{T} 223 \mathrm{~N}$ mutants than in the WT. Similar results were also seen in the case of other multiple mutants containing L382V (data not shown), whereas few hits, if any, were observed for the remaining four single mutants, as shown for the N312L mutant (Fig. 2.2B). A quantitative analysis of the hits for each enzyme-substrate complex revealed that the number of hits for L382V, L382V/T223N, and L382V/T223N/N312L mutants were 2-, 4-, and 5-fold higher, respectively, than that for the WT (Table 2.4). In contrast, zero or few hits were obtained for T124S, T223N, V227G, and N312L mutants during 100-ps dynamics. It is possible that some hits might be recorded during a longer simulation time. Overall, the results of MD simulations are, like those from docking experiments, consistent with the kinetic and stoichiometric analyses of P450 1A2 WT and mutants.

A possible drawback of the simulations described previously might have been the use of the distance-dependent dielectric constant instead of explicit solvent. Therefore, we have also conducted MD simulations of phenacetin docked in the active site of P450 1A2 WT and the L382V mutant with the solvent molecules present and the dielectric constant of 1. In the presence of water, 70 hits were recorded for the WT enzyme and 144 hits for the L382V mutant. Thus, in both cases, the percentage of hits increased less than $10 \%$ and to a very similar extent (9.4\% for the WT and $7.5 \%$ for the mutant) compared with the results from MD simulations without water (see Table 2.4). This result indicates that, although some changes may be observed with solvent present, simulations with distancedependent dielectric provide a reasonable approach to explain the observed experimental findings. 


\subsection{Discussion}

Our previous studies indicated that residue 382 plays an important role in controlling the specificity of alkoxyresorufin O-dealkylation by P450 1A1 and 1A2 (Liu et al., 2003; 2004; Tu et al., 2008). Because phenacetin is another important probe substrate for P450 1A2, the studies to address the effects of reciprocal mutations, particularly L382V, on phenacetin oxidation may broaden our understanding of the role of this residue in substrate specificity. In the present study, nine single and multiple mutants were investigated using a battery of complementary approaches, such as kinetic assays, stoichiometry measurements and molecular modeling methods. The results showed that the $\mathrm{L} 382 \mathrm{~V}$ substitution resulted in a significant increase in catalytic activity and substrate specificity of P450 1A2. All of the multiple mutants that contained this substitution displayed very similar kinetics, stoichiometry, and dynamic mobility as the single L382V mutant. Thus, the presence of this single residue was critical for dramatically improving the efficiency of phenacetin oxidation by P450 1A2.

To date, many residues of P450 1A2 have been identified that may play a role in enzyme-ligand interactions by site-directed mutagenesis and/or molecular modeling studies (Yun et al., 2000; Liu et al., 2004; Zhou et al., 2009). In the case of single mutants, most of the mutations, including T124S, T223N, V227G, and N312L in the present study, resulted in decreased catalytic activity and substrate specificity compared to the WT enzyme (Parikh et al., 1999; Liu et al., 2004). A number of P450 1A2 mutants obtained from random mutagenesis showed increased catalytic activities and substrate specificities toward phenacetin (Parikh et al., 1999), but none of them was as highly active as the L382V mutant reported in this study (Table 2.1). It is worth mentioning that 
the kinetic parameters for phenacetin O-dealkylation by P450 1A2 WT determined in the present investigation were very similar to those reported by Parikh et al. (1999). Although the $\mathrm{L} 382 \mathrm{~V}$ mutation dramatically increased oxidation of phenacetin, it led to a significant decrease in 7-methoxyresorufin O-dealkylation (Liu et al., 2004). Thus, the functional effect of residue substitution appears to be dependent on the substrate (Zhou et al., 2009).

Moreover, the binding constants determined for P450 1A2 WT and mutants showed that the L382V substitution leads to tighter phenacetin binding in the active site of the L382V-containing mutants, consistent with enzyme kinetics results. This effect may increase phenacetin residence time, resulting in higher activity.

To better explain the effects of mutations on catalytic activity and substrate specificity of P450 1A2, stoichiometry studies were performed. The coupling efficiencies of different mutants, expressed in terms of product/NADPH, $\mathrm{H}_{2} \mathrm{O}_{2} / \mathrm{O}_{2}$, and $\mathrm{H}_{2} \mathrm{O} /$ product ratios, were compared to those of WT. A similar approach has been used by Fang et al. (1997) and Kobayashi et al. (1998) to evaluate coupling efficiencies of P450 2B1 mutants. Frequently, the mutation decreases the coupling efficiency of the P450, as observed with P450 2B1 (Fang et al., 1997; Kobayashi et al., 1998) and P450cam (French et al., 2002), but the effect depends upon the substrate. Previously studied P450 1A2 mutants showed only a small increase in coupling efficiency with phenacetin as a substrate (Yun et al., 2000), in contrast to our results with the L382V-containing mutants. In the present studies, the L382V mutant and multiple mutants containing the L382V substitution were similar or more efficient at coupling reducing equivalents to acetaminophen formation than the WT (Table 2.3). In general, the increased ratios of product/NADPH for the 
L382V mutant and multiple mutants and the decreased ratios for T124S, T223N, V227G, and $\mathrm{N} 312 \mathrm{~L}$ mutants were in agreement with the kinetic data regarding phenacetin turnover rates. Although no significant changes of uncoupling to $\mathrm{H}_{2} \mathrm{O}_{2}$ at the first and the second branching points were observed in all the mutants, those that contained the L $382 \mathrm{~V}$ substitution showed less uncoupling to water (decreased $\mathrm{H}_{2} \mathrm{O}$ /product ratio; Table 2.3). Thus, it seems reasonable to suggest that the L382V substitution in P450 1A2 yields the mutants that use $\mathrm{NADPH}$ and $\mathrm{O}_{2}$ more efficiently to oxidize phenacetin to products and display less uncoupling to water, so that the overall coupling efficiency of the enzyme increases, which is consistent with enzyme kinetics results (Table 2.1).

Molecular modeling studies provide another possible explanation of the effects of mutations on phenacetin specificity, as indicated by changes in kinetic parameters. For these simulations, we used the X-ray structure of P450 1A2, and the structures of the mutants were derived from the crystal. As reported by Sansen et al. (2007), this P450 1A2 structure has a closed compact active site, without clear solvent or substrate access channels, with a relatively small volume of the cavity, estimated at $375 \AA^{3}$. The active site of $1 \mathrm{~A} 2$ is about $44 \%$ larger than that of P450 2A6 $\left(260 \AA^{3}\right)$ and significantly smaller than that of P450 3A4 (1385 $\AA^{3}$ ) (Sansen et al., 2007). Consequently, only planar compounds, such as $\alpha$-naphthoflavone, and typical P450 1A2 substrates such as phenacetin, 7-ethoxyresorfin, caffeine, tacrine, or theophylline can be fitted well with the narrow and flat active site cavity of enzyme. Leu382 of P450 1A2 is a critical residue located close to the heme iron, and its replacement with a smaller Val increases the volume of the active site near heme. The L382V substitution allows phenacetin to move closer to heme, so that one of the hydrogens at the oxidation site is within a hydrogen- 
bonding distance from the ferryl oxygen (Figure 2.1), which promotes hydrogen abstraction. This is consistent with the MD results (Table 2.4, Figure 2.2). Consequently, the movement of phenacetin closer to the ferryl oxygen in the L382V mutants helps to explain not only the substantial increase in $k_{\mathrm{cat}}$ and a decrease in $\mathrm{K}_{\mathrm{m}}$ for the production of acetaminophen (Table 2.1) but also more efficient coupling of the P450 reaction cycle with less water formation (Table 2.3).

MD simulations similar to those described in this work have been successfully used in our previous studies for fairly rapid predictions or interpretation of experimental results (Ericksen and Szklarz, 2005; Tu et al., 2008). The present studies suggest that the use of the distance dependent dielectric constant can be a reasonable substitute for the presence of explicit water molecules. We have observed only a small increase in the percentage of hits (less than 10\%) from MD simulations with water. These conclusions may be further verified by more extensive MD simulations of the complete proteinsubstrate complexes on nanosecond timescales. More recently, longer 2-ns MD simulations have been successfully used to predict the effect of mutations on the catalytic efficiency of CYP2B6 (Nguyen et al., 2008).

In summary, our results show that the L382V substitution in P450 1A2 can alter the binding orientation of phenacetin within the active site of the enzyme, so that the site of metabolism moves closer to the heme iron. This provides a good mechanistic explanation for the increased catalytic efficiency as well as coupling efficiency of phenacetin O-dealkylation in $1 \mathrm{~A} 2$ mutants containing the L382V substitution. The current studies also show that a combination of several experimental approaches with molecular modeling methods can improve our understanding of P450 catalysis. These 
different methodologies complement each other well to offer a mechanistic interpretation of P450 function on a molecular level.

\subsection{Acknowledgments}

We thank Dr. Rahul Deshmukh for help and advice concerning expression and purification of P450 enzymes. Molecular modeling studies were performed at the Computational Chemistry and Molecular Modeling Laboratory, Department of Basic Pharmaceutical Sciences, School of Pharmacy, West Virginia University, Morgantown, WV. 
Table 2.1. Kinetic Parameters for Phenacetin $O$-deethylation by Purified P450 1A2 WT and Mutants

\begin{tabular}{|c|c|c|c|c|}
\hline \multirow{2}{*}{ P450 1A2 } & \multicolumn{4}{|c|}{ Phenacetin $O$-deethylation } \\
\hline & $k_{\text {cat }}(/ \min )^{\mathrm{a}}$ & $\mathrm{K}_{\mathrm{m}}(\mu \mathrm{M})^{\mathrm{a}}$ & $k_{\text {cat }} / \mathrm{K}_{\mathrm{m}}(\mathrm{Mm} / \mathrm{min})^{\mathrm{b}}$ & {$\left[\left(k_{\text {cat }} / \mathrm{K}_{\mathrm{m}}\right)_{\text {mutant }} /\left(k_{\mathrm{cat}} / \mathrm{K}_{\mathrm{m}}\right)_{\mathrm{WT}}\right]$} \\
\hline WT & $1.28 \pm 0.08$ & $59.70 \pm 1.82$ & $0.02 \pm 0.01$ & 1.00 \\
\hline T124S & $0.29 \pm 0.03$ & $28.90 \pm 1.10$ & $0.01 \pm 0.01$ & 0.47 \\
\hline $\mathrm{T} 223 \mathrm{~N}$ & $0.30 \pm 0.01$ & $26.99 \pm 0.01$ & $0.01 \pm 0.01$ & 0.52 \\
\hline V227G & $0.38 \pm 0.02$ & $32.36 \pm 2.93$ & $0.01 \pm 0.01$ & 0.55 \\
\hline N312L & $0.31 \pm 0.01$ & $25.26 \pm 0.01$ & $0.01 \pm 0.01$ & 0.57 \\
\hline L382V & $3.03 \pm 0.06$ & $5.75 \pm 0.57$ & $0.53 \pm 0.04$ & 24.77 \\
\hline L382V/T223N & $3.91 \pm 0.10$ & $7.77 \pm 0.80$ & $0.51 \pm 0.06$ & 23.65 \\
\hline L382V/N312L & $3.05 \pm 0.15$ & $16.14 \pm 2.05$ & $0.19 \pm 0.02$ & 8.87 \\
\hline L382V/T223N/N312L & $3.67 \pm 0.10$ & $32.42 \pm 11.31$ & $0.12 \pm 0.04$ & 5.61 \\
\hline L382V/T124S/N312L & $2.81 \pm 0.03$ & $10.13 \pm 2.40$ & $0.28 \pm 0.07$ & 13.34 \\
\hline
\end{tabular}

${ }^{a}$ Data are means of triplicate determinations.

${ }^{\mathrm{b}} k_{\mathrm{cat}} / \mathrm{K}_{\mathrm{m}}$ represents substrate specificity. 
Table 2.2. Rates [nmol/min/(nmol of P450)] Determined for Phenacetin Metabolism by P450 1A2 Wild-Type and Mutants ${ }^{\mathrm{a}}$

\begin{tabular}{|c|c|c|c|c|c|}
\hline $\mathrm{P} 4501 \mathrm{~A} 2$ & NADPH oxidized & $\mathrm{O}_{2}$ consumed & Product formed & $\mathrm{H}_{2} \mathrm{O}_{2}$ produced & Excess $\mathrm{H}_{2} \mathrm{O}^{\mathrm{b}}$ \\
\hline WT & $43 \pm 4$ & $22.7 \pm 0.9$ & $1.28 \pm 0.08$ & $14 \pm 2$ & $15 \pm 2$ \\
\hline $\mathrm{T} 124 \mathrm{~S}$ & $27 \pm 2$ & $14.8 \pm 0.4$ & $0.29 \pm 0.03$ & $10 \pm 0$ & $9 \pm 1$ \\
\hline $\mathrm{T} 223 \mathrm{~N}$ & $41 \pm 3$ & $17.3 \pm 0.7$ & $0.30 \pm 0.00$ & $10 \pm 1$ & $14 \pm 2$ \\
\hline V227G & $40 \pm 3$ & $16.9 \pm 0.5$ & $0.38 \pm 0.02$ & $9 \pm 1$ & $15 \pm 2$ \\
\hline N312L & $32 \pm 2$ & $18.3 \pm 0.3$ & $0.31 \pm 0.00$ & $13 \pm 2$ & $10 \pm 1$ \\
\hline L382V & $84 \pm 6$ & $47.0 \pm 1.3$ & $3.03 \pm 0.06$ & $29 \pm 3$ & $30 \pm 4$ \\
\hline $\mathrm{L} 382 \mathrm{~V} / \mathrm{T} 223 \mathrm{~N}$ & $98 \pm 7$ & $57.9 \pm 2.5$ & $3.91 \pm 0.10$ & $38 \pm 3$ & $32 \pm 5$ \\
\hline $\mathrm{L} 382 \mathrm{~V} / \mathrm{N} 312 \mathrm{~L}$ & $70 \pm 4$ & $41.0 \pm 2.0$ & $3.05 \pm 0.15$ & $29 \pm 3$ & $18 \pm 3$ \\
\hline L382V/T223N/N312L & $72 \pm 5$ & $41.7 \pm 1.1$ & $2.18 \pm 0.03$ & $28 \pm 3$ & $23 \pm 3$ \\
\hline L382V/T124S/N312L & $42 \pm 3$ & $34.2 \pm 0.9$ & $3.67 \pm 0.10$ & $26 \pm 2$ & $9 \pm 2$ \\
\hline
\end{tabular}

${ }^{a}$ Data are means of triplicate determinations.

${ }^{b}$ Excess water $\left(\mathrm{H}_{2} \mathrm{O}\right)$ was calculated from the equation: $\mathrm{H}_{2} \mathrm{O}=\mathrm{NADPH}-\mathrm{H}_{2} \mathrm{O}_{2}$ - product 
Table 2.3. Effect of Mutations on Coupling Efficiency of P450 1 A2 at Different Branching Points of P450 Cycle

\begin{tabular}{|c|c|c|c|}
\hline $\mathrm{P} 4501 \mathrm{~A} 2$ & Product/NADPH ${ }^{\mathrm{b}}$ & $\mathrm{H}_{2} \mathrm{O}_{2} / \mathrm{O}_{2}{ }^{\mathrm{c}}$ & $\mathrm{H}_{2} \mathrm{O} /$ Product $^{\mathrm{d}}$ \\
\hline WT & 0.030 & 0.62 & 11.72 \\
\hline $\mathrm{T} 124 \mathrm{~S}$ & 0.011 & 0.68 & 31.03 \\
\hline $\mathrm{T} 223 \mathrm{~N}$ & 0.007 & 0.58 & 46.67 \\
\hline V227G & 0.010 & 0.53 & 39.47 \\
\hline N312L & 0.010 & 0.71 & 32.26 \\
\hline L382V & 0.036 & 0.62 & 9.9 \\
\hline $\mathrm{L} 382 \mathrm{~V} / \mathrm{T} 223 \mathrm{~N}$ & 0.040 & 0.66 & 8.18 \\
\hline L382V/N312L & 0.044 & 0.71 & 5.9 \\
\hline L382V/T223N/N312L & 0.030 & 0.67 & 10.55 \\
\hline L382V/T124S/N312L & 0.087 & 0.76 & 2.45 \\
\hline
\end{tabular}

${ }^{\mathrm{a}}$ Ratios were calculated from parameters in Table 2.2.

${ }^{\mathrm{b}}$ Efficiency of coupling reducing equivalents to product.

${ }^{c}$ Effect on uncoupling at first or second branch point.

${ }^{\mathrm{d}}$ Effect on uncoupling at third branch point. 


\section{Table 2.4. Geometric Analysis of MD Results for P450 1A2 WT and Mutants}

Hits represent the MD frames where phenacetin was in the productive binding orientation, as evaluated by the geometric criterion: $r \leq 3.5 \AA \& \theta \geq 120^{\circ}$.

\begin{tabular}{|c|c|}
\hline P450 1A2 & Number of Hits \\
\hline WT & 64 \\
\hline $\mathrm{T} 124 \mathrm{~S}$ & 0 \\
\hline $\mathrm{T} 223 \mathrm{~N}$ & 0 \\
\hline V227G & 4 \\
\hline N312L & 0 \\
\hline L382V & 134 \\
\hline $\mathrm{L} 382 \mathrm{~V} / \mathrm{T} 223 \mathrm{~N}$ & 252 \\
\hline L382V/T223N/N312L & 308 \\
\hline
\end{tabular}



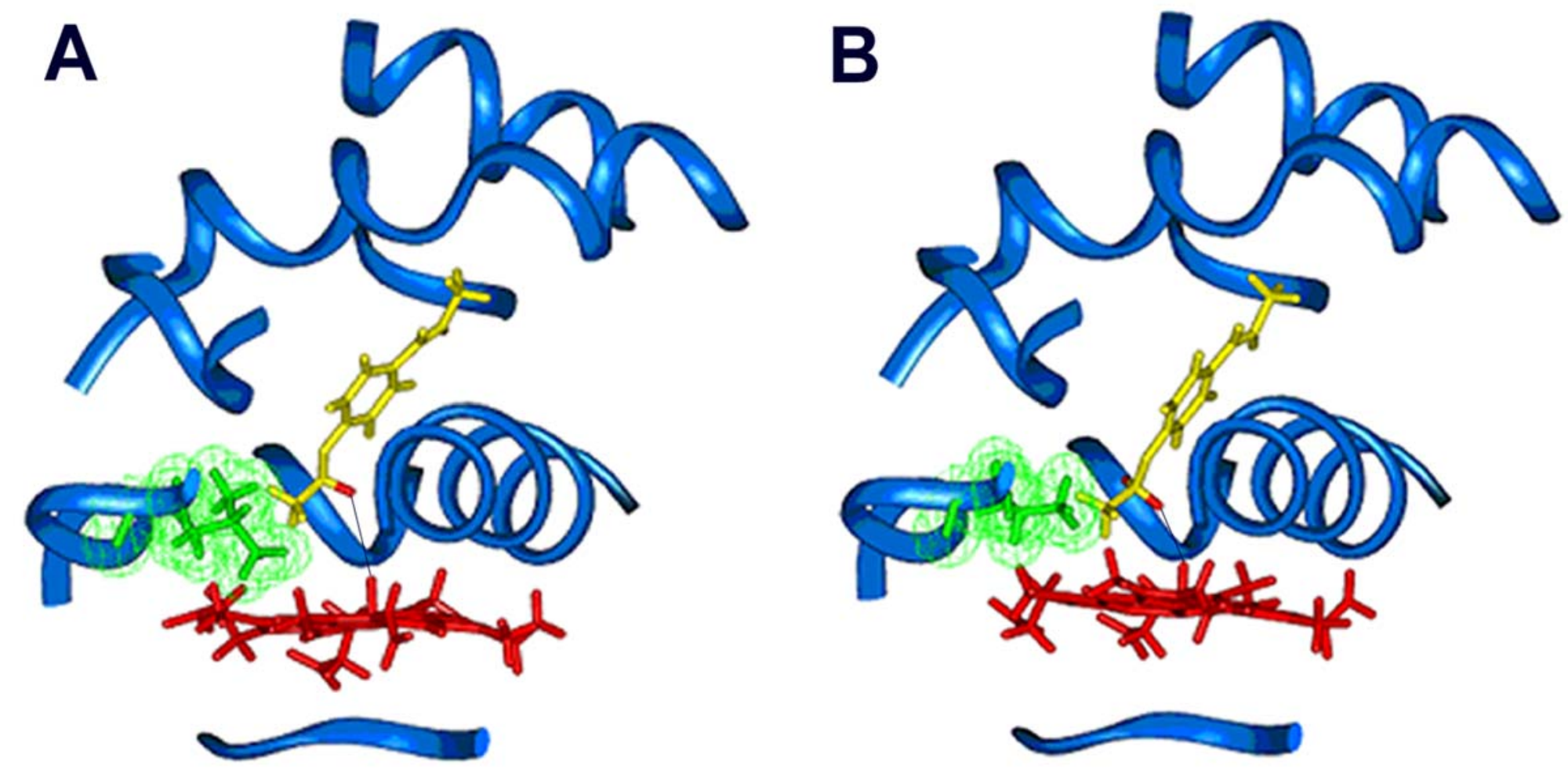

Figure 2.1. Binding Orientation of Phenacetin within the Active Site of P450 1A2 WT (A) and the L382V Mutant (B)

The protein backbone is depicted as a blue ribbon; the side chain of residue 382 is green, with van der Waals surface displayed; heme is red; and phenacetin is yellow, with hydrogens at the oxidation site shown in red. The distance between the hydrogen to be abstracted and ferryl oxygen (marked with a black line) is $3.6 \AA$ in the WT and $2.9 \AA$ in the L $382 \mathrm{~V}$ mutant. 

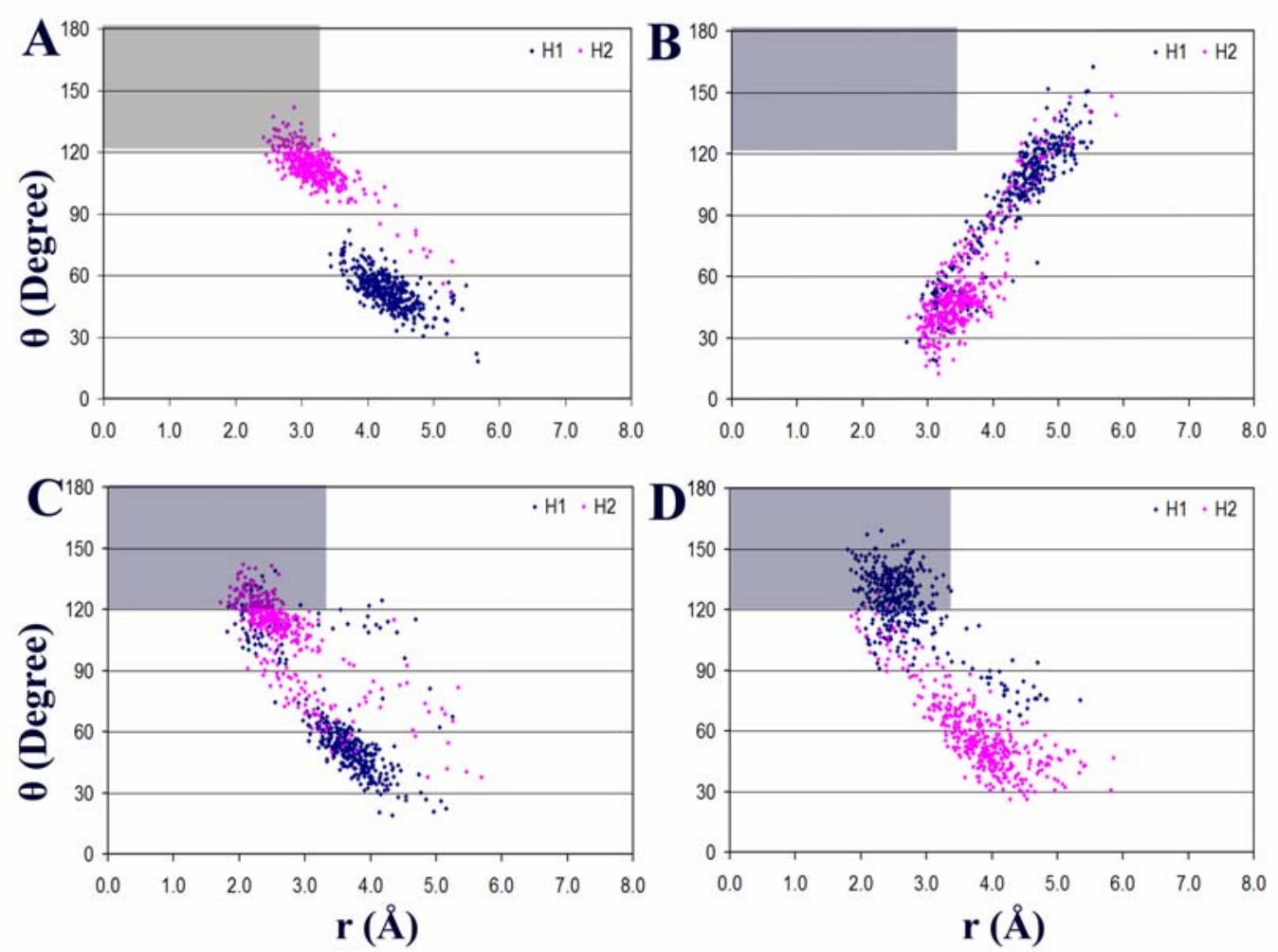

Figure 2.2. Ensembles of Substrate Orientations Obtained from 100-ps MD Simulations of Phenacetin-Enzyme Complexes, Described by Geometric Parameters, Distance $(r)$ and Angle ( $\theta)$.

$\mathrm{H} 1$ in $-\mathrm{OCH}_{2}$ - group of phenacetin is blue, and $\mathrm{H}_{2}$ is red. Gray regions, where the criterion $\left(\mathrm{r} \leq 3.5 \AA \& \theta \geq 120^{\circ}\right)$ is satisfied, represent productive binding orientations of phenacetin within the active site. P450 1A2 enzymes were: WT (A), N312L mutant (B), L382V mutant (C) and L382V/T223N mutant (D). 
Chapter 3

Binding of Phenacetin within the Active Site of Human Cytochrome P450 1A2 Wild Type and Mutants 


\subsection{Introduction}

Cytochromes P450 (P450s) are responsible for the oxidation of a large variety of drugs, carcinogens, and other xenobiotics in species ranging from bacteria to humans. A P450 enzyme usually has the ability to metabolize a number of different substrates, and different P450s often display overlapping substrate specificities and inhibitor susceptibilities (Guengerich et al., 1993).

P450 1A subfamily has two isoforms: 1A1 and 1A2. P450 1A1 and 1A2 share $72 \%$ sequence identity but display different substrate specificities and inhibitor susceptibilities. P450 1A2 is a hepatic enzyme responsible for about $11 \%$ of drug metabolism in humans (Shimada et al., 1994). P450 1A2 was first characterized as phenacetin O-dealkylase (Distlerath et al., 1985), and phenacetin O-dealkylation has been used as the most common marker reaction for P450 1A2 activity in the in vitro studies (Yuan et al., 2002).

Residue Leu382 in P450 1A2 is located near the heme iron and thus may play a role in determining substrate specificity. This was confirmed by the finding that the L382V mutation altered enzyme specificity with alkoxyresorufins and phenacetin (Liu et al., 2004; Tu et. al., 2008; Huang and Szklarz, 2010). Enzyme kinetics studies have shown that the L382V mutant and other multiple mutants containing the L382V mutation displayed about 2- or 3-fold higher catalytic activities with phenacetin, than the WT enzyme, while single mutants such as T124S, T223N, V227G, N312L and L382V showed much lower activities (Huang and Szklarz, 2010). MD studies have shown that the substitution of Leu by a smaller Val increased the volume of the active site, and allowed the substrate phenacetin to move closer to the heme iron, thereby promoting hydrogen abstraction and increasing P450 catalysis (Huang and Szklarz, 2010). However, no direct 
experimental evidence has been available so far to support this mechanism. Thus, in the current studies, we employed NMR longitudinal $\left(T_{1}\right)$ relaxation measurements to elucidate the differences in binding orientations of substrate phenacetin within the active sites of P450 1A2 wild type and mutants. In the presence of paramagnetic molecules such as iron, nuclear magnetic resonance (NMR)-derived $\mathrm{T}_{1}$ relaxation time is shortened in a distance-dependent manner (Regal and Nelson, 2000; Mildvan and Gupta, 1978). Therefore, the distance of ligand protons from the heme of cytochrome P450 can be estimated by calculating the difference of $\mathrm{T}_{1}$ relaxation times before and after P450 is bubbled with carbon monoxide and the $T_{1}$ times of substrate protons closest to the heme iron will show larger decreases than $\mathrm{T}_{1}$ times of those farther away (Regal and Nelson, 2000; Mildvan and Gupta, 1978). NMR $\mathrm{T}_{1}$ relaxation measurement has been successfully utilized to study the following ligand-P450 complexes: sodium laurate-P450 $\mathrm{BM}_{3}$, caffeine-P450 1A1, codeine-P450 2D6 and diclofenac-P450 2C9 (Regal and Nelson, 2000; Modi et al., 1995; 1996; Poli-Scaife et al., 1997). However, $T_{1}$ relaxation measurement has not been applied as extensively as other spectroscopic technologies for P450 research due to the requirement of large amounts of highly purified enzymes and sufficiently water-soluble substrates.

Our previous molecular modeling studies only provided an explanation for the possible mechanism(s) involved in the alteration of catalytic activities of mutants. Therefore, we adopt ${ }^{1} \mathrm{H}$ NMR $\mathrm{T}_{1}$ relaxation technique as an experimental method to investigate the differences in binding orientation of phenacetin within the active site of P450 1A2 WT and the mutants in order to give direct evidence to support the proposed mechanism(s). 
This study reports the application of NMR $T_{1}$ relaxation measurements to determine the heme iron-substrate proton distance in P450 1A2 WT and the mutants. A model for the binding orientation of phenacetin in the active sites of P450 1A2 WT and the mutants is proposed using the constraint distances derived from NMR data. The purpose of these studies was to gain additional information on mechanism(s) involved in altered catalytic activities of P450 1A2 WT and some mutants.

\subsection{Materials and Methods}

Materials. $\mathrm{D}_{2} \mathrm{O}$, sodium dithionite, and phenacetin were purchased from SigmaAldrich (St. Louis, MO). Potassium phosphate and EDTA were purchased from Thermo Fisher Scientific (Waltham, MA). All other chemicals were of analytical grade and were obtained from standard commercial sources.

Protein Expression and Purification. P450 1A2 WT, single mutants N312L and L382V, and a multiple mutant L382V/N312L, were expressed in E. coli according to previously established methods (Liu et al., 2004; Tu et al., 2008; Huang and Szklarz, 2010).

Binding Constant Determination. Spectral binding constants for phenacetin bound in the active site of P450 1A2 WT and mutants were obtained as previously reported (Huang and Szklarz, 2010). The spectrophotometer was set to record spectra from 350 to $500 \mathrm{~nm}$ wavelengths. All samples contained $100 \mathrm{mM}$ phosphate $(\mathrm{pH} 7.4)$ and the temperature was held at a constant $27^{\circ} \mathrm{C}$. The spectral binding constant (Ks) was 
calculated using Eq. [1]

$\Delta \mathrm{A}=(\mathrm{Bmax} * \mathrm{~S}) /(\mathrm{Ks}+\mathrm{S})$

Spin State Shift Induced by Substrate Binding. The percentages of high and low spin in P450 1A2 enzymes with phenacetin were determined as described previously (Hummel et al., 2008) with some modifications. Phenacetin-induced spin state changes with P450 1A2 WT and mutants were performed as described under Binding Constant Determination. Spectra titrations with phenacetin in P450 1A2 enzymes were performed with the concentrations of phenacetin used in samples identical to those used in NMR measurements. Absorbance spectra were deconvoluted into three components: a low spin component, a high spin component and the board $\delta$-band by using the multiple peak fitting package of Igor Pro 5.0 (Wavemetrics, Inc., Lake Oswego, Oregon), as described

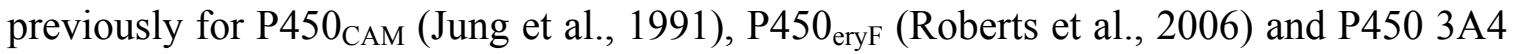
(Roberts et al., 2005). The relative areas for high spin and low spin components were calculated and compared to the low spin reference spectra in order to obtain percentages of high and low spin.

$T_{1}$ Relaxation Measurements. NMR $T_{1}$ relaxation studies were carried out on a Varian Spectrometer operating at $600 \mathrm{MHz}$, internally locked on the deuterium signal of the solvent, $\mathrm{D}_{2} \mathrm{O}$, as described previously (Hummel et al., 2008). Signals were internally referenced to HDO peak at $4.8 \mathrm{ppm}$. A standard inversion recovery sequence $\left(\mathrm{d}_{1}-180^{\circ}\right.$ $\mathrm{d}_{2}-90^{\circ}$ ) was employed, along with presaturation of the residual HDO signal. The PW90 was calibrated on each sample. The preacquisition delay $\mathrm{d}_{1}$ was set to $10 \times \mathrm{T}_{1}(40 \mathrm{~s})$ of 
the longest relaxation time. The spectra associated with at least $10 \mathrm{~d}_{2}$ values were acquired. Line broadening and gaussian function were applied for precise calculations of $\mathrm{T}_{1}$ values for the protons. The value of the longitudinal relaxation time was obtained by a nonlinear least square fitting of the peak height as a function of the delay $\mathrm{d}_{2}$, using the Varian software. $\mathrm{T}_{1}$ was measured in the initial substrate solution and after addition of the enzyme to each substrate. No significant P420 formation was observed throughout the course of the experiment.

$T_{1}$ Temperature Dependence. That the temperature dependence of the $T_{1 P}$ for phenacetin protons must behave in a temperature dependent manner is one of the requirements for valid proton to heme distance estimates in order to confirm that the molecules that come in contact with heme iron and those in the bulk solution are operating under fast-exchange conditions. This can be demonstrated by conducting $T_{1}$ measurements over a range of temperatures (Regal and Nelson, 2000). In this experiment, $\mathrm{T}_{1}$ measurements were performed as described in the section on $T_{1}$ Relaxation Measurements at three different temperatures (283, 298, and 310 K). Data were collected both in the absence $\left(\mathrm{T}_{1, \mathrm{Fe} 3+}\right)$ and the presence $\left(1 / \mathrm{T}_{1, \mathrm{Fe} 2+-\mathrm{CO}}\right)$ of $\mathrm{CO} /$ sodium dithionite. To ensure adequate diffusion of $\mathrm{CO}$ and mixing of sodium dithionite, samples were removed from the NMR tube and placed in a test tube, $\mathrm{CO}$ was bubbled, and sodium dithionite was added, and then the sample was placed back into the NMR tube. Plots of $T_{1, \mathrm{Fe}^{+},}, 1 / \mathrm{T}_{1, \mathrm{Fe} 2+}$ $-\mathrm{CO}$, and $1 / \mathrm{T}_{1} \mathrm{p}$ versus $1 /$ temperature were drawn in all cases.

Distance calculations. A more precise method for the distance $(r)$ calculation using 
spin-state data was adopted, described in detail earlier (Hummel et al., 2008). Briefly, the equation for distance calculation can be written as:

$\left.r=\left[9.78 \times 10^{16} \mathrm{~T}_{1 \mathrm{P}} \alpha_{\mathrm{m}} S(S+1) \tau_{\mathrm{c}}\right)\right]^{1 / 6}$

The distance is given by $r$. The tumbling coefficient $\tau_{\mathrm{c}}$ represents the correlation time of the dipolar interactions of the protein in solution and can be calculated by measuring $\mathrm{T}_{1 \mathrm{P}}$ at several magnetic field strengths (Mildvan and Gupta, 1978). An estimate for $\tau_{\mathrm{c}}$ of P450 1A2 is $3.38 \times 10^{-10} \mathrm{~s}^{-1}$, as reported previously (Regal and Nelson, 2000). $\mathrm{T}_{1 \mathrm{P}}$ is the portion of $T_{1}$ due to paramagnetic affects alone and is given by the following equation:

$1 / \mathrm{T}_{1 \mathrm{P}}=\mathrm{T}_{1, \mathrm{Fe} 3+}-1 / \mathrm{T}_{1, \mathrm{Fe} 2+-\mathrm{CO}}$

assuming that all of the diamagnetic contribution is represented by $1 / \mathrm{T}_{1, \mathrm{Fe} 2+-\mathrm{CO}}$ (Regal and Nelson, 2000). This assumption appears to be generally valid when used in many similar studies (Paine et al., 1996; Poli-Scaife et al., 1997; Mock et al., 2002). The parameter $\alpha_{\mathrm{m}}$, the fractional binding coefficient, is obtained by the equation $\alpha_{\mathrm{m}}=$ $[\mathrm{P} 450] /(\mathrm{Ks}+[$ Substrate] $)$ under conditions of fast exchange when only one substrate is present (Regal and Nelson, 2000). Ks values determined from visible spectroscopy were utilized for the distance calculations rather than $\mathrm{K}_{\mathrm{D}}$ determined by NMR for phenacetin because of the equal or slight difference between Ks and $\mathrm{K}_{\mathrm{D}}$ based on Michaelis-Menten kinetics (Regal and Nelson, 2000). The $S(S+1)$ term was simplified by Eq. [4] $S(S+1)=8.75 f_{\mathrm{HS}}+0.75 f_{\mathrm{LS}}$

where $f_{H S}$ and $f_{L S}$ refer to the fractions of the high spin and low spin iron, respectively (Hummel et al., 2008).

Molecular Modeling. Molecular modeling was conducted on an SGI Octane 
workstation using the Insight II software (Accelrys, Inc). The crystal structure of P450 1A2 was obtained courtesy of Dr. Eric F. Johnson (the Scripps Research Institute, La Jolla, CA). The mutants were constructed by the replacement of amino acid residue(s) followed by 500 steps of steepest descent minimization. Substrate phenacetin was built using the Builder module of Insight II. The substrate was initially placed into the active site manually avoiding steric overlaps and docked using the Affinity module. From 20 orientations obtained, the most energetically favorable complex was subjected to MD simulations and minimization with NMR-based distance restraints imposed. To reduce possible protein deformation resulting from restraint forces, the protein backbone was tethered to its initial coordinates by a harmonic restraint force. Substrate protons were guided to suitable distances from the heme iron by a gradually strengthening harmonic restraint $(\mathrm{k}=2-32 \mathrm{kcal} / \mathrm{mol} \AA)$ over $50 \mathrm{ps}$ of MD. The nonbond cutoff was set at $15 \AA$, and distance-dependent dielectric was used. Residues farther than $10 \AA$ from the initial substrate position were held fixed. After MD simulations, the structure was minimized by 1000 steps of steepest descents and 1000 steps of conjugate gradients minimizations.

\subsection{Results}

Interactions of Phenacetin with P450 1A2 WT and the Mutants. The chemical structure along with the proton numbering schemes used for phenacetin appears in Figure 3.1. The addition of different concentrations of phenacetin to purified P450 1A2 WT and mutants led to an increase of their Soret peak at $390 \mathrm{~nm}$ and a decrease of a band at 417 $\mathrm{nm}$, as shown in Figure 3.2A. Thus, for all enzymes, we observed a typical Type I spectrum, which indicates a change of the spin state of the heme iron from low spin $(S=$ 
1/2) to high spin $(S=5 / 2)$ due to the binding of the substrate to the protein in close proximity of heme (Dawson, 1988). The dependence of UV absorption changes on the concentration of substrates was used to calculate the spectral binding constants, Ks, for the P450-phenacetin complexes at $27^{\circ} \mathrm{C}$. Table 3.1 presents the Ks values obtained for phenacetin binding, with P450 1A2 WT and the mutants, respectively. The Ks values for N312L, L382V, L382V/N312L mutants decreased compared to the WT enzyme (Figure $3.2 \mathrm{~B})$.

The UV/vis spectra (wavelength 320-500 nm) of P450 1A2 WT and the mutants can be deconvoluted into a low spin component ( 416-420 nm), a high spin component $(\sim 390-405 \mathrm{~nm})$, and $\delta$ bands $(\sim 360 \mathrm{~nm})$. The concentrations of phenacetin used in the percentage determination of spin state were identical to those used in NMR $T_{1}$ studies. The percentages of low and high spin calculated from the Soret bands of P450 1A2 WT and the mutants in the absence and presence of substrate are shown in Table 3.2. In the absence of substrate, P450 1A2 WT and the mutants, L312N, L382V, and L382V/N312L, existed primarily in the low spin state (93\%-97\% low spin). The addition of phenacetin increased the percentage of high spin enzyme to approximately 2 - to 3 -fold. It is critical to know these relative percentages for interpreting NMR data because the increasing concentration of high spin results in paramagnetic broadening and shifting (Bertini et al., 2001; Pintacuda et al., 2003).

Validation of fast-exchange conditions. The validity of distances derived from $\mathrm{T}_{1}$ relaxation times of substrate protons is dependent on the substrate under fast-exchange conditions, meaning that substrate molecules in the active site must be rapidly 
exchanging with those in the bulk solution. To verify fast-exchange conditions, the temperature dependence of the $T_{1}$ relaxation of the substrate protons is used. A positive slope in the double reciprocal plot of $\mathrm{T}_{1} \mathrm{p}$ versus temperature indicates that the fast exchange condition is being met. This condition also requires that double reciprocal plots of $T_{1, \mathrm{Fe} 3+}$ or $T_{1, \mathrm{Fe} 2+-\mathrm{CO}}$ versus temperature have positive slopes. The double reciprocal plots of $\mathrm{T}_{1} \mathrm{p}$ versus temperature for P450 1A2 WT, L312N, L382V, and L382V/N312L mutants are shown in Figure 3.3 and demonstrate that the fast exchange requirement has been satisfied.

Calculation of Distances between Substrate Protons and Heme Iron. The average distances between the substrate protons and the heme iron for phenacetin with each of the enzymes, P450 1A2 WT, N312L, L382V, and L382V/N312L mutants, were obtained from $T_{1}$ relaxation experiments (Table 3.3). $T_{1}$ relaxation times decreased for all protons of phenacetin in the presence of enzymes compared to those measured in the presence of enzymes and carbon monoxide. There is a substantial difference in $T_{1}$ relaxation times between the samples with and without carbon monoxide. All the aromatic protons of phenacetin are nearly equidistant from the heme iron. The distance between the proton of the $-\mathrm{OCH}_{2}$ group, which is abstracted during phenacetin oxidation, and the heme iron is much shorter in the L382V mutant ( $3.73 \AA$ ) and L382V/N312L mutant (3.96 $\AA$ ) than that in WT (4.55 $\AA$ ). In contrast, the distance between the proton of the $-\mathrm{OCH}_{2}$ group and the heme iron is longer in the N312L mutant (5.84 $\AA$ ) than that in WT, consistent with the previous modeling results. The ${ }^{1} \mathrm{H}$ NMR spectrum of phenacetin consists of wellresolved signals which can be easily followed during the experiment (Figure 3.4). In 
addition, the distances obtained by averaging the 20 lowest conformations of the phenacetin are also presented in Table 3.3. The calculated distances between the protons of phenacetin and heme iron have a good correlation with $\mathrm{T}_{1}$ data.

\section{Position of Phenacetin Relative to the Heme of P450 1A2 Based on NMR Data and}

Molecular Modeling. 3D models consisting of the substrate phenacetin and P450 1A2 and various mutants that correspond to the proton-heme distance of Table 3.3 were constructed. The energy of substrate conformations found in those models with the constraints of NMR-derived distances was never higher than $5 \mathrm{kcal} / \mathrm{mol}$. Figure 3.5 only displays the binding orientations of phenacetin within the active sites of P450 1A2 WT and L382V mutant (P450 1A2 WT and L382V mutant are superimposed and only P450 1A2 WT is shown). Phenacetin displays similar binding orientations in both P450 1A2 WT and $\mathrm{L} 382 \mathrm{~V}$ mutant. The protons of $-\mathrm{OCH}_{2}$ group of phenacetin, the site of metabolism, are shown closer to the heme-iron in L382V mutant than WT. The orientations of phenacetin within the active sites of P450 1A1 WT, 1A2 N312L and L382V/N312L mutants are not displayed to avoid the crowded demonstration.

\subsection{Discussion}

The methods to study the structure-function relationships of P450s have often involved a combination of molecular modeling and experimental techniques, such as enzyme catalytic assays and site-directed mutagenesis (Szklarz and Halpert, 1997; Szklarz et al., 2000). P450 1A1 and 1A2 are major members of P450 1A subfamily and display high sequence identity. Therefore, it is of great interest to determine whether the 
substitutions of key residues of one enzyme with the residues of the other will convert the activity for various substrates. Molecular modeling and experimental studies have shown that single and multiple reciprocal mutants of P450 1A1 and 1A2 displayed altered specificities toward alkoxyresorufins (Liu et al., 2004; Tu et al., 2008). Similar changes of substrate specificities resulting from reciprocal mutations were also found in P450 2B4 and 2B5 (Szklarz et al., 1996; He et al., 1996), P450 2A6 and 2A13 (DeVore et al., 2008).

The substitution of certain P450 residue(s) by site-directed mutagenesis may change the structure and function of P450s by affecting such events as the orientation of the substrate in the active site, the folding of the enzyme, the electron transfer from redox partners, or the catalytic efficiency of the enzyme through some other unknown mechanism(s) (Hummel et al., 2008). Based on our previous molecular modeling studies, The L382V substitution results in the substrate phenacetin closer to the oxo-heme, with the sites of oxidation closer to the active oxygen, which might play a role in the increase of catalytic activity (Huang and Szklarz, 2010). Other similar studies have confirmed that the distance between heme iron and substrate protons, especially the sites of the oxidation, correlates well with observed catalytic efficiency of the enzymes (Poli-Scaife et al., 1997; Regal and Nelson, 2000; Hummel et al., 2008).

P450 1A2 single and multiple mutants were constructed based on the strategy of reciprocal mutation, related to $\mathrm{P} 4501 \mathrm{~A} 1$. Thus, the distance between phenacetin proton and heme iron for P450 1A1 was calculated (data not shown). The substrate proton-heme iron distances of $\mathrm{P} 4501 \mathrm{~A} 1$ are similar as those of $\mathrm{P} 4501 \mathrm{~A} 2$, except for the $-\mathrm{OCH}_{2}$ group. The distance between the protons of the $-\mathrm{OCH}_{2}$ group and heme iron is larger than $6.7 \AA$, which is similar to that of P450 1A2 N312L. In contrast, the sites of the oxidation for 
P450 1A2 L382V and L382V/N312L mutants display closer to the heme iron than those of the WT enzyme (Table 3.3). Ks values for P450s suggest that phenacetin binds much tighter to P450 1A2 L382V and L382V/N312L than to WT and N312L (Table 3.1), as well as P450 1A1 (data not shown). Therefore, these findings provide the reasons for the fact that P450 1A2 and mutants containing L382V substitution display increased phenacetin O-dealkoxylation, while P450 1A1 and P450 1A2 N312L catalyze phenacetin with a very low efficiency, as shown in our previous studies (Huang and Szklarz, 2010).

In terms of the calculating methods for the distance (r) between substrate protonsheme iron, there are two primary ways described in NMR $T_{1}$ relaxation measurements. An earlier method used the equation $r=C\left[\mathrm{~T}_{1 \mathrm{p}} \alpha_{\mathrm{m}} f\left(\tau_{\mathrm{c}}\right)\right]^{1 / 6}$, where constant $C$ for Fe (III) low spin is 539 , (Mildvan and Gupta, 1978). The current method takes into account the fact that the spin state may change when the substrate binds and, therefore, the value of $C$ may be incorrect. To correct it, the following equation is used: $r=\left[9.78 \times 10^{16} \mathrm{~T}_{1 \mathrm{P}}\right.$ $\left.\left.\alpha_{m} S(S+1) \tau_{c}\right)\right]^{1 / 6}$, which is shown as Eq. [2]. $T_{1 P}$ is not exactly the same as the $T_{1 P}$ in the earlier method in that it is the weighted average of individual equivalent nuclei that give rise to the resonance. $\alpha_{\mathrm{m}}$ is calculated as in the earlier method assuming only one substrate molecule in the binding site. The calculation of $\alpha_{\mathrm{m}}$ is more complicated if more than one substrate is available in the active site (Hummel et al., 2008). The current method provides a more precise calculation of the distance when spin-state data are obtained, and it has been successfully used to calculate substrate-heme distance in P450 2C9 allelic variants with and without the presence of the heterotropic activator dapsone (Hummel et al., 2008).

Distances derived from NMR $T_{1}$ relaxation (experimental distance) represent the 
time-averaged binding orientation of phenacetin within the active site of P450 1A2 WT and the mutants if this substrate can adopt different conformations or positions in the active site. In this study, substrate docking and MD were also performed to obtain the calculated distances by averaging the conformations obtained from MD (Table 3.3), which has been described in previous P450 2C9 study (Hummel et al., 2004). The calculated and experimental values are slight different, in part, because the distances calculated from MD are based on a very small subset of orientations, while the distances calculated from the $T_{1}$ data represent a large number of possible orientations. Therefore, these values should be very similar if MD run time is long enough.

In summary, the L382V substitution for P450 1A2 led to the site of metabolism of phenacetin oriented more closely to the heme iron than in the WT enzyme. Spectral binding studies revealed that the L382V mutation increased the affinity of the mutants for phenacetin to a large extent. These results demonstrate that both the distance of phenacetin protons from the heme-iron and the alteration of substrate binding affinity are likely responsible for the changes of enzyme catalytic efficiency, which is consistent with our previous findings regarding enzyme kinetics and stoichiometry, as well as predictions from molecular modeling studies (Huang and Szklarz, 2010).

\subsection{Acknowledgments}

We thank Dr. Novruz G. Akhmedov for excellent technical support. Molecular modeling studies were performed at the Computational Chemistry and Molecular Modeling Laboratory, Department of Basic Pharmaceutical Sciences, School of Pharmacy, West Virginia University, Morgantown, WV. 
Table 3.1. Spectral Binding Constants for Phenacetin with Purified P450 1A2 WT and the Mutants at $27^{\circ} \mathrm{C}^{\mathrm{a}}$

\begin{tabular}{lc}
\hline P450 1A2 & Ks $(\mu \mathrm{M})$ \\
\hline WT & 17.1 \\
N312L & 10.2 \\
L382V & 0.7 \\
L382V/N312L & 3.5 \\
\hline
\end{tabular}

${ }^{\mathrm{a}}$ The two cuvettes contained $0.5 \mu \mathrm{M}$ P450 1A2 WT or the mutants in $0.1 \mathrm{M}$ phosphate buffer, $\mathrm{pH} 7.4$, with $20 \%$ glycerol. 
Table 3.2. Percentages of Low Spin and High Spin in P450 1A2 WT and the Mutants in the Absence and the Presence of Phenacetin at $27^{\circ} \mathrm{C}^{\text {a }}$

\begin{tabular}{lcc}
\hline P450 1A2 (+substrate) & \% Low Spin & \% High Spin \\
\hline WT (unbound) & 93 & 7 \\
WT + Phenacetin & 84 & 16 \\
N312L (unbound) & 94 & 6 \\
N312L + Phenacetin & 79 & 5 \\
L382V (unbound) & 95 & 14 \\
L382V + Phenacetin & 86 & 6 \\
L382V/N312L (unbound) & 94 & 17 \\
L382V/N312L + Phenacetin & 83 & 21 \\
\hline
\end{tabular}


Table 3.3. $T_{1}$ and Calculated Distances of Phenacetin Protons from the Heme Iron in the Active Site of P450 1 A2 WT and the Mutants ${ }^{\mathrm{a}}$.

\begin{tabular}{|c|c|c|c|c|c|c|c|c|}
\hline \multirow{2}{*}{ Phenacetin $^{\mathrm{b}}$} & \multicolumn{4}{|c|}{$\mathrm{P} 4501 \mathrm{~A} 2 \mathrm{WT}^{\mathrm{c}}$} & \multicolumn{4}{|c|}{$\mathrm{P} 4501 \mathrm{~A} 2 \mathrm{~L} 382 \mathrm{~V}^{\mathrm{d}}$} \\
\hline & $\mathrm{T}_{1, \mathrm{Fe} 3+}$ & $\mathrm{T}_{1, \mathrm{Fe} 2+-\mathrm{CO}}$ & $\mathrm{r}^{\mathrm{g}}(\AA)$ & $\mathrm{R}^{\mathrm{h}}(\AA)$ & $\mathrm{T}_{1, \mathrm{Fe} 3+}$ & $\mathrm{T}_{1, \mathrm{Fe} 2+-\mathrm{CO}}$ & $r(\AA)$ & $\mathrm{R}(\AA)$ \\
\hline Ar 2,6 & $2.35(0.18)$ & $3.00(0.21)$ & $4.79(0.33)$ & $5.22(1.22)$ & $2.28(0.11)$ & $2.57(0.24)$ & $4.34(0.26)$ & $4.99(0.71)$ \\
\hline Ar 3.5 & $1.84(0.10)$ & $2.13(0.11)$ & $4.72(0.14)$ & $5.12(1.21)$ & $3.07(0.22)$ & $3.38(0.28)$ & $4.39(0.31)$ & $4.80(0.79)$ \\
\hline$-\mathrm{OCH}_{2}$ & $1.58(0.15)$ & $1.80(0.18)$ & $4.55(0.32)$ & $4.68(1.26)$ & $2.43(0.18)$ & $3.09(0.17)$ & $3.73(0.26)$ & $3.90(1.52)$ \\
\hline$-\mathrm{COCH}_{3}$ & $1.34(0.07)$ & $1.45(0.06)$ & $5.85(0.13)$ & $5.84(2.33)$ & $1.64(0.13)$ & $1.72(0.14)$ & $4.79(0.23)$ & $5.04(2.44)$ \\
\hline$-\mathrm{CH}_{3}$ & $1.44(0.07)$ & $1.61(0.06)$ & $4.69(0.09)$ & $4.94(1.33)$ & $2.03(0.13)$ & $2.05(0.20)$ & $4.13(0.61)$ & $4.22(1.32)$ \\
\hline \multirow{2}{*}{ Phenacetin $^{\mathrm{b}}$} & \multicolumn{4}{|c|}{$\mathrm{P} 4501 \mathrm{~A} 2 \mathrm{~N} 312 \mathrm{~L}^{\mathrm{e}}$} & \multicolumn{4}{|c|}{$\mathrm{P} 4501 \mathrm{~A} 2 \mathrm{~L} 382 \mathrm{~V} / \mathrm{N} 312 \mathrm{~L}^{\mathrm{f}}$} \\
\hline & $\mathrm{T}_{1, \mathrm{Fe} 3+}$ & $\mathrm{T}_{1, \mathrm{Fe} 2+-\mathrm{CO}}$ & $\mathrm{r}(\AA)$ & $\mathrm{R}(\AA)$ & $\mathrm{T}_{1, \mathrm{Fe} 3+}$ & $\mathrm{T}_{1, \mathrm{Fe} 2+-\mathrm{CO}}$ & $r(\AA)$ & $\mathrm{R}(\AA)$ \\
\hline Ar 2,6 & $2.32(0.10)$ & $3.13(0.15)$ & $6.03(0.21)$ & $6.22(1.23)$ & $2.43(0.07)$ & $2.64(0.19)$ & $4.32(0.15)$ & $4.26(0.99)$ \\
\hline Ar 3.5 & $1.94(0.09)$ & $2.12(0.11)$ & $5.94(0.12)$ & $6.18(1.21)$ & $2.95(0.09)$ & $3.26(0.11)$ & $4.37(0.14)$ & $4.35(1.21)$ \\
\hline
\end{tabular}




\begin{tabular}{|c|c|c|c|c|c|c|c|c|}
\hline$-\mathrm{OCH}_{2}$ & $1.62(0.04)$ & $1.70(0.18)$ & $5.84(0.77)$ & $5.94(3.21)$ & $1.98(0.12)$ & $2.53(0.09)$ & $3.96(0.54)$ & $4.15(0.78)$ \\
\hline$-\mathrm{COCH}_{3}$ & $1.54(0.12)$ & $1.98(0.21)$ & $6.19(0.32)$ & $6.73(2.04)$ & $2.12(0.24)$ & $2.43(0.22)$ & $4.62(0.25)$ & $5.00(1.96)$ \\
\hline$-\mathrm{CH}_{3}$ & $1.87(0.12)$ & $2.39(0.06)$ & $5.83(0.36)$ & $5.99(1.33)$ & $2.23(0.23)$ & $2.54(0.21)$ & $4.32(0.23)$ & $4.45(1.02)$ \\
\hline
\end{tabular}

${ }^{a}$ Errors for measurements are shown in parentheses. Errors in the $\mathrm{T}_{1}$ values were those reported by the fitting routine. Errors in the reported distances $(r)$ were determined by propagation of error from the $T_{1}$ calculation. Generally, the error is $<10 \%$.

${ }^{\mathrm{b}}$ See Fig. 1 for numbering scheme of the protons for phenacetin.

${ }^{\mathrm{c}}[\mathrm{P} 4501 \mathrm{~A} 2 \mathrm{WT}]=0.017 \mu \mathrm{M},[\mathrm{phenacetin}]=171 \mu \mathrm{M}, \mathrm{K}_{\mathrm{S}}(\mathrm{P} 4501 \mathrm{~A} 2 \mathrm{WT})=17.1 \mu \mathrm{M}$.

${ }^{\mathrm{d}}[\mathrm{P} 4501 \mathrm{~A} 2 \mathrm{~L} 382 \mathrm{~V}]=0.007 \mu \mathrm{M},[$ phenacetin $]=7 \mu \mathrm{M}, \mathrm{K}_{\mathrm{S}}(\mathrm{P} 4501 \mathrm{~A} 2 \mathrm{~L} 382 \mathrm{~V})=0.7 \mu \mathrm{M}$.

${ }^{\mathrm{e}}[\mathrm{P} 4501 \mathrm{~A} 2 \mathrm{~N} 312 \mathrm{~L}]=0.011 \mu \mathrm{M}$, [phenacetin] $=102 \mu \mathrm{M}, \mathrm{K}_{\mathrm{S}}(\mathrm{P} 4501 \mathrm{~A} 2 \mathrm{~N} 312 \mathrm{~L})=10.2 \mu \mathrm{M}$.

$\mathrm{f}[\mathrm{P} 4501 \mathrm{~A} 2 \mathrm{~L} 382 \mathrm{~V} / \mathrm{N} 312 \mathrm{~L}]=0.004 \mu \mathrm{M},\left[\right.$ phenacetin] $=35 \mu \mathrm{M}, \mathrm{K}_{\mathrm{S}}(\mathrm{P} 4501 \mathrm{~A} 2 \mathrm{~L} 382 \mathrm{~V} / \mathrm{N} 312 \mathrm{~L})=3.5 \mu \mathrm{M}$.

${ }^{\mathrm{g}}$ Values were calculated by $\left.r=\left[9.78 \times 10^{16} \mathrm{~T}_{1 \mathrm{P}} \alpha_{\mathrm{m}} S(S+1) \tau_{\mathrm{c}}\right)\right]^{1 / 6}$

${ }^{\mathrm{h}}$ Values were obtained by averaging the 20 lowest-energy conformations obtained from molecular dynamics. 


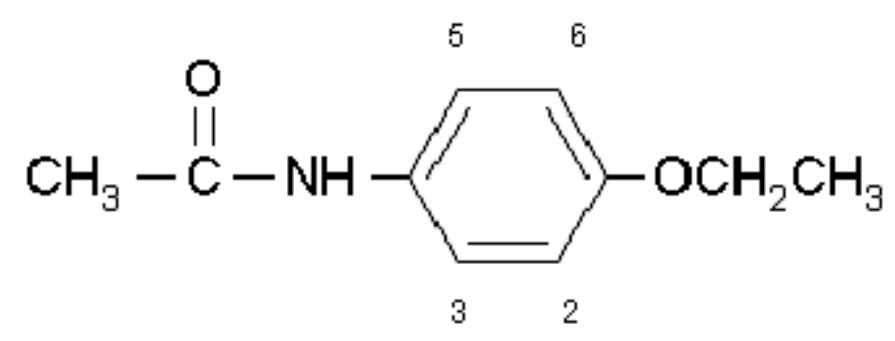

Figure 3.1. Chemical Structure of Phenacetin

Numbering scheme used in the text is shown. 
(A)

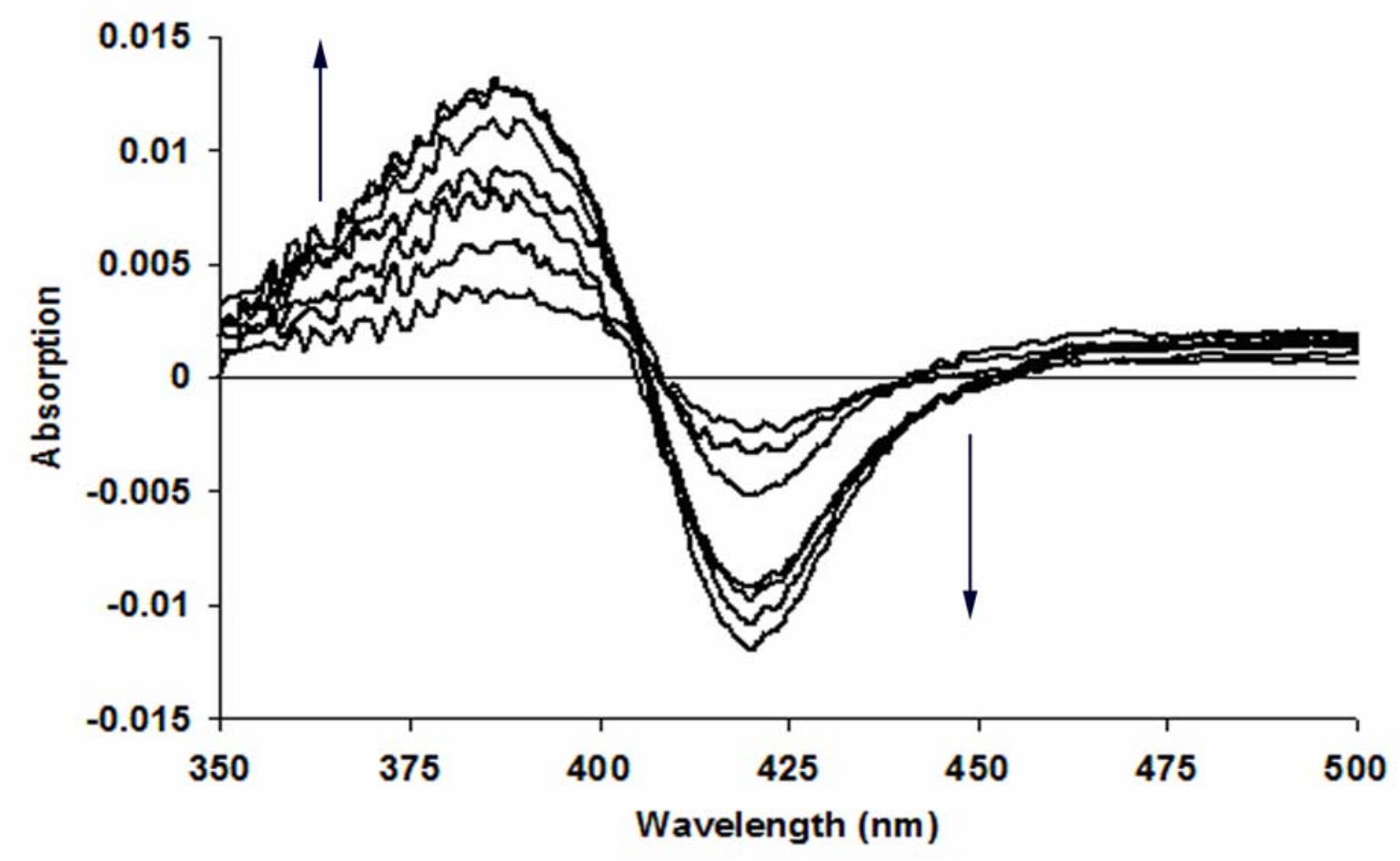

(B)

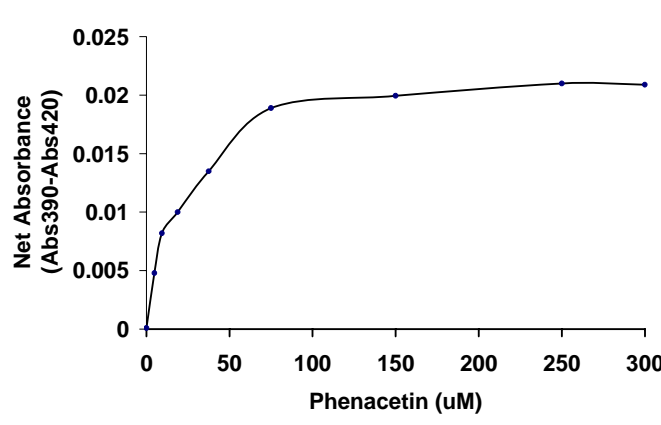

$\mathrm{K}_{\mathrm{S}(1 \mathrm{~A} 2 \mathrm{WT})}=17 \mu \mathrm{M}$

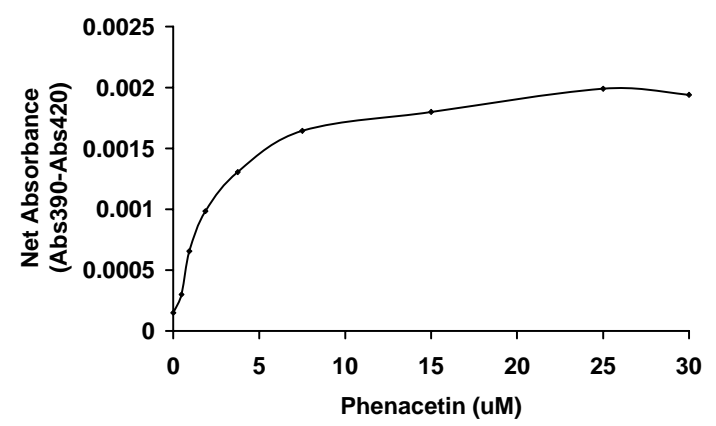

$\mathrm{K}_{\mathrm{S}(1 \mathrm{~A} 2 \mathrm{~L} 382 \mathrm{~V})}=0.7 \mathrm{mM}$

Figure 3.2. Phenacetin Spectral Binding Determined in P450 1A2 Mutants by UV/Vis Spectroscopy

Spectral binding curves for phenacetin bound in P450 1A2 L382V. P450 1A2 WT, N312L, L382V/N312L have a similar UV/Vis binding spectra (not shown). A type I spectrum is evident with a peak at $\sim 390 \mathrm{~nm}$ and a trough at $\sim 420 \mathrm{~nm}$. The arrows indicate the increase of concentrations of phenacetin. (B) Binding curves for phenacetin in P450 WT and the L382V mutant and the $\mathrm{K}_{\mathrm{S}}$ values derived from fitting of the data to Eq. [1]. 
(A)

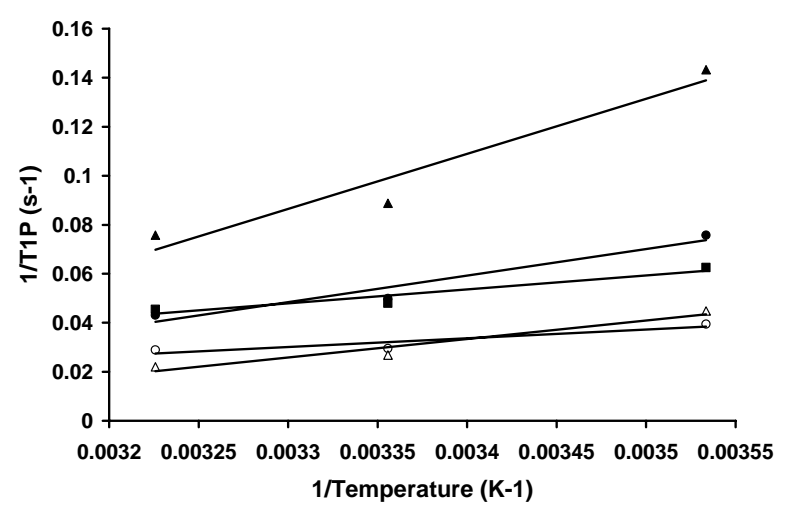

(C)

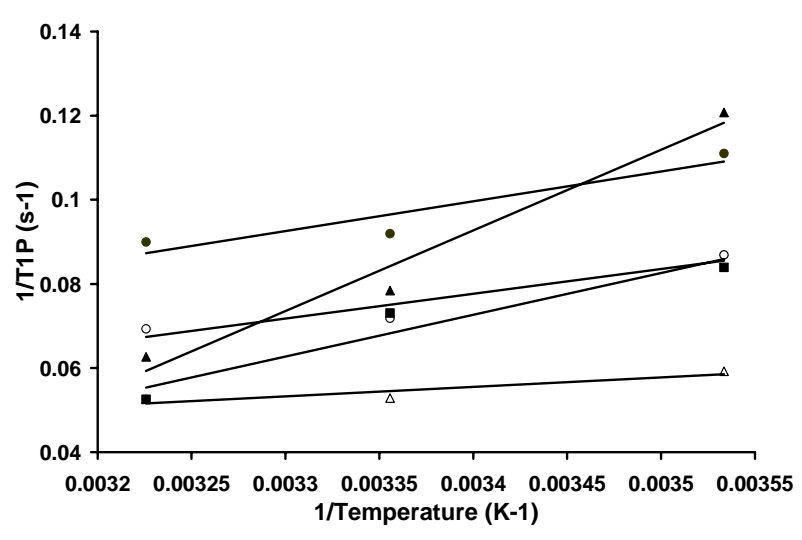

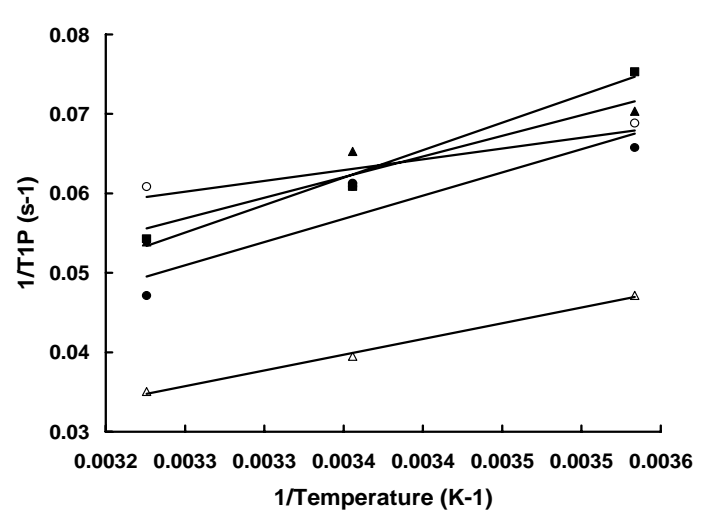

(B)

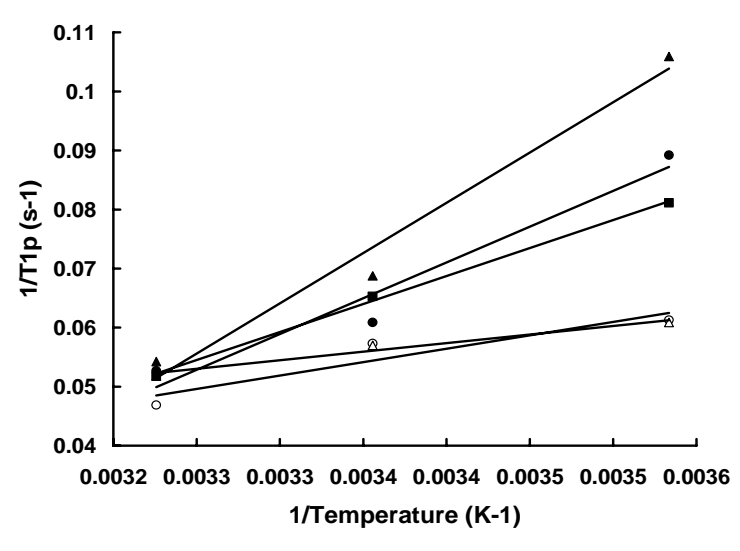

Figure 3.3. Temperature Dependence of the Longitudinal Relaxation Time of the NMR Resonances of Phenacetin Protons in P450 1A2 WT and Mutants

The plots present P450 1A2 WT (A), N312L (B), L382V (C) and L382V/N312L mutants (D), respectively. A positive linear slope is indicative of fast-exchange conditions. Legend: Phenacetin $\operatorname{Ar} 2,6(\bullet), \operatorname{Ar} 3,5(\circ),-\mathrm{CH}_{2}(\mathbf{\Delta}),-\mathrm{COCH}_{3}(\triangle)$, and $-\mathrm{CH}_{3}(\mathbf{\bullet})$. 


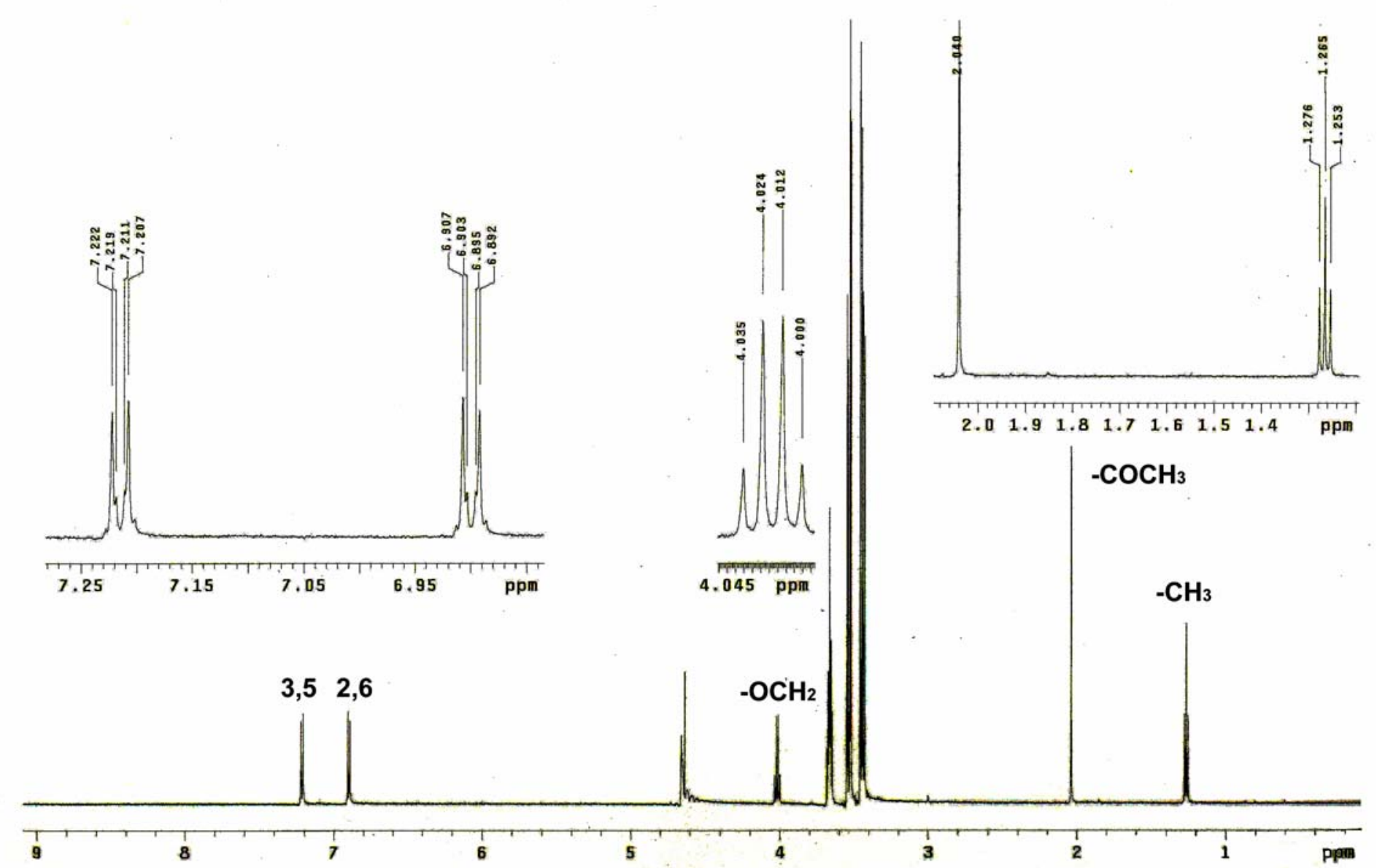

Figure 3.4. NMR Spectrum of the Protons of Phenacetin Obtained under Conditions Used for $\mathrm{T}_{1}$ Measurements

The numbering scheme used is the same as shown in Figure 3.1. 


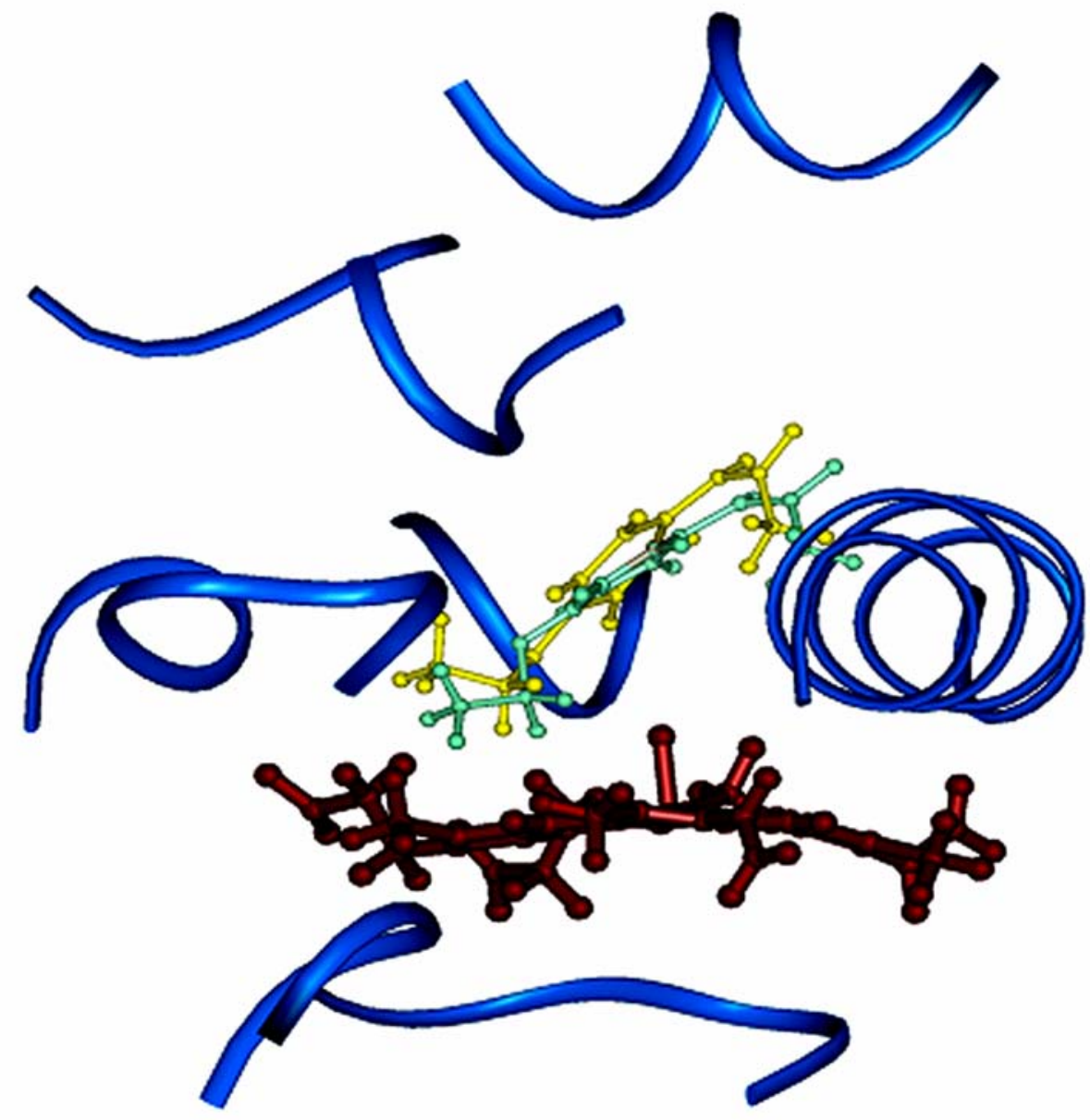

Figure 3.5. Phenacetin Binding Orientation in the Active Site of P450 1A2 WT (yellow) and the L382V Mutant (green).

The enzymes were superimposed using a protein backbone as a basis. Optimal orientations for the docked substrate were refined by incorporating NMR-derived distance restraints. The substrate adopts very similar binding positions in both enzymes. 
Chapter 4

Application of Molecular Modeling to Study Cytochrome P450 1A2

Inhibition by Various Selective Inhibitors 


\subsection{Introduction}

Cytochromes P450 (P450s) are unique monoxygenases, which are found in every biological kingdom and almost every tissue in mammals (Nelson et al., 1996). Most P450s detoxify xenobiotics by forming hydrophilic metabolites which can be readily excreted from the body. However, P450s also play an important role in activating procarcinogens and other toxic compounds (Ortiz de Montellano, 1996). In general, the catalytic mechanism involves a two-electron reduction of molecular oxygen to form a reactive oxygen species able to oxidize a substrate, and water (Porter and Coon, 1991).

P450 1A2, which is a member of P450 1A subfamily, is one of the major hepatic enzymes in human beings, and accounts for about $13 \%$ of the total cytochrome P450 content of human liver microsomes (Faber et al., 2005). P450 1A2 is responsible for the metabolism of a large number of compounds of both exogenous and endogenous origin, such as theophylline, caffeine, imipramine, acetaminophen, and propranolol as well as 17-estradiol and uroporphyrinogen III (Brøsen K., 1995; Guengerich FP and Shimada T., 1991). In addition, P450 1A2 is of particular importance in carcinogenesis due to its activation of heterocyclic amines that are present in cooked meat and fish (Turesky et al., 1996). These amines are converted to hydroxyamino derivatives, which ultimately produce DNA adducts (Yamashita et al., 1988). Thus, high levels of P450 1A2 could enhance an individual's susceptibility to carcinogenesis and modulation of P450 1A2 activity by selective inhibitors could have important implications for cancer prevention (Chohan et al., 2005).

Moreover, P450 1A2 inhibition may explain some drug-drug interactions in patients. A good example is fluvoxamine, a potent P450 1A2 selective inhibitor, which increased 
the plasma concentrations of caffeine when coadministered with this compound, indicating that the intake of caffeine during fluvoxamine treatment may lead to caffeine intoxication (Jeppesen et al., 1996).

At this time, many P450 1A2 selective inhibitors have been identified. The fluoroquinolone ciprofloxacin (Fuhr et al., 1992), the antidepressant fluvoxamine (Brøsen et al., 1993) and methylxanthine furafylline (Kunze and Trager, 1993) have been used as model inhibitors of P450 1A2. However, till now, little data have been available on the mechanism(s) of inhibitor binding, which hampered further determination of biological roles and structure-based design of potent and selective inhibitors.

In order to study the function of P450 1A2, a number of homology models (Dai et al., 1998; Liu et al., 2004; Cho et al., 2003) were built based on mammalian P450 templates before human P450 1A2 crystal structure in complex with $\alpha$-naphthoflavone was solved by Sansen et al. (Sansen et al., 2007). The structure has been described previously in Chapter 1. Briefly, P450 1A2 has a relatively narrow, flat active site due to several surrounding aromatic residues, which determines that its substrates and inhibitors are usually small lipophilic and planar molecules (Korhonen et al., 2005). P450 1A2 structure provides a useful template to study structure-function relationships of 1A2 with alternative substrates and inhibitors.

To introduce inhibitors into the active site of P450 model, docking programs were utilized to study the possible interactions and binding energies in inhibitor-enzyme complexes. Docking programs include rigid docking programs and flexible docking programs. Rigid docking programs such as Autodock (http://autodock.scripps.edu/), DOCK, FlexX, GOLD and ICM are suites of automated docking tools allowing for full 
ligand flexibility and limited flexibility for the receiptor. AutoDock is the most commonly cited docking program in the scientific literature (Sousa et al., 2006). AutoDock $4.2 \mathrm{v}$ has a free-energy scoring function based on a linear regression analysis, the AMBER force field, and a large set of diverse protein-ligand complexes with known inhibition constants. Flexible docking programs, such as Affinity docking (Insight II), perform flexible ligand docking in flexible receptor. In general, rigid docking is very fast, while high-quality flexible docking takes much longer. Additional methods, such as MD, and evaluation of enzyme-inhibitor interaction energies provide us with more information on P450 catalysis and the motion of the inhibitor in the active site.

The aim of the present study was to reveal the possible mechanism(s) involved in the interaction between the inhibitors and P450 1A2. First, we docked furafylline in the active site of P450 1A2 WT as well as single mutants. MD simulations were then conducted to investigate possible interaction(s) between the inhibitor and enzymes and the altered inhibition caused by the mutations of the WT enzyme. Secondly, we described the use of structure-based in silico approach to evaluate the relationship between the docking score and inhibitory effects (Ki) of both competitive and mechanism-based inhibitors of P450 1A2 using AutoDock program.

\subsection{Materials and Methods}

Affinity Docking and MD Simulations. Molecular modeling was performed on SGI workstation with Insight II software (Accelrys, Inc) using consistent valence force field (CVFF) supplemented with parameters for heme and ferryl oxygen. The crystal structure of P450 1A2 (Protein Data Bank: 2hi4) represented WT enzyme and served as a basis to 
construct single mutants, including T124S, T223N, V227G, N312L, L382V and F226L, as described previously (Liu et al., 2004; Tu et al., 2008). Furafylline was built and energy optimized using the Insight II/Builder module. Initially, this ligand was placed manually into the active site of P450 1A2 WT or six single mutants in order to avoid steric overlaps, and then affinity docking was performed using the Insight II/Affinity module. Out of 20 final orientations, the most energetically favorable complex leading to inhibitor oxidation was subjected to $5 \mathrm{ps}$ MD simulations with distance restraints imposed to obtain the optimal enzyme-inhibitor complex. The distance between the ferryl oxygen and hydrogens at the oxidation site of furafylline was constrained to 2.75$3.25 \AA$. After the MD run, the structure was minimized with 500 steps of steepest descents and 500 steps of conjugate gradients minimizations. Inhibitor mobility was then investigated by 100 ps MD simulations with no restraints and the MD frames were saved every $500 f s$ for further analysis. Both the inhibitor and active site residues within $15 \AA$ from the inhibitor were allowed to move during MD simulations.

Docking and Binding Energy Calculation Using AutoDock. Docking of several selective P450 1A2 inhibitors, including competitive and mechanism-based inhibitors, was performed with AutoDock 3.0v. The P450 1A2 crystal structure was used for docking, and the docking procedure was conducted using the standard protocol. The auxiliary program AutoGrid generated the grid maps. The grids (one for each atom type in the inhibitors, plus one for electrostatic interactions) were chosen to be sufficiently large to include significant portions of the active site of P450 1A2. The grid dimensions were thus $60 \times 60 \times 60 \AA^{3}$, with points separated by $0.375 \AA$. Docking was carried out 
using the empirical free energy function and the Lamarckian algorithm. The number of docking runs was 100 and, after docking, the 50 solutions were clustered into groups with the RMS deviations lower than $0.5 \AA$. The clusters were ranked by the lowest-energy representative of each bunch.

\subsection{Results}

Furafylline Docking. Furafylline was docked within the active sites of P450 1A2 WT and mutants using Affinity docking program. MD simulations were then conducted to observe the binding orientation and the mobility of furafylline. Figure 4.1 displays the binding orientation of furafylline in the active site of P450 1A2 WT and the location of six residues of interest, namely Thr124, Thr223, Phe226, Val227, Asn312, and Leu382 in P450 1A2 WT, five of which have been reported to determine the specificity of P450 1A2 toward alkoxyresorufin (Liu et al., 2004). These six residues are located on the surface of the active site cavity and are in direct contact with furafylline. The mutation of these residues might change the binding orientation of furafylline, thereby altering the susceptibility of the mutant enzymes to inhibition by this compound. As shown in Figure 4.1, Phe226 and furafylline might have $\pi-\pi$ stacking interactions, which play a pivotal role in stabilizing the binding orientation of furafylline in the active site of P450 1A2. Therefore, MD simulations were performed to predict the effect of the mutation of several residues on the mobility of furafylline. Thr124, Thr223, Val227, Asn312, and Leu382 were replaced by the residues found at the equivalent locations in P450 1A1, that is Ser122, Asn221, Gly225, Leu312, and Val382, respectively. Phe226 was replaced by Leu, which does not have phenol group, in order to investigate the role of $\pi$ - $\pi$ stacking 
interactions in determining the binding orientation of furafylline in the active site of P450 1A2. The plots of the distance $(r)$ between the hydrogens at the oxidation site of furafylline and the ferryl oxygen vs. simulation times are shown in Figure 4.2 for P450 1A2 WT, T124S, F226L and L382V. The distance $(r)$ did not change for T124S and L382V mutants, as well as T223N, V227G, N312L mutant (data not shown), compared with the WT enzyme. Interestingly, the distance $(r)$ showed a significant increase when Phe226 was replaced by Leu, suggesting a decreased inhibitory effect of furafylline on the enzyme. Figure 4.3 shows the distance $(r)$ for the MD frames collected during the 100ps MD simulation for P450 1A2 WT and mutants. P450 1A2 T124S and L382V displayed very similar mobility as P450 WT, in contrast to the F226L mutant, in which furafylline moved further away from the heme iron.

P450 1A2 Affinities of Various Inhibitors. Various potent selective inhibitors, including eight competitive inhibitors and ten mechanism-based inhibitors, could be successfully docked into the active site of P450 1A2. The values of docking scores (dock energy) range from -11.83 to $-9.5 \mathrm{kcal} / \mathrm{mol}$ (Figure 4.4 ). In general, the more negative the value, the tighter the binding. The docking score values for these 18 inhibitors correlate well with the experimental $\mathrm{Ki}$ values, with $r^{2}=0.72$ for eight competitive inhibitors and two mechanism-based inhibitors NPS100524 and furafylline; $r^{2}=0.96$ for eight mechanism-based inhibitors. Surprisingly, the data for NPS100524 and furafylline fits well with those for competitive inhibitors instead of mechanism-based inhibitors.

\subsection{Discussion}


Cytochrome P450 1A2 selective inhibitors play a key role in the prevention of P450 1A2-mediated toxic metabolite formation. Therefore, the elucidation of the molecular mechanism of enzyme inactivation would give some insight into P450-linked carcinogenesis and have important implications for the rational design of anticancer drugs. In the current studies, we have studied the interactions between P450 1A2 and its selective inhibitors in silico using the newly crystallized P450 1A2 structure. Docking of inhibitors into the active site of the enzyme model can help to explain enzyme-inhibitor interactions as well as the role of certain residues in catalysis (Szklarz and Halpert, 1998).

In this study, we chose two different docking programs to meet our aims. Furafyline docking within the active site of P450 1A2 WT and mutants using Affinity docking program provided us with more accurate information although the simulations took longer. Therefore, to dock eighteen inhibitors, we adopted Autodock 3.0v, which is able to quickly calculate the docking scores for those compounds (about 2 hours for each compound). The choice of the orientation of the inhibitor bound in the active site and corresponding docking score is important.

Docking and MD simulation studies indicated that the inhibition of furafylline does not change in P450 1A2 T124S, T223N, V227G, N312L and L382V mutants, compared to the WT enzyme, which has been confirmed by inhibition assays (data not shown). In contrast, the replacement of Phe-226 with Leu led to a significant increase in the ferryl oxygen-hydrogen distance, suggesting that the mutant becomes resistant to inactivation, probably due to the loss of $\pi-\pi$ stacking interactions with Phe which stabilize the productive binding orientation of furafylline. This prediction needs to be verified experimentally in the future. Similarly, hydrogen bonding, $\pi-\pi$ stacking or a combination 
of the two plays a role in the interactions between P450 2C subfamily enzymes and their selective inhibitors (Lewis et al., 2006).

P450 1A2 selective inhibitors were divided into two groups for docking based on the mechanisms of the inhibition. The set of mechanism-based inhibitors displayed very poor correlation between the docking score and Ki values $\left(r^{2}=0.54\right)$. In the plot of mechanism-based inhibitors, the points for NPS100524 and furafylline are far away from the correlation line. Surprisingly, they fitted very well with the correlation equation of competitive inhibitors. The reasons might lie in the different mechanisms involved in the fate of their reactive metabolites, such as reacting with amino acids present in the active site, reacting with the porphyrinnitrogen atoms or even coordinating to the iron to form a tight bond (Murray, 1997), which led to significant differences in docking scores.

In conclusion, we demonstrated the $\pi-\pi$ stacking interactions might be primarily involved in furafylline binding in the active site of P450 1A2. Other reciprocal 1A2 mutants, such as T124S, T223N, V227G, N312L and L382V did not alter their susceptibility to inhibition by furafylline with enzymes. Using AutoDock program, good correlations between docking score and experimental $\mathrm{Ki}$ were obtained for competitive and mechanism-based inhibitors of P450 1A2. Knowledge of the interactions between the inhibitors and the enzymes may provide deep insights for the future design of potent selective inhibitors.

\subsection{Acknowledgments}

Molecular modeling studies were performed at the Computational Chemistry and Molecular Modeling Laboratory, Department of Basic Pharmaceutical Sciences, School 
of Pharmacy, West Virginia University, Morgantown, WV. 


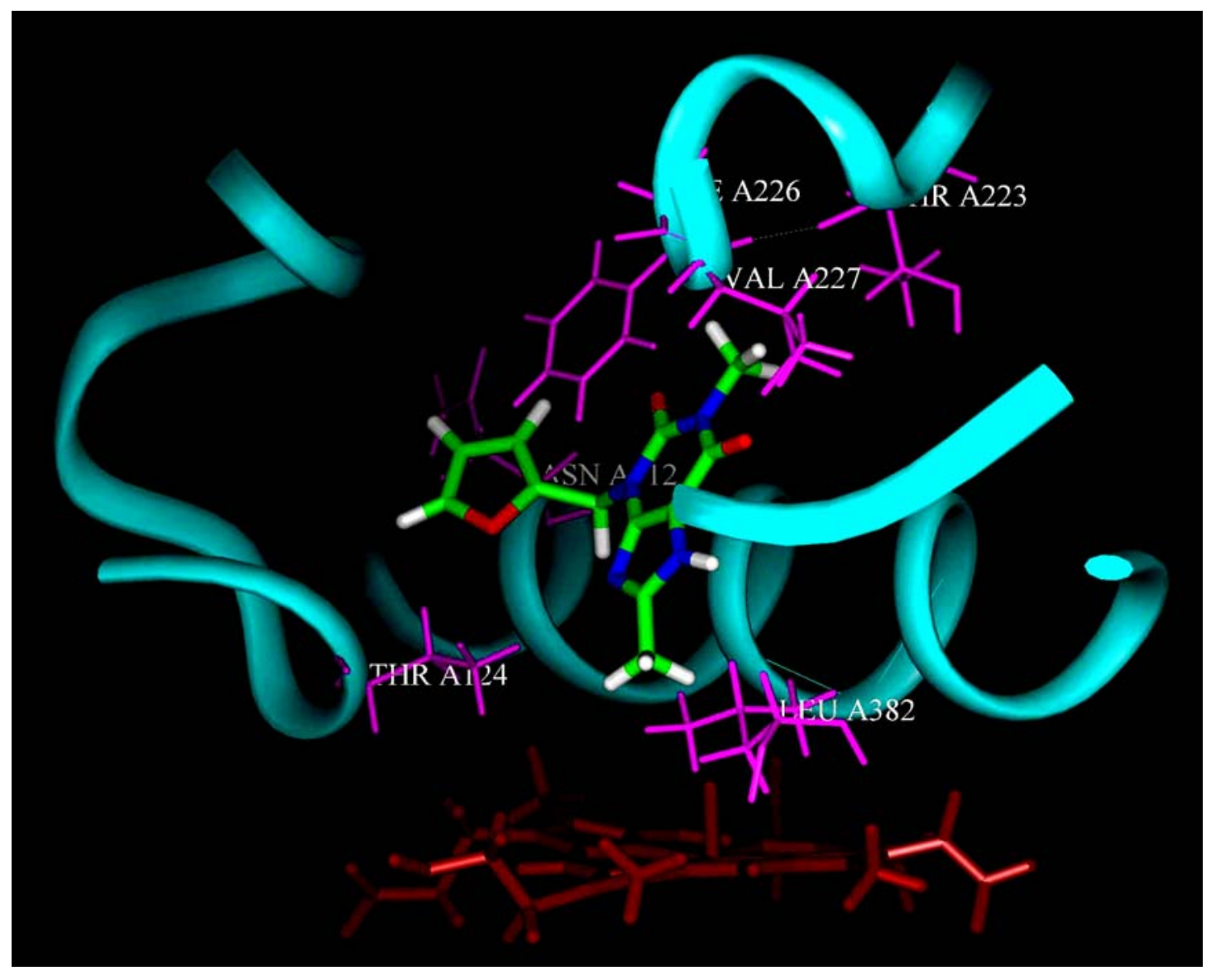

Figure 4.1. Binding Orientation of Furafylline within the Active Site of P450 1A2 Crystal Structure

The protein backbone is depicted as cyan ribbons, the side chains of residues of interest (within $3 \AA$ distance from furaffyline) are pink, heme is red, and furafylline is colored by atom type. 

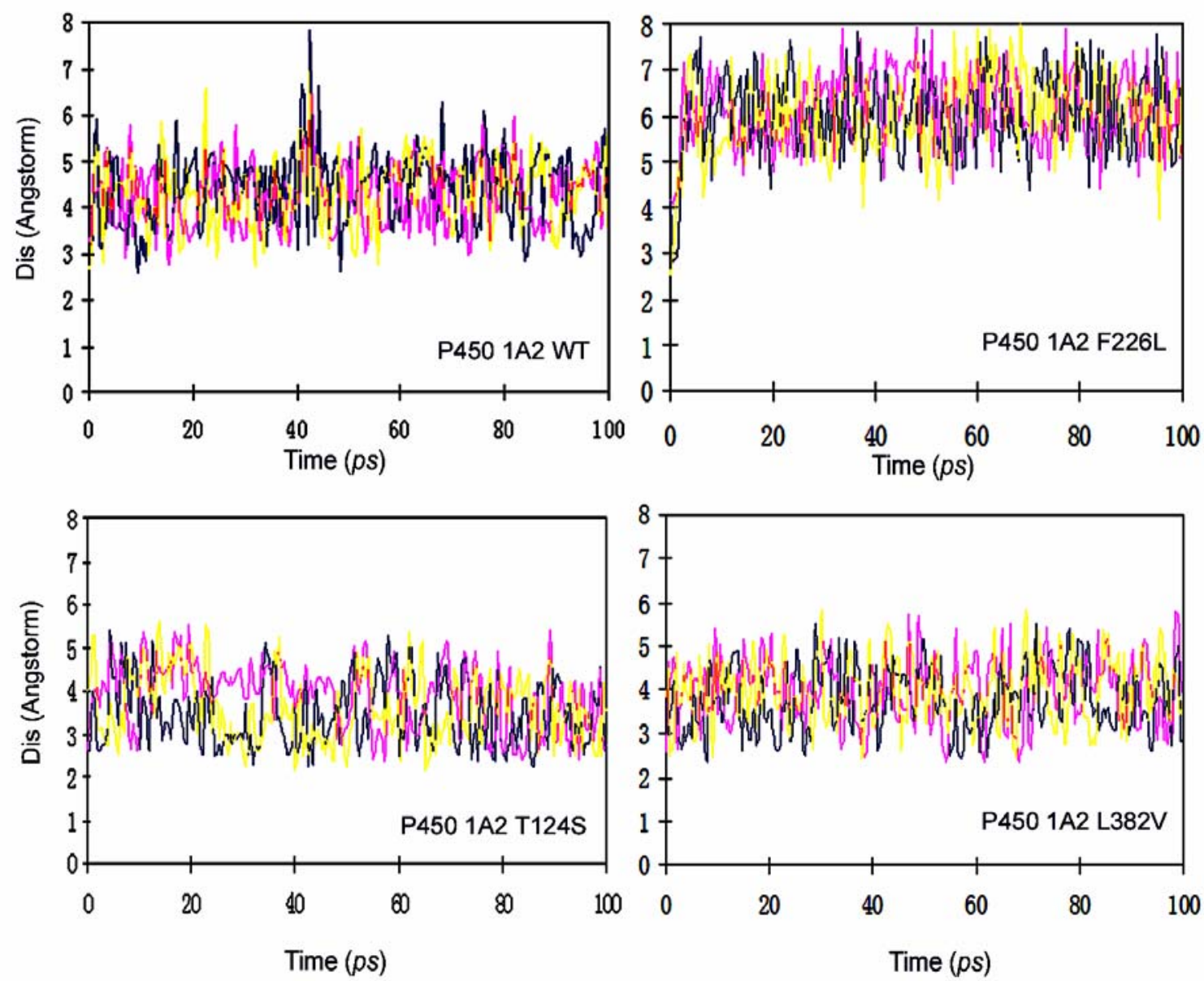

Figure 4.2. The Distance ( $r$ ) Changes as a Function of Time during 100 ps MD simulations

The $r$ presents the distance between the ferryl oxygen and hydrogens at the oxidation site of furafylline bound in the active site of the P450 1A2 WT, F226L, T124S, and L382V mutants. The ideal distance leading to the reaction is $2.75-3.25 \AA$. 


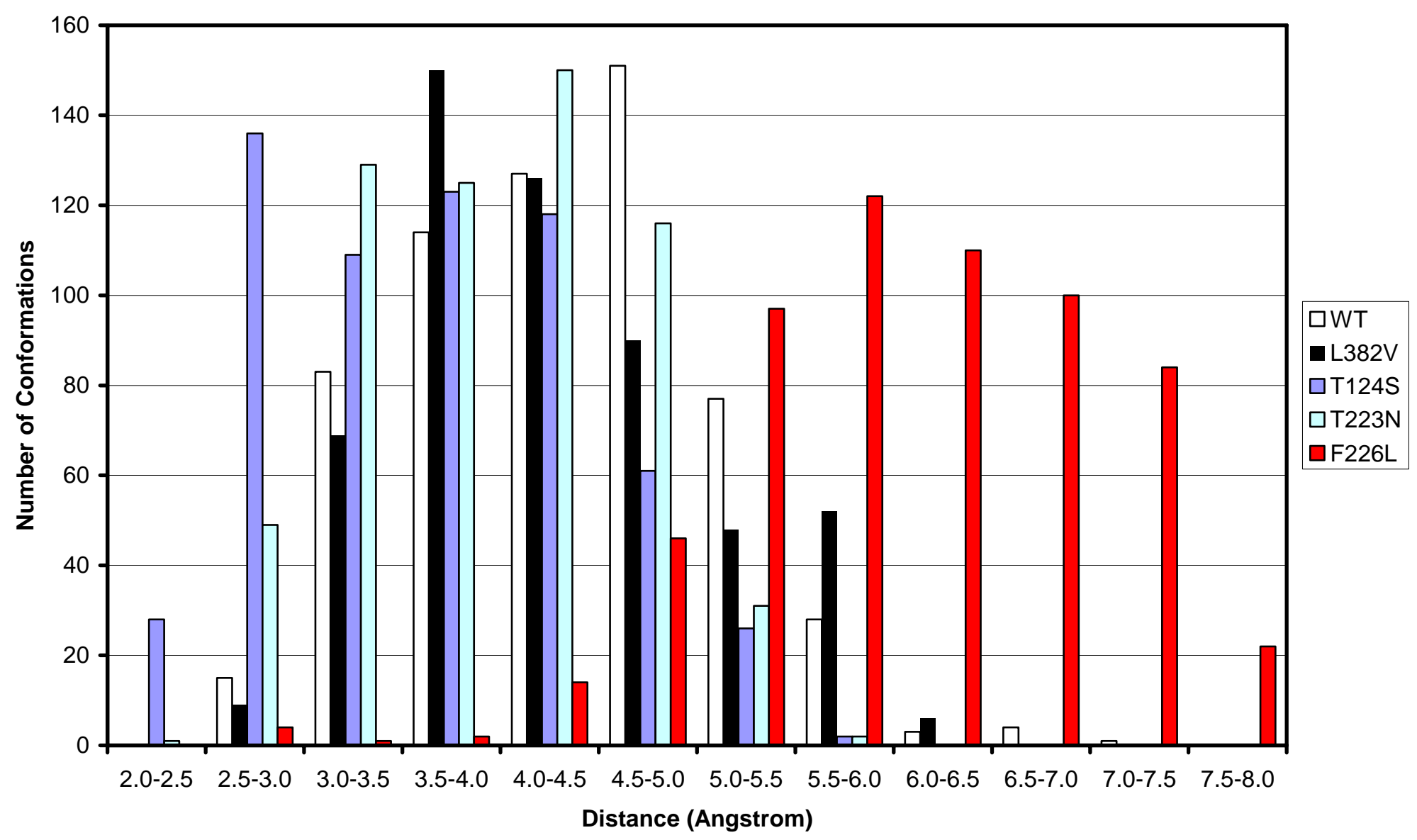

Figure 4.3. Histogram of Distances between the Ferryl Oxygen and Hydrogens at the Oxidation Site of Furafylline

The inhibitor was bound in the active site of the P450 1A2 wide type and four selected single mutants. The replacement of Phe226 with Leu led to a significant increase in the ferryl oxygen-hydrogen distance, suggesting that the mutant becomes resistant to inactivation. 
(A)

P450 1A2 competetive inhibitors

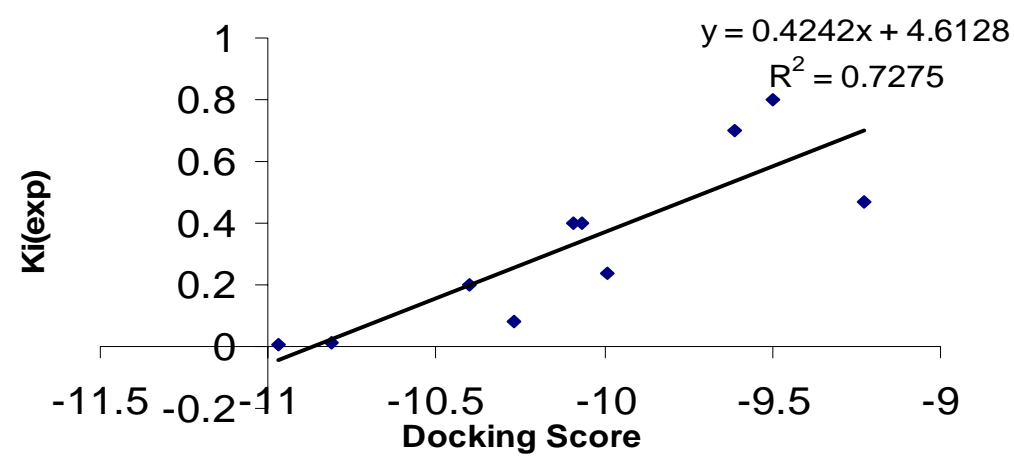

(B)

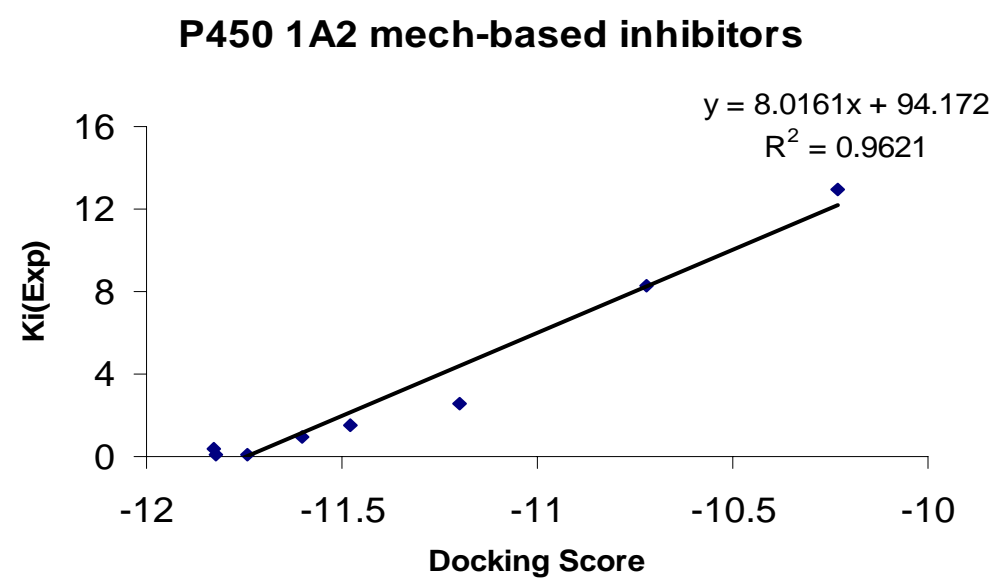

\begin{tabular}{|l|c|c|}
\hline \multicolumn{1}{|c|}{ Competitive Inhibitors } & $\begin{array}{c}\mathrm{Ki}_{(\text {Expt.) }} \\
(\mu \mathrm{M})\end{array}$ & $\begin{array}{c}\text { Docking Score } \\
\text { Dock Energy(kcal/mol) }\end{array}$ \\
\hline$\alpha$-naphthoflavone & 0.013 & -10.81 \\
\hline acacetin & 0.08 & -10.27 \\
\hline$(+)$-aranidipine & 0.20 & -10.40 \\
\hline fluvoxamine & 0.24 & -9.99 \\
\hline sulconazole & 0.40 & -10.09 \\
\hline tioconazole & 0.40 & -10.07 \\
\hline nifedipine & 0.47 & -9.23 \\
\hline 8-phenyltheophylline & 0.7 & -9.61 \\
\hline
\end{tabular}

\begin{tabular}{|l|c|c|}
\hline $\begin{array}{c}\text { Mechanism-based } \\
\text { Inhibitors }\end{array}$ & $\begin{array}{c}\mathrm{Ki}_{(\text {Expt. }} \\
(\mu \mathrm{M})\end{array}$ & $\begin{array}{c}\text { Docking Score } \\
\text { Dock Energy(kcal/mol) }\end{array}$ \\
\hline NPS100524* & 0.006 & -10.97 \\
\hline $\mathrm{B}[b] \mathrm{FA}$ & 0.11 & -11.74 \\
\hline 5MeCh & 0.12 & -11.82 \\
\hline B $[j] \mathrm{FA}$ & 0.38 & -11.83 \\
\hline Furafylline* & 0.8 & -9.5 \\
\hline DB[a,j]Ac & 0.95 & -11.6 \\
\hline DMBA & 1.5 & -11.48 \\
\hline B $[a]$ A & 2.6 & -11.2 \\
\hline B $[a] \mathrm{P}$ & 8.3 & -10.72 \\
\hline Chrysin & 13 & -10.23 \\
\hline
\end{tabular}

Figure 4.4. The linear correlation between the docking score and experimental Ki for several selective P450 $1 \mathrm{A2}$ inhibitors

*Mechanism-based inhibitors, NPS100524 and furafylline, were plotted in (A), which displayed a good correlation with competitive inhibitors 
Chapter 5

Summary and Conclusions 
We have investigated substrate specificity and inhibitor susceptibility to reveal the structure-function relationships of P450 1A2. A combination of computational approaches such as ligand docking and molecular dynamics simulations, and experimental techniques such as kinetic assays, site-directed mutagenesis and stoichiometry, were utilized to give us a better understanding of the mechanism(s) involved in ligand-enzyme interactions.

In Chapter 2, we explored the roles of five key residues in SRS regions of P450 1A2, namely Thr124, Thr223, Val227, Asn312, and Leu382, in determining the enzyme specificity using phenacetin as a probe substrate. Surprisingly, catalytic assays indicated that the of L382V substitution significantly increased the catalytic efficiency of P450 1A2 enzyme toward phenacetin $O$-deethylation while other four single mutations lowered catalytic efficiency of the enzyme. In addition, stoichiometry analysis revealed that less water formation during the P450 catalytic cycle contributed to the increased catalytic efficiency of P450 $1 \mathrm{~A} 2 \mathrm{~L} 382 \mathrm{~V}$ and multiple mutants containing the of $\mathrm{L} 382 \mathrm{~V}$ substitution, compared with $1 \mathrm{~A} 2 \mathrm{WT}$. We then used molecular modeling to study the mobility of phenacetin within the active sites of P450 1A2 WT and single and multiple mutants. MD simulations suggested that the $\mathrm{L} 382 \mathrm{~V}$ substitution provides more space for phenacetin and enable it to move closer to the heme iron, which promotes substrate oxidation. Thus, molecular modeling study provided a rationale to explain the higher catalytic efficiencies of the enzymes containing L382V substitution.

Although the results of molecular modeling were consistent with enzymatic assays, direct experimental evidences were still needed to confirm the mechanism proposed from molecular modeling study. Therefore, NMR $T_{1}$ relaxation time measurements were 
utilized as described in Chapter 3 to extend our studies on the binding orientation of phenacetin within the active sites of P450 1A2 WT and mutants. By comparing the distances between the protons of substrate phenacetin and the ferryl oxygen of the heme, we concluded that the distances between the site of metabolism of phenacetin and the oxo-heme of P450 L382V and mutants containing the of L382V substitution are significantly shorter than those of P450 1A2 WT and N312L as well as P450 1A1 WT. Thus, NMR measurements provide concrete evidence to explain the increased catalytic efficiencies of the enzymes.

In Chapter 4, we used selective inhibitors as another type of ligand to investigate their interactions with P450 1A2 WT and mutants. Furafylline docking and site-directed mutagenesis suggested that $\pi-\pi$ stacking might play a role in stabilizing the binding orientation of furafylline within the active site of P450 1A2. No hydrogen bonds were found in the interaction between furafylline and P450 1A2. The inhibitory potential of an inhibitor correlated well with the binding score. The stronger the inhibitor, the higher the binding interaction with the enzyme.

Taken together, we have tried to use computational approaches and experimental techniques to elucidate the mechanism(s) involved in determining the substrate specificity and inhibitor susceptibility of P450 1A2. A better understanding of the catalytic mechanism, substrate binding and turnover, the mechanism(s) of P450 inhibition, as well as the structural basis for enzyme function, would give us some insight into P450linked carcinogenesis and have important implications for the rational design of anticancer drugs. 


\section{References}




\section{Chapter 1 Reference List}

Afzelius L, Arnby CH, Broo A, Carlsson L, Isaksson C, Jurva U, Kjellander B, Kolmodin K, Nilsson K, Raubacher F, and Weidolf L (2007) State-of-the-art tools for computational site of metabolism predictions: comparative analysis, mechanistical insights, and future applications. Drug Metab Rev. 39:61-86.

Atkins WM and Sligar SG (1989) Molecular recognition in cytochrome P450: alteration of regioselective alkane hydroxylation via protein engineering J. Bio. Chem. 111:2715-2717.

Bachmann K, White D, Jauregui L, Schwartz JI, Agrawal NG, Mazenko R, Larson PJ, and Porras AG (2003) An evaluation of the dose-dependent inhibition of CYP1A2 by rofecoxib using theophylline as a CYP1A2 probe. J Clin Pharmacol. 43:1082-1090.

Backman JT, Karjalainen MJ, Neuvonen M, Laitila J, and Neuvonen PJ (2006) Rofecoxib is a potent inhibitor of cytochrome P450 1A2: studies with tizanidine and caffeine in healthy subjects. Br J Clin Pharmacol. 62:345-357.

Bauer E, Guo Z, Ueng YF, Bell LC, Zeldin D, and Guengerich FP (1995) Oxidation of benzo[a]pyrene by recombinant human cytochrome P450 enzymes. Chem Res Toxicol. 8:136-142.

Becquemont L, Ragueneau I, Le Bot MA, Riche C, Funck-Brentano C, and Jaillon P (1997) Influence of the CYP1A2 inhibitor fluvoxamine on tacrine pharmacokinetics in humans. Clin Pharmacol Ther. 61:619-627.

Bridges A, Gruenke L, Chang YT, Vakser IA, Loew G, and Waskell L (1998) Identification of the binding site on cytochrome P450 2B4 for cytochrome b5 and cytochrome P450 reductase. J Biol Chem. 273:17036-17049.

Brøsen K, Skjelbo E, Rasmussen BB, Poulsen HE, and Loft S (1993) Fluvoxamine is a potent inhibitor of cytochrome P4501A2. Biochem Pharmacol. 45:1211-1214.

Cameron MD, Wen B, Roberts AG, Atkins WM, Campbell AP, and Nelson SD (2007) Cooperative binding of acetaminophen and caffeine within the P450 3A4 active site. Chem Res Toxicol. 20:1434-1441.

Caron G, Ermondi G, and Testa B (2007) Predicting the oxidative metabolism of statins: an application of the MetaSite algorithm. Pharm Res. 24:480-501.

Cho US, Park EY, Dong MS, Park BS, Kim K, and Kim KH (2003) Tight-binding inhibition by alpha-naphthoflavone of human cytochrome P450 1A2. Biochim Biophys Acta. 1648:195-202.

Correia, MA. and Ortiz de Montellano, PR (2004) Structures of Eukaryotic Cytochrome P450 Enzymes, in Cytochrome P-450: structure, mechanism, and biochemistry (Ortiz 
de Montellano PR., Ed.) 3rd Ed., pp 247-322, Plenum Press, New York.

de Groot MJ (2006) Designing better drugs: predicting cytochrome P450 metabolism. Drug Discov Today. 11:601-606.

Fang X, Kobayashi Y, and Halpert JR (1997) Stoichiometry of 7-ethoxycoumarin metabolism by cytochrome P450 2B1 wild-type and five active-site mutants. FEBS Lett. 416:77-80.

Fuhr U, Strobl G, Manaut F, Anders EM, Sörgel F, Lopez-de-Brinas E, Chu DT, Pernet AG, Mahr G, and Sanz F (1993) Quinolone antibacterial agents: relationship between structure and in vitro inhibition of the human cytochrome P450 isoform CYP1A2. Mol Pharmacol. 43:191-199.

Guengerich FP (1994) Catalytic selectivity of human cytochrome P450 enzymes: relevance to drug metabolism and toxicity. Toxicol Lett. 70:133-138.

Guengerich FP (2008) Cytochrome p450 and chemical toxicology. Chem Res Toxicol. 21:70-83.

Hummel MA, Gannett PM, Aguilar JS, and Tracy TS (2004) Effector-mediated alteration of substrate orientation in cytochrome P450 2C9. Biochemistry. 43:7207-7214.

Imai Y., Sato R., and Iyanagi T (1977) Rate-limiting step in the reconstituted microsomal drug hydroxylase system. J. of Biochem. 82:1237-1246.

Jacobs RE, Singh J, and Vickery LE (1987) NMR studies of cytochrome P-450scc. Effects of steroid binding on water proton access to the active site of the ferric enzyme. Biochemistry. 26:4541-4545.

Jerina DM, Michaud DP, Feldman RJ, Armstrong RN, Vyas KP, Thakker DR, Yagi H, Thomas PE, Ryan DE, and Levin W (1982) Stereochemical modeling of the catalytic site of cytochrome P450c., In Microsomes, drug oxidations, and drug toxicity. Sato R., Kato R. Ed., Japan Scientific Societies Press,Tokyo, pp 195-201.

Johnson EF (1992) Mapping determinants of the substrate selectivities of P450 enzymes by site-directed mutagenesis. Trends Pharmacol Sci. 13:122-126.

Kadlubar FF and Hammons GJ (1987) The role of cytochrome P-450 in the metabolism of chemical carcinogens. In Mammalian cytochromes P450. Guengerich FP. Ed. CRC Press, Boca Raton, pp 81-130.

Katagiri M, Ganguli BN, and Gunsalus IC (1968) A soluble cytochrome P-450 functional in methylene hydroxylation. J Biol Chem. 243:3543-3546.

Kawajiri K and Fujii-Kuriyama Y (1991) P450 and human cancer. Jpn J Cancer Res. 82:1325-1335. 
Lee H, Ortiz de Montellano PR, and McDermott AE (1999) Deuterium magic angle spinning studies of substrates bound to cytochrome P450. Biochemistry. 38:1080810813.

Lewis DF (1998) The CYP2 family: models, mutants and interactions. Xenobiotica. 28:617-661.

Lewis DF, Lake BG, Dickins M, Ueng YF, and Goldfarb PS (2003) Homology modelling of human CYP1A2 based on the CYP2C5 crystallographic template structure. Xenobiotica. 33:239-254.

Lisitsa A, Archakov A, Lewi P, and Janssen P (2003) Bioinformatic insight into the unity and diversity of cytochromes P450. Methods Find Exp Clin Pharmacol. 25:733-745.

Liu J, Ericksen SS, Besspiata D, Fisher CW, and Szklarz GD (2003) Characterization of substrate binding to cytochrome P450 1A1 using molecular modeling and kinetic analyses: case of residue 382. Drug Metab Dispos. 31:412-420.

Liu J, Ericksen SS, Sivaneri M, Besspiata D, Fisher CW, and Szklarz GD (2004) The effect of reciprocal active site mutations in human cytochromes P450 1A1 and 1A2 on alkoxyresorufin metabolism. Arch Biochem Biophys. 424:33-43.

Lozano JJ, Pastor M, Cruciani G, Gaedt K, Centeno NB, Gago F, and Sanz F (2000) 3DQSAR methods on the basis of ligand-receptor complexes. Application of COMBINE and GRID/GOLPE methodologies to a series of CYP1A2 ligands. J Comput Aided Mol Des. 14(4):341-353.

Modi S, Primrose WU, Boyle JM, Gibson CF, Lian LY, and Roberts GC (1995) NMR studies of substrate binding to cytochrome P450 BM3: comparisons to cytochrome P450 cam. Biochemistry. 34:8982-8988.

Modi S, Paine MJ, Sutcliffe MJ, Lian LY, Primrose WU, Wolf CR, and Roberts GC (1996) A model for human cytochrome P450 2D6 based on homology modeling and NMR studies of substrate binding. Biochemistry. 35:4540-4550.

Modi S, Gilham DE, Sutcliffe MJ, Lian LY, Primrose WU, Wolf CR, and Roberts GC (1997) 1-methyl-4-phenyl-1,2,3,6-tetrahydropyridine as a substrate of cytochrome P450 2D6: allosteric effects of NADPH-cytochrome P450 reductase. Biochemistry. 36:4461-4470.

Myers TG, Thummel KE, Kalhorn TF, and Nelson SD (1994) Preferred orientations in the binding of 4'-hydroxyacetanilide (acetaminophen) to cytochrome P450 1A1 and $2 \mathrm{~B} 1$ isoforms as determined by $13 \mathrm{C}$ - and $15 \mathrm{~N}-\mathrm{NMR}$ relaxation studies. $J$ Med Chem. 37:860-867.

Nelson DR, Koymans L, Kamataki T, Stegeman JJ, Feyereisen R, Waxman DJ, 
Waterman MR, Gotoh O, Coon MJ, Estabrook RW, Gunsalus IC, and Nebert DW (1996) P450 superfamily: update on new sequences, gene mapping, accession numbers and nomenclature. Pharmacogenetics. 6:1-42.

Nerurkar PV, Park SS, Thomas PE, Nims RW, and Lubet RA (1993) Methoxyresorufin and benzyloxyresorufin: substrates preferentially metabolized by cytochromes P4501A2 and 2B, respectively, in the rat and mouse. Biochem Pharmacol. 46:933943.

Orengo CA, Michie AD, Jones S, Jones DT, Swindells MB, and Thornton JM (1997) CATH--a hierarchic classification of protein domain structures. Structure. 5:10931108.

Ortiz de Montellano PR (2005) Cytochrome P450: structure, mechanism, and biochemistry, 3rd edn. Kluwer/Plenum, New York.

Otyepka M, Skopalík J, Anzenbacherová E, and Anzenbacher P (2007) What common structural features and variations of mammalian P450s are known to date? Biochim Biophys Acta. 1770:376-389.

Paine MF, Schmiedlin-Ren P, and Watkins PB (1999) Cytochrome P-450 1A1 expression in human small bowel: interindividual variation and inhibition by ketoconazole. Drug Metab Dispos. 27:360-364.

Pastrakuljic A, Tang BK, Roberts EA, and Kalow W (1997) Distinction of CYP1A1 and CYP1A2 activity by selective inhibition using fluvoxamine and isosafrole. Biochem Pharmacol. 53:531-538.

Poli-Scaife S, Attias R, Dansette PM, and Mansuy D (1997) The substrate binding site of human liver cytochrome P450 2C9: an NMR study. Biochemistry. 36:12672-12682.

Poulos TL, Finzel BC, and Howard AJ (1987) High-resolution crystal structure of cytochrome P450cam. J Mol Biol. 195:687-700.

Poulos TL (2003) Cytochrome P450 flexibility Proc.Natl.Acad.Sci.U.S.A 100:1312113122.

Rasmussen BB, Maënpää J, Pelkonen O, Loft S, Poulsen HE, Lykkesfeldt J, and Brøsen K (1995) Selective serotonin reuptake inhibitors and theophylline metabolism in human liver microsomes: potent inhibition by fluvoxamine. $\mathrm{Br} J$ Clin Pharmacol. 39:151-159.

Regal KA and Nelson SD (2000) Orientation of caffeine within the active site of human cytochrome P450 1A2 based on NMR longitudinal (T1) relaxation measurements. Arch Biochem Biophys. 384:47-58. 
Rendic S and Di Carlo FJ (1997) Human cytochrome P450 enzymes: a status report summarizing their reactions, substrates, inducers, and inhibitors. Drug Metab. Rev. 29:413-580.

Sansen S, Yano JK, Reynald RL, Schoch GA, Griffin KJ, Stout CD, Johnson EF. (2007) Adaptations for the oxidation of polycyclic aromatic hydrocarbons exhibited by the structure of human P450 1A2. J Biol Chem. 282:14348-14355.

Schoch GA, Yano JK, Wester MR, Griffin KJ, Stout CD, and Johnson EF (2004) Structure of human microsomal cytochrome P450 2C8. Evidence for a peripheral fatty acid binding site. J Biol Chem. 279:9497-9503.

Schwartz JI, Bugianesi KJ, Ebel DL, De Smet M, Haesen R, Larson PJ, Ko A, Verbesselt R, Hunt TL, Lins R, Lens S, Porras AG, Dieck J, Keymeulen B, and Gertz BJ (2000) The effect of rofecoxib on the pharmacodynamics and pharmcokinetics of warfarin. Clin Pharmacol Ther. 68:626-636.

Schweikl H, Taylor JA, Kitareewan S, Linko P, Nagorney D, and Goldstein JA (1993) Expression of CYP1A1 and CYP1A2 genes in human liver. Pharmacogenetics. 3:239-249.

Sesardic D, Boobis AR, Murray BP, Murray S, Segura J, de la Torre R, and Davies DS (1990) Furafylline is a potent and selective inhibitor of cytochrome P450 1A2 in man. Br J Clin Pharmacol. 29:651-663.

Shimada T, Yamazaki H, Mimura M, Inui Y, and Guengerich FP (1994) Interindividual variations in human liver cytochrome P-450 enzymes involved in the oxidation of drugs, carcinogens and toxic chemicals: studies with liver microsomes of 30 Japanese and 30 Caucasians. J Pharmacol Exp Ther. 270:414-423.

Shimada T, Yamazaki H, Foroozesh M, Hopkins NE, Alworth WL, Guengerich FP. (1998) Selectivity of polycyclic inhibitors for human cytochrome P450s 1A1, 1A2, and 1B1. Chem Res Toxicol. 11:1048-1056.

Sykes MJ, McKinnon RA, and Miners JO (2008) Prediction of metabolism by cytochrome P450 2C9: alignment and docking studies of a validated database of substrates. J Med Chem. 51:780-791.

Szklarz GD and Halpert JR (1997) Use of homology modeling in conjunction with sitedirected mutagenesis for analysis of structure-function relationships of mammalian cytochromes P450. Life Sci. 61:2507-2520.

Szklarz GD and Halpert JR (1998) Molecular basis of P450 inhibition and activation: implications for drug development and drug therapy. Drug Metab Dispos. 26:11791184. 
Szklarz GD, Graham SE, and Paulsen MD (2000) Molecular modeling of mammalian cytochromes P450: application to study enzyme function. Vitam Horm. 58:53-87.

Tassaneeyakul W, Mohamed Z, Birkett DJ, McManus ME, Veronese ME, Tukey RH, Quattrochi LC, Gonzalez FJ, and Miners JO (1992) Caffeine as a probe for human cytochromes P450: validation using cDNA-expression, immunoinhibition and microsomal kinetic and inhibitor techniques. Pharmacogenetics. 2:173-183.

Tassaneeyakul W, Birkett DJ, Veronese ME, McManus ME, Tukey RH, Quattrochi LC, Gelboin HV, and Miners JO (1993) Specificity of substrate and inhibitor probes for human cytochromes P450 1A1 and 1A2. J Pharmacol Exp Ther. 265:401-407.

Tu Y, Deshmukh R, Sivaneri M, and Szklarz GD (2008) Application of molecular modeling for prediction of substrate specificity in cytochrome P450 1A2 mutants. Drug Metab Dispos. 36:2371-2380.

von Moltke LL, Greenblatt DJ, Duan SX, Schmider J, Kudchadker L, Fogelman SM, Harmatz JS, and Shader RI (1996) Phenacetin O-deethylation by human liver microsomes in vitro: inhibition by chemical probes, SSRI antidepressants, nefazodone and venlafaxine. Psychopharmacology (Berl). 128:398-407.

Wei JY, Pochapsky TC, and Pochapsky SS (2005) Detection of a high-barrier conformational change in the active site of cytochrome P450cam upon binding of putidaredoxin. J Am Chem Soc. 127:6974-6976.

Williams PA, Cosme J, Vinkovic DM, Ward A, Angove HC, Day PJ, Vonrhein C, Tickle IJ, and Jhoti H (2004) Crystal structures of human cytochrome P450 3A4 bound to metyrapone and progesterone. Science. 305:683-686.

Yang SK (1988) Stereoselectivity of cytochrome P-450 isozymes and epoxide hydrolase in the metabolism of polycyclic aromatic hydrocarbons. Biochem Pharmacol. 37:6170 .

Yano JK, Hsu MH, Griffin KJ, Stout CD, and Johnson EF (2005) Structures of human microsomal cytochrome P450 2 A6 complexed with coumarin and methoxsalen. Nat Struct Mol Biol. 12:822-823.

Zhou D, Afzelius L, Grimm SW, Andersson TB, Zauhar RJ, and Zamora I (2006) Comparison of methods for the prediction of the metabolic sites for CYP3A4mediated metabolic reactions. Drug Metab Dispos. 34:976-983.

Zhou SF, Yang LP, Zhou ZW, Liu YH, and Chan E (2009) Insights into the substrate specificity, inhibitors, regulation, and polymorphisms and the clinical impact of human cytochrome P450 1A2. AAPS J. 11:481-494. 


\section{Chapter 2 Reference List}

Burke MD, Thompson S, Weaver RJ, Wolf CR, and Mayer RT (1994) Cytochrome P450 specificities of alkoxyresorufin O-dealkylation in human and rat liver. Biochem Pharmacol 48:923-936.

Distlerath LM, Reilly PE, Martin MV, Davis GG, Wilkinson GR, and Guengerich FP (1985) Purification and characterization of the human liver cytochromes P-450 involved in debrisoquine 4-hydroxylation and phenacetin O-deethylation, two prototypes for genetic polymorphism in oxidative drug metabolism. J Biol Chem. 260:9057-9067.

Ericksen SS and Szklarz GD (2005) Regiospecificity of human cytochrome P450 1A1mediated oxidations: the role of steric effects. J Biomol Struct Dyn 23: 243-256.

Fang X, Kobayashi Y, and Halpert JR (1997) Stoichiometry of 7-ethoxycoumarin metabolism by cytochrome P450 2B1 wild-type and five active-site mutants. FEBS Lett 416:77-80.

French KJ, Rock DA, Rock DA, Manchester JI, Goldstein BM, and Jones JP (2002) Active site mutations of cytochrome P450cam alter the binding, coupling, and oxidation of the foreign substrates $(R)$ - and (S)-2-ethylhehanol. Arch Bioch Biophys 398: $188-197$.

Guengerich FP and Shimada T (1991) Oxidation of toxic and carcinogenic chemicals by human cytochrome P-450 enzymes. Chem Res Toxicol 4:391-407.

Jiang ZY, Woollard AC, and Wolff SP (1990) Hydrogen peroxide production during experimental protein glycation. FEBS Lett 268:69-71.

Kedzie KM, Balfour CA, Escobar GY, Grimm SW, He Y, Pepperl DJ, Regan JW, Stevens JC, and Halpert JR (1991) Molecular basis for a functionally unique cytochrome P450IIB1 variant. J Biol Chem 266: 22515-22521.

Kobayashi Y, Fang X, Szklarz GD, and Halpert JR (1998) Probing the active site of cytochrome P450 2B1: Metabolism of 7-alkoxycoumarins by the wild type and five site-directed mutants. Biochemistry 37: 6679-6688.

Lewis DF, Moereels H, Lake BG, Ioannides C, and Parke DV (1994) Molecular modeling of enzymes and receptors involved in carcinogenesis: QSARs and compact-3D. Drug Metab Rev 26:261-285.

Liu J, Ericksen SS, Besspiata D, Fisher CW, and Szklarz GD (2003) Characterization of substrate binding to cytochrome P450 1A1 using molecular modeling and kinetic analyses: case of residue 382. Drug Metab Dispos 31:412-420. 
Liu J, Ericksen SS, Sivaneri M, Besspiata D, Fisher CW, and Szklarz GD (2004) The effect of reciprocal active site mutations in human cytochromes P450 1A1 and 1A2 on alkoxyresorufin metabolism. Arch Biochem Biophys 424:33-43.

Lowry OH, Rosenbrough NJ, Farr AL and Randall RJ (1951) Protein measurement with the Folin phenol reagent. J Biol Chem 193:265-275.

Modi S, Primrose WU, Boyle JM, Gibson CF, Lian LY, and Roberts GC (1995) NMR studies of substrate binding to cytochrome P450 BM3: comparisons to cytochrome P450 cam. Biochemistry 34:8982-8988.

Nerurkar PV, Park SS, Thomas PE, Nims RW and Lubet RA (1993) Methoxyresorufin and benzyloxyresorufin: substrates preferentially metabolized by cytochromes P450 $1 \mathrm{~A} 2$ and 2B, respectively, in the rat and mouse. Biochem Pharmacol 46: 933-943.

Nguyen TA, Tychopoulos M, Bichat F, Zimmermann C, Flinois JP, Diry M, Ahlberg E, Delaforge M, Corcos L, Beaune P, Dansette P, André F, and de Waziers I (2008) Improvement of cyclophosphamide activation by CYP2B6 mutants: from in silico to ex vivo. Mol Pharmacol. 73:1122-1133.

Omura T and Sato R (1964) The carbon monoxide-binding pigment of liver microsomes. J Biol Chem 239:2379-2387.

Parikh A, Josephy D, and Guengerich FP (1999) Selection and characterization of human cytochrome P450 1A2 mutants with altered catalytic properties. Biochemistry 38: 52835289.

Paulsen MD and Ornstein RL (1991) A 175-psec molecular dynamics simulation of camphor-bound cytochrome P-450cam. Proteins 11:184-204.

Paulsen MD and Ornstein RL (1992) Predicting the product specificity and coupling of cytochrome P450cam. J Comput Aided Mol Des 6:449-460.

Sansen S, Yano JK, Reynald RL, Schoch GA, Griffin KJ, Stout CD, and Johnson EF (2007) Adaptations for the oxidation of polycyclic aromatic hydrocarbons exhibited by the structure of human P450 1A2. J Biol Chem 282:14348-14355.

Shimada T, Yamazaki H, Mimura M, Inui Y, and Guengerich FP (1994) Interindividual variations in human liver cytochrome P-450 enzymes involved in the oxidation of drugs, carcinogens and toxic chemicals: studies with liver microsomes of 30 Japanese and 30 Caucasians. J Pharmacol Exp Ther 270:414-423.

Tu Y, Deshmukh R, Sivaneri M, and Szklarz GD (2008) Application of molecular modeling for prediction of substrate specificity in cytochrome P450 1A2 mutants. Drug Metab Dispos 36:2371-2380. 
von Moltke LL, Greenblatt DJ, Duan SX, Schmider J, Kudchadker L, Fogelman SM, Harmatz JS, and Shader RI (1996) Phenacetin O-deethylation by human liver microsomes in vitro: inhibition by chemical probes, SSRI antidepressants, nefazodone and venlafaxine. Psychopharmacology (Berl) 128:398-407.

Yuan R, Madani S, Wei XX, Reynolds K, and Huang SM (2002) Evaluation of cytochrome $\mathrm{P} 450$ probe substrates commonly used by the pharmaceutical industry to study in vitro drug interactions. Drug Metab Dispos 30:1311-1319.

Yun CH, Miller GP, and Guengerich FP (2000) Rate-determining steps in phenacetin oxidations by human cytochrome P450 1A2 and selected mutants. Biochemistry 39:11319-11329.

Zhou SF, Yang LP, Wei MQ, Duan W, and Chan E (2009) Insights into the structure, function, and regulation of human cytochrome P450 1A2. Curr Drug Metab 10:713729. 


\section{Chapter 3 Reference List}

Bertini I, Luchinat C, and Piccioli M (2001) Paramagnetic probes in metalloproteins. Methods Enzymol. 339:314-340.

Dawson JH (1988) Probing structure-function relations in heme-containing oxygenases and peroxidases. Science. 240:433-439.

DeVore NM, Smith BD, Urban MJ, and Scott EE (2008) Key residues controlling phenacetin metabolism by human cytochrome P450 2A enzymes. Drug Metab Dispos. 36:2582-2590.

Distlerath LM, Reilly PE, Martin MV, Davis GG, Wilkinson GR, and Guengerich FP (1985) Purification and characterization of the human liver cytochromes P-450 involved in debrisoquine 4-hydroxylation and phenacetin O-deethylation, two prototypes for genetic polymorphism in oxidative drug metabolism. J Biol Chem. 260:9057-9067.

Guengerich FP, Gillam EM, Ohmori S, Sandhu P, Brian WR, Sari MA, and Iwasaki M (1993) Expression of human cytochrome P450 enzymes in yeast and bacteria and relevance to studies on catalytic specificity. Toxicology. 82:21-37.

He YQ, Szklarz GD, and Halpert JR (1996) Interconversion of the androstenedione hydroxylase specificities of cytochromes P450 2B4 and 2B5 upon simultaneous sitedirected mutagenesis of four key substrate recognition residues. Arch Biochem Biophys. 335:152-160.

Huang Q. and Szklarz GD (2010) Significant increase in phenacetin oxidation upon Leu$382 \rightarrow$ Val substitution in human cytochrome P450 1A2. Drug Metab. Disp. doi:10.1124/dmd.109.030767.

Hummel MA, Gannett PM, Aguilar JS, and Tracy TS (2004) Effector-mediated alteration of substrate orientation in cytochrome P450 2C9. Biochemistry. 43:7207-7214.

Hummel MA, Gannett PM, Aguilar JS, and Tracy TS (2008) Substrate proton to heme distances in CYP2C9 allelic variants and alterations by the heterotropic activator, dapsone. Arch Biochem Biophys. 475:175-183.

Jung C, Ristau O, and Rein H. (1991) The high-spin/low-spin equilibrium in cytochrome P-450--a new method for determination of the high-spin content. Biochim Biophys Acta. 1076:130-136.

Liu J, Ericksen SS, Sivaneri M, Besspiata D, Fisher CW, and Szklarz GD (2004) The effect of reciprocal active site mutations in human cytochromes P450 1A1 and 1A2 on alkoxyresorufin metabolism. Arch Biochem Biophys. 424:33-43. 
Mildvan AS, and Gupta RK (1978) Nuclear relaxation measurements of the geometry of enzyme-bound substrates and analogs. Methods Enzymol. 49:322-359.

Modi S, Primrose WU, Boyle JM, Gibson CF, Lian LY, and Roberts GC (1995) NMR studies of substrate binding to cytochrome P450 BM3: comparisons to cytochrome P450 cam. Biochemistry 34:8982-8988.

Modi S, Paine MJ, Sutcliffe MJ, Lian LY, Primrose WU, Wolf CR, and Roberts GC (1996) A model for human cytochrome P450 2D6 based on homology modeling and NMR studies of substrate binding. Biochemistry 35:4540-4550.

Pintacuda G, Hohenthanner K, Otting G, and Müller N (2003) Angular dependence of dipole-dipole-Curie-spin cross-correlation effects in high-spin and low-spin paramagnetic myoglobin. J Biomol NMR. 27:115-132.

Poli-Scaife S, Attias R, Dansette PM, and Mansuy D (1997) The substrate binding site of human liver cytochrome P450 2C9: An NMR study. Biochemistry 36: 12672-12682.

Regal KA, and Nelson SD (2000) Orientation of caffeine within the active site of human cytochrome P450 1A2 based on NMR longitudinal $\left(\mathrm{T}_{1}\right)$ relaxation measurements. Arch. Biochem. Biophys. 384:47-58.

Roberts AG, Campbell AP, and Atkins WM. (2005) The thermodynamic landscape of testosterone binding to cytochrome P450 3A4: ligand binding and spin state equilibria. Biochemistry. 44:1353-1366.

Roberts AG, Díaz MD, Lampe JN, Shireman LM, Grinstead JS, Dabrowski MJ, Pearson JT, Bowman MK, Atkins WM, and Campbell AP. (2006) NMR studies of ligand binding to $\mathrm{P} 450$ (eryF) provides insight into the mechanism of cooperativity. Biochemistry. 45:1673-1684.

Shafirovich V, Mock S, Kolbanovskiy A, and Geacintov NE (2002) Photochemically catalyzed generation of site-specific 8-nitroguanine adducts in DNA by the reaction of long-lived neutral guanine radicals with nitrogen dioxide. Chem Res Toxicol. 15:591597.

Shimada T, Yamazaki H, Mimura M, Inui Y, and Guengerich FP (1994) Interindividual variations in human liver cytochrome P450 enzymes involved in the oxidation of drugs, carcinogens and toxic chemicals. J. Pharmacol. Exp. Ther. 270:414-423.

Szklarz GD, Graham SE, and Paulsen MD (2000) Molecular modeling of mammalian cytochromes P450: application to study enzyme function. Vitam Horm. 58:53-87.

Szklarz GD, and Halpert JR (1997) Use of homology modeling in conjunction with sitedirected mutagenesis for analysis of structure-function relationships of mammalian cytochromes P450. Life Sci. 61:2507-2520. 
Szklarz GD, He YQ, Kedzie KM, Halpert JR, and Burnett VL (1996) Elucidation of amino acid residues critical for unique activities of rabbit cytochrome P450 2B5 using hybrid enzymes and reciprocal site-directed mutagenesis with rabbit cytochrome P450 2B4. Arch Biochem Biophys. 327:308-318.

Szklarz GD and Paulsen MD (2002) Molecular modeling of cytochrome P450 1A1: enzyme-substrate interactions and substrate binding affinities. J. Biomol Struct Dyn. 20:155-162.

Tu Y, Deshmukh R, Sivaneri M, and Szklarz GD (2008) Application of molecular modeling for prediction of substrate specificity in cytochrome P450 1A2 mutants. Drug Metab Dispos 36:2371-2380.

Yuan R, Madani S, Wei XX, Reynolds K, and Huang SM (2002) Evaluation of cytochrome $\mathrm{P} 450$ probe substrates commonly used by the pharmaceutical industry to study in vitro drug interactions. Drug Metab Dispos 30:1311-1319.

Zhou SF, Yang LP, Wei MQ, Duan W, and Chan E (2009) Insights into the structure, function, and regulation of human cytochrome P450 1A2. Curr Drug Metab 10:713729. 


\section{Chapter 4 Reference List}

Brøsen K, Skjelbo E, Rasmussen BB, Poulsen HE, and Loft S (1993) Fluvoxamine is a potent inhibitor of cytochrome P4501A2. Biochem Pharmacol. 45:1211-1214.

Cho US, Park EY, Dong MS, Park BS, Kim K, and Kim KH (2003) Tight-binding inhibition by alpha-naphthoflavone of human cytochrome P450 1A2. Biochim Biophys Acta. 1648: 195-202.

Chohan KK, Paine SW, Mistry J, Barton P, and Davis AM (2005) A rapid computational filter for cytochrome P450 1A2 inhibition potential of compound libraries. J Med Chem. 48:5154-5161.

Dai R, Zhai S, Wei X, Pincus MR, Vestal RE, and Friedman FK (1998) Inhibition of human cytochrome P450 1A2 by flavones: a molecular modeling study. J Protein Chem. 17:643-650.

Faber MS, Jetter A, and Fuhr U (2005) Assessment of CYP1A2 activity in clinical practice: why, how, and when? Basic Clin Pharmacol Toxicol. 97:125-134.

Fuhr U, Anders EM, Mahr G, Sörgel F, and Staib AH (1992) Inhibitory potency of quinolone antibacterial agents against cytochrome P450IA2 activity in vivo and in vitro. Antimicrob Agents Chemother. 36:942-948.

Jeppesen U, Loft S, Poulsen HE, and Brśen K (1996) A fluvoxamine-caffeine interaction study. Pharmacogenetics. 6:213-222.

Korhonen LE, Rahnasto M, Mähönen NJ, Wittekindt C, Poso A, Juvonen RO and Raunio H (2005) Predictive three-dimensional quantitative structure-activity relationship of cytochrome P450 1A2 inhibitors. J Med Chem. 48:3808-3815.

Kunze KL and Trager WF (1993) Isoform-selective mechanism-based inhibition of human cytochrome P450 1A2 by furafylline. Chem Res Toxicol. 6:649-656.

Lewis DF, Lake BG, Ito Y, and Dickins M (2006) Lipophilicity relationships in inhibitors of CYP2C9 and CYP2C19 enzymes. J Enzyme Inhib Med Chem. 21:385-389.

Liu J, Ericksen SS, Sivaneri M, Besspiata D, Fisher CW and Szklarz GD (2004) The effect of reciprocal active site mutations in human cytochromes P450 1A1 and 1A2 on alkoxyresorufin metabolism. Arch Biochem Biophys. 424:33-43.

Murray M (1997) Drug-mediated inactivation of cytochrome P450. Clin Exp Pharmacol Physiol. 24:465-470.

Modi S, Primrose WU, Boyle JM, Gibson CF, Lian LY, and Roberts GC (1995) NMR studies of substrate binding to cytochrome P450 BM3: comparisons to cytochrome 
P450 cam. Biochemistry 34:8982-8988.

Nelson DR, Koymans L, Kamataki T, Stegeman JJ, Feyereisen R, Waxman DJ, Waterman MR, Gotoh O, Coon MJ, and Estabrook RW (1996) P450 superfamily: update on new sequences,gene mapping, accession numbers and nomenclature. Pharmacogenetics 6:2-42.

Ortiz de Montellano PR (1996) Cytochrome P450. Structure, Mechanism and Biochemistry, $2^{\text {nd }}$ ed, Plenum Press, New York.

Porter TD and Coon MJ (1991) Cytochrome P450. Multiplicity of isoforms, substrates and catalytic and regulatory mechanisms. J Biol Chem 266:13469-13472.

Sansen S, Yano JK, Reynald RL, Schoch GA, Griffin KJ, Stout CD, and Johnson EF (2007) Adaptations for the oxidation of polycyclic aromatic hydrocarbons exhibited by the structure of human P450 1A2. J. Biol. Chem. 282:14348-14355.

Sousa SF, Fernandes PA, and Ramos MJ (2006) Protein-ligand docking: current status and future challenges. Proteins. 65:15-26.

Szklarz GD and Halpert JR (1998) Molecular basis of P450 inhibition and activation: implications for drug development and drug therapy. Drug Metab Dispos. 26:11791184.

Tu Y, Deshmukh R, Sivaneri M, and Szklarz GD (2008) Application of molecular modeling for prediction of substrate specificity in cytochrome P450 1A2 mutants. Drug Metab Dispos. 36:2371-2380.

Turesky RJ, Constable A, Richoz J, Varga N, Markovic J, Martin MV, and Guengerich FP (1998) Activation of heterocyclic aromatic amines by rat and human liver microsomes and by purified rat and human cytochrome P450 1A2. Chem Res Toxicol. 11:925-936.

Yamashita K, Umemoto A, Grivas S, Kato S, Sato S, and Sugimura T (1988) Heterocyclic amine-DNA adducts analyzed by 32P-postlabeling method. Nucleic Acids Symp Ser. 19:111-114. 